\title{
WestVirginiaUniversity
}

THE RESEARCH REPOSITORY @ WVU

Graduate Theses, Dissertations, and Problem Reports

2006

\section{Model and software development for predicting fish growth in trout raceways}

Yin-Han Wang

West Virginia University

Follow this and additional works at: https://researchrepository.wvu.edu/etd

\section{Recommended Citation}

Wang, Yin-Han, "Model and software development for predicting fish growth in trout raceways" (2006). Graduate Theses, Dissertations, and Problem Reports. 4279.

https://researchrepository.wvu.edu/etd/4279

This Thesis is protected by copyright and/or related rights. It has been brought to you by the The Research Repository @ WVU with permission from the rights-holder(s). You are free to use this Thesis in any way that is permitted by the copyright and related rights legislation that applies to your use. For other uses you must obtain permission from the rights-holder(s) directly, unless additional rights are indicated by a Creative Commons license in the record and/ or on the work itself. This Thesis has been accepted for inclusion in WVU Graduate Theses, Dissertations, and Problem Reports collection by an authorized administrator of The Research Repository @ WVU. For more information, please contact researchrepository@mail.wvu.edu. 


\title{
Model and Software Development
}

\section{for Predicting Fish Growth in Trout Raceways}

\author{
Yin-Han Wang \\ Thesis Submitted to the \\ College of Engineering and Mineral Resources \\ at West Virginia University \\ in partial fulfillment of the requirements \\ for the degree of \\ Master of Science in Chemical Engineering \\ Dr. Richard Turton, Chair \\ Dr. Kenneth J. Semmens \\ Dr. Joseph A. Shaeiwitz
}

Department of Chemical Engineering

Morgantown, West Virginia

2006

Keywords: Visual Basic for Application, Raceway, Trout

Copyright 2006 Yin-Han Wang 


\title{
Abstract \\ Model and Software Development \\ for Predicting Fish Growth in Trout Raceways
}

\author{
Yin-Han Wang
}

A software program was built using Visual Basic for Applications (VBA) in Microsoft ${ }^{\circledR}$ Excel. The purpose of the software is to allow users to manage their raceways more efficiently by providing a tool to simulate the performance of an existing raceway or to predict the behavior of a raceway under a wide variety of operating scenarios. The program considers the behavior of a system of multiple raceways arranged both in series and parallel configurations, and allows for the addition, removal and combination of different cohorts at different times in different raceways. Input data required include properties of the incoming water such as temperature, flowrate, oxygen and nitrogen content, and salinity. Fish growth is predicted using these input data along with food composition and feeding rates. Oxygen and nitrogen levels in the raceways are predicted using input data and stocking information that is provided by the user and fish mortality and density are also computed. In addition, the costs of food and purchases of fish, and the revenue from the sale of fish are also tracked.

A comprehensive user manual for the software is included that provides information on: the basic operation of the program and all the programming features; troubleshooting and error messages; and, a worked example showing many of the features of the program. 


\section{Dedication}

This Thesis is dedicated to Father and Mother. 


\section{Acknowledgements}

I am sincerely grateful to Dr. Richard Turton, for his guidance and support during my master program in Chemical Engineering. Especially, He concerns us not only with academic affairs, but our lives.

I specially thank Dr. Kenneth J. Semmens, for providing ideas and aquacultural information while I was designing the program. He helped me make the program professional and flawless.

I highly appreciate Dr. Joseph A. Shaeiwitz, for his suggestions for my proposal and thesis to make my research better.

In addition, I am sincerely indebted to my labmates from Dr. Turton's laboratory and members from Aquaculture in West Virginia University, for always being available and supportive when I need help.

Finally, I thank my husband, Tze-Wei, my sister, Chiao-Ying, my family and friends in Taiwan. They give me the best encouragement to help me get through the hard times while pursuing my degree. 


\section{Table of Contents}

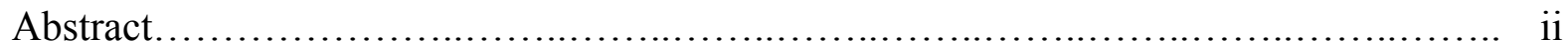

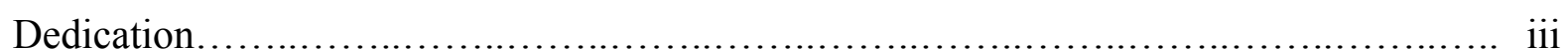

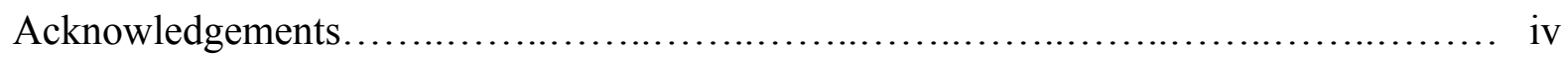

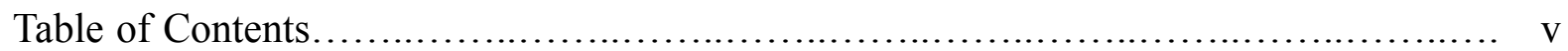

List of Figures.................................................................... vii

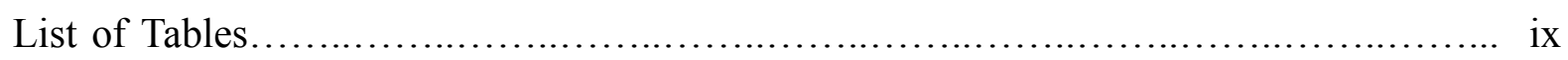

Nomenclature ............................................................

Chapter 1 Introduction..................................................... 1

Chapter 2 Literature Review................................................ 4

2.1 Program Development for Simulations of Fish-Cultured Farms................... 4

2.2 Estimation of the Age and Length Distributions of Fish........................ 7

Chapter 3 Software and Models Used in The Program ........................ 9

3.1 Excel VBA................................................................ 9

3.2 Design and Simulation of a Raceway...................................... 9

3.3 Condition Factors for Fish............................................... 11

3.4 Fish Growth Rate.......................................................... 12

3.5 Nutrition.............................................................. 14

3.5.1 Food Conversion.................................................... 14

3.5.2 Feeding Rate......................................................... 15

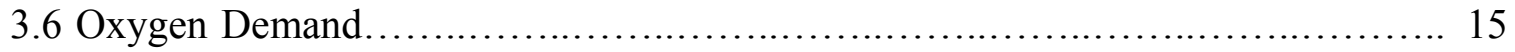

3.6.1 Oxygen Solubility in Water......................................... 15

3.6.2 Concentration of Dissolved Solids...................................... 16

3.6.3 Oxygen Consumption Rate of Fish.................................. 16

3.6.4 Production of Ammonia................................................. 18

3.7 Procedure for Calculations Performed in The Program........................... 19 
Chapter 4 Program Usage and Simulation Description................................ 21

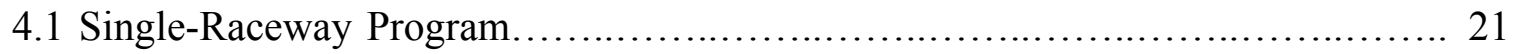

4.1.1 Activation of the Program..................................................... 21

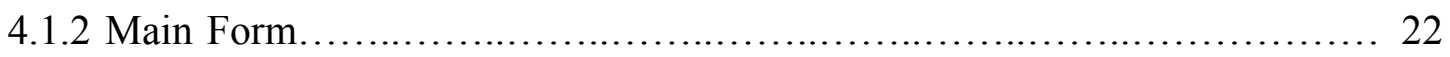

4.1.3 Water and Food Data Form................................................ 22

4.1.3.1 Water Temperature and Water Flow Rate.............................. 23

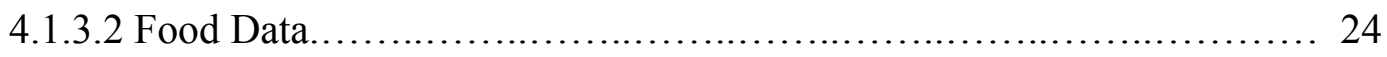

4.1.4 Raceway Design Form.................................................. 25

4.1.4.1 Design of New Raceway......................................... 26

4.1.4.2 Simulation of Raceway............................................ 27

4.1.5 Calculation of Fish Growth............................................. 28

4.1.5.1 Fish and Gas Data................................................. 28

4.1.5.2 Worksheet with Daily Conditions Recorded........................... 35

4.1.5.3 Removal of Fish................................................. 36

4.1.5.4 Plot and Print Functions............................................ 37

4.2. Multiple-Raceway Program.................................................... 39

4.2.1 Additional Considerations in Multiple-Raceway Program..................... 39

4.2.2 Simulation Description................................................ 43

Chapter 5 Conclusion and Future Work ........................................ 46

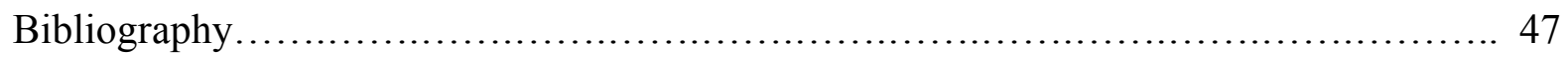

Appdndix: Software Manual............................................................ 48 


\section{List of Figures}

Figure 3.1 Simple Illustration of Raceways.................................. 10

Figure 3.2 Plots of Daily Growth Rate versus Water Temperature................... 13

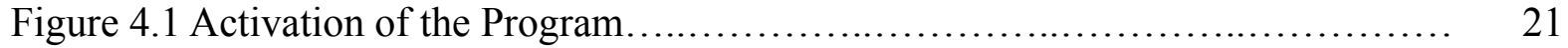

Figure 4.2 Main Form used to set the location and the species of trout................. 22

Figure 4.3 Water \& Food Data - Input form for water and food data...................... 24

Figure 4.4 Input form for Food Data............................................. 25

Figure 4.5 Design of New Raceway............................................... 26

Figure 4.6 Simulation of Raceway............................................... 27

Figure 4.7 Simulation of Fish Growth.......................................... 29

Figure 4.8 Worksheet with daily conditions recorded................................ 35

Figure 4.9 Simulation of Removal of Fish...................................... 37

Figure 4.10 Plot of Effluent Oxygen Concentration vs. Time........................ 38

Figure 4.11 Illustration of settings of the distance of water fall...................... 40

Figure 4.12 Addition, Movement and Removal of Fish............................... 41

Figure 4.13 Numbered Raceways in the Multiple-raceway Program................... 43

Figure 4.14 Illustration of Movement of Fish...................................... 44

Figure 4.15 Flowchart of Process of Simulation in Multiple-Raceway Program.......... 45

Figure A1 Setting of Security Level............................................. 52

Figure A2 Addition of Fish in a Raceway ........................................ 54

Figure A3 Add /Move /Remove Fish Schedule......................................... 55

Figure A4 Setting of Water Temperature and Water Flow Rate........................ 57

Figure A5 Constant Water Temperature and Flow Rate............................. 58

Figure A6 Monthly-Changed Water Temperature and Flow Rate........................ 58

Figure A7 Setting of Number of Raceways and Gas Data.............................. 60

Figure A8 Three Choices for Setting of Food Data................................. 62

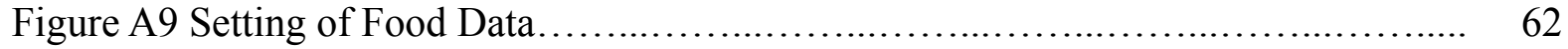

Figure A10 Selection of Food................................................... 63

Figure A11 Selection of Food....................................................... 63

Figure A12 Setting of Water Flow Rate of Branch Flow and Height of Water Fall....... 65 
Figure A13 Simulation Form.......................................................... 66

Figure A14 Cancellation of a Movement................................................. 68

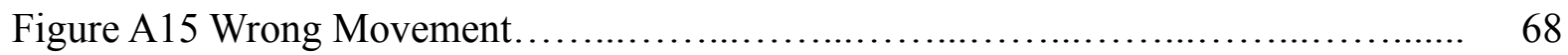

Figure A16 Settings of Tank Specific Data and Fish Data................................... 69

Figure A17 Setting Data for a Specific Raceway........................................... 69

Figure A18 Simulation of Raceways..................................................... 71

Figure A19 Conditions of Water Flow .................................................... 72

Figure A20 Conditions on a Specific Day.................................................. 73

Figure A21 Situation of an Inappropriate Input of Target Size............................ 74

Figure A22 Situation when the conditions of a specific is unavailable...................... 74

Figure A23 Feed Conversion depending on Food.......................................... 76

Figure A24 Customized Feed Conversion.................................................. 76

Figure A25 Food Required on the End of Each Month...................................... 77

Figure A26 Type of feed required in each month......................................... 78

Figure A27 Type of Feed Required During a Year.......................................... 78

Figure A28 Oxygen Concentration....................................................... 79

Figure A29 Ammonia Concentration.................................................... 80

Figure A30 Food Cost and Revenue from Fish Sales.................................... 82

Figure A31 Conditions of the Whole System on a Specific Day........................... 84

Figure A32 Today's Condition......................................................... 86

Figure A33 Error in Selection of Food................................................. 92

Figure A34 Inappropriate Input for Water Flow Rate of Branch Flow.................... 94

Figure A35 Acceptable Input for Water Flow Rate of Branch Flow........................... 95

Figure A36 Revenue................................................................ 104 


\section{List of Tables}

Table 1.1 Factors affecting the production of farm-raised rainbow trout................. 2

Table 2.1 Sample output from gas saturation calculation............................. 5

Table 2.2 An example of Cook and Canton's spreadsheet used to

calculate gas pressures and gas saturation.......................................... 6

Table 4.1 Summary of parameters from the "Calculation of Fish Growth" form............. 30 
Nomenclature

\begin{tabular}{|c|c|c|}
\hline$\alpha$ & Length of a raceway & $(\mathrm{ft})$ \\
\hline$\beta$ & Width of a raceway & $(\mathrm{ft})$ \\
\hline$\gamma$ & Depth of a raceway & $(\mathrm{ft})$ \\
\hline$A$ & Ammonia production rate & ( $\mathrm{g} / \mathrm{kg}$ food) \\
\hline$C_{a c c u, i}$ & $\begin{array}{l}\text { Accumulated cost on food from the beginning } \\
\text { day to the } i \text { th day }\end{array}$ & (dollars) \\
\hline Cal & Calorie content of the food & (Calories $/ \mathrm{kg}$ food) \\
\hline Carb & Ratio of carbohydrate of food by weight & $(\%)$ \\
\hline $\mathrm{Ce}$ & $\begin{array}{l}\text { Saturated oxygen concentration in water } \\
\text { considered elevation and salinity }\end{array}$ & $(\mathrm{mg} / \mathrm{L})$ \\
\hline$C e^{\prime}$ & $\begin{array}{l}\text { Saturated oxygen concentration in water } \\
\text { considered elevation only }\end{array}$ & $(\mathrm{mg} / \mathrm{L})$ \\
\hline$C e_{S L}$ & $\begin{array}{l}\text { Saturated oxygen concentration in water at sea } \\
\text { level }\end{array}$ & $(\mathrm{mg} / \mathrm{L})$ \\
\hline$C_{f o o d, i}$ & Cost on food on the $i$ th day & (dollars) \\
\hline COR & $\begin{array}{l}\text { Factor for correction of oxygen concentration } \\
\text { due to elevation }\end{array}$ & \\
\hline$d$ & Distance of water fall & $(\mathrm{ft})$ \\
\hline Ds & $\begin{array}{l}\text { Reduction in the saturated oxygen } \\
\text { concentration due to salinity }\end{array}$ & $(\mathrm{mg} / \mathrm{L})$ \\
\hline$E$ & Water exchange rate & $\left(\mathrm{hr}^{-1}\right)$ \\
\hline$f$ & $\begin{array}{l}\text { ratio of } \mathrm{NH}_{3} \text { to the total ammonia nitrogen } \\
\text { concentration }\end{array}$ & \\
\hline Fat & Ratio of fat of food by weight & $(\%)$ \\
\hline$F C$ & $\begin{array}{l}\text { Food conversion, ratio of amount of food fed to } \\
\text { the weight of fish gained }\end{array}$ & \\
\hline$F_{i}$ & $\begin{array}{l}\text { Feeding rate on the } i \text { th day, raio of amount of } \\
\text { food required to weight of fish }\end{array}$ & $(\%)$ \\
\hline$\sigma_{i}$ & amount of food required on the $i$ th day & $(\mathrm{lb})(\mathrm{kg})$ \\
\hline
\end{tabular}




\begin{tabular}{|c|c|c|}
\hline$P$ & Pressure & $(\mathrm{mm} \mathrm{Hg})$ \\
\hline K & Condition factor & \\
\hline$\Delta L$ & Daily growth rate of fish & $(\mathrm{mm} /$ day)(in/day) \\
\hline$L i$ & Length of fish on the $i$ th day & \\
\hline$M$ & $\begin{array}{l}\text { Mortality rate of fish, ratio of total number of } \\
\text { fish per month }\end{array}$ & $(\%)$ \\
\hline$n_{i}$ & Number of fish lost on the $i$ th day & \\
\hline$N_{i}$ & Number of fish on the $i$ th day & \\
\hline$C_{N H_{3, i}}$ & Concentration of $\mathrm{NH}_{3}$ in water on the $i$ th day & $(\mathrm{mg} / \mathrm{L})$ \\
\hline$M_{N H_{3}}$ & Maximum Allowable $\mathrm{NH}_{3}$ Concentration & $(\mathrm{mg} / \mathrm{L})$ \\
\hline$\pi_{i}$ & $\begin{array}{l}\text { ratio of } \mathrm{NH}_{3} \text { concentration production to the } \\
\text { maximum allowable value }\end{array}$ & $(\%)$ \\
\hline$O c_{i}$ & Oxygen consumption rate on the $i$ th day & $\left(\frac{\mathrm{mg} \text { of oxygen }}{\mathrm{kg} \text { of fish } \bullet \text { hour }}\right)$ \\
\hline$O_{i n, i}$ & $\begin{array}{l}\text { Oxygen concentration in the influent flow on } \\
\text { the } i \text { th day }\end{array}$ & $(\mathrm{mg} / \mathrm{L})$ \\
\hline$O_{\text {out }, i}$ & $\begin{array}{l}\text { Oxygen concentration in the effluent flow on } \\
\text { the } i \text { th day }\end{array}$ & $(\mathrm{mg} / \mathrm{L})$ \\
\hline$\theta$ & $\begin{array}{l}\text { ratio of oxygen concentration to saturated } \\
\text { concentration expressed in percentage }\end{array}$ & $(\%)$ \\
\hline$\theta_{i}$ & $\begin{array}{l}\text { ratio of oxygen concentration to saturated } \\
\text { concentration in the effluent flow on the } i \text { th day, } \\
\text { expressed in percentage }\end{array}$ & $(\%)$ \\
\hline$\theta_{\text {aer }}$ & $\begin{array}{l}\text { ratio of oxygen concentration to saturated } \\
\text { concentration after a gravity aeration }\end{array}$ & \\
\hline$P_{\text {flings }}$ & Cost on fingerlings purchase & (dollars) \\
\hline$P_{\text {food }}$ & Price of food & (dollars /lb) \\
\hline$p K a$ & $\begin{array}{l}\text { Negative log of the acid dissociation constant } \\
\text { for ammonia }\end{array}$ & \\
\hline Pro & Ratio of protein of the food by weight & $(\%)$ \\
\hline
\end{tabular}




$\begin{array}{lll}Q & \text { Water flow rate } & (\mathrm{gpm}) \\ S & \text { Salinity } & \mathrm{ppt} \\ T & \text { Water temperature } & \left({ }^{\circ} \mathrm{C}\right) \\ T A N_{i} & \begin{array}{l}\text { Concentration of total ammonia nitrogen on the } \\ i \text { th day }\end{array} & (\mathrm{mg} / \mathrm{L}) \\ u & \text { Water velocity } & (\mathrm{ft} / \mathrm{s}) \\ V & \text { Volume of a raceway } & \left(\mathrm{ft}^{3}\right) \\ \Delta W_{i} & \begin{array}{l}\text { Weight of fish gained from the }(i-1) \text { th day to the } \\ \text { ith day }\end{array} & (\mathrm{lb})(\mathrm{kg}) \\ W_{i} & \text { Average weight per fish on the } i \text { th day } & (\mathrm{lb})(\mathrm{g}) \\ W_{t o t, i} & \text { Total weight of fish in a raceway on the } i \text { th day } & (\mathrm{lb})(\mathrm{kg})\end{array}$




\section{CHAPTER 1 INTRODUCTION}

Intensive fish production was begun in the mid-1800s (Soderberg, 1994), and is now an important source of fish for the marketplace. In order to cater to purchasers' needs and for the management of raceways, farmers must have knowledge of the daily conditions of the whole fish-rearing system. For example, they need to know when oxygen concentration in the raceway reaches a critical level for healthy fish production, and subsequently must take action to prevent an undesirable condition in the raceway.

The productivity and conditions of a farm are generally affected by five major factors which are: fish, water, container, nutrition, and management practices (Klontz, 1991). The factors associated with these five groups are shown in Table 1.1.

"In the 1950s David Haskell, an engineer employed by the New York Conservation Department, first applied analytical investigation to the art of flowing water fish culture." (Soderberg, 1994) He established quantitative approaches to predict fish conditions. Since then, increasing numbers of models and equations have been developed to predict various conditions in hatcheries.

The basic purpose of this project is to build a software program to help fish growers design and manage their own raceways. This software helps keep track of daily conditions in the tanks and forecasts the growth rates, oxygen demand, waste production, food requirements for optimal growth, and a variety of economic parameters. The required input from a user/grower includes the starting date, initial fish length or weight, predicted water temperatures, etc. Once this information has been entered, the simulation is run and the state of the fish and raceways during the following year is predicted and displayed. It is the intent of this work that fish growers will be able to manage their raceways more efficiently using this program. 
Table 1.1 Factors affecting the production of farm-raised rainbow trout (Klontz, 1991)

A. Fish-Associated

- Ammonia

- Behavior

- Nutritional requirements

- Environmental requirements

- Physical

- Chemical

- Product definition

- Growth-rate potential

- Disease history

- Condition factor

- Cannibalism

- Oxygen uptake

- Oxygen demand

- Fecal solids

- $\mathrm{CO}_{2}$

- Stress response

B. Water-Associated

- Dissolved oxygen

- Nitrite

- Alkalinity

- $\mathrm{pH}$

- Inflow rate

- Suspended solids

- Settleable solids

- Temperature

- Carrying capacity

- Agricultural contaminants

- Industrial contaminants

- Municipal contaminants

- Natural contaminants

- $\mathrm{N}_{2}$

- $\mathrm{CO}_{2}$

- $\mathrm{H}_{2} \mathrm{~S}$

- $\mathrm{Fe}$

- Utilization

- Salinity

- Hardness $\left(\mathrm{Ca}^{++}\right)$

- B.O.D.

- Viscosity

C. Container-Associated

- Water volume

- Water velocity

- Composition

- Water replacement time

- Outfall design

- Shape

- Water-flow pattern

D. Nutrition-Associated

- Feeding rate

- Feed efficiency

- Feed style

- Nutritional quality

- Proximate analysis

- Energy content

- Feed storage

E. Management-Associated

- Fish sampling techniques

- Feeding frequency

- Feeding techniques

- Record keeping

- Fish-size grading

- Management planning

- Management objectives

- Production economics

- Pond cleaning 
The software has evolved as two separate programs. The first program considers the balances associated with the growth of a single cohort of fish in a single raceway. The second program considers the behavior of a system of multiple tanks arranged both in series and parallel configurations, and allows for the addition, removal and combination of different cohorts at different times in different raceways. This second program closely simulates most of the operations that occur in commercial raceways. 


\section{CHAPTER 2 LITERATURE REVIEW}

\subsection{PROGRAM DEVELOPMENT FOR SIMULATIONS OF FISH-CULTURED FARMS}

Nitrogen supersaturation is a damaging and often lethal problem in fish culture. Many methods and expressions have been developed to estimate the nitrogen concentration in water, including direct measurement of gas pressure using instrumentation. The procedure used to calculate the pressures of the principal gases requires a series of equations, and these equations need several parameters such as barometric pressure, water temperature and salinity, etc., in order to complete the calculations (Dawson, 1986).

Dawson (1986) wrote a computer program using Applesoft BASIC language to determine the dissolved gas composition in water. The required input parameters for this calculation process are: barometric pressure $(\mathrm{mm} \mathrm{Hg})$, water temperature $\left({ }^{\circ} \mathrm{C}\right)$, differential dissolved gas pressure (mm Hg), oxygen concentration $(\mathrm{mg} / \mathrm{L})$ and salinity. An example of the output from this program is shown in Table 2.1 .

Gas bubble disease is one of the illnesses caused by supersaturation of air in aquacultural water supplies. When the dissolved gas pressures exceeds the sum of the hydrostatic, blood and tissue pressures, and surface tension, gas bubbles form in the blood. Therefore, the difference between total dissolved gas pressure and the ambient hydrostatic pressure $(\Delta P)$ is the key factor that causes gas bubble disease in fish (Cook and Canton, 1988). 
Table 2.1 Sample output from gas saturation calculation

\title{
Saturometer Calculations
}

\author{
$\mathrm{SITE}=$ TEST WELL \#1 \\ $\mathrm{DATE}=10-23-83$ \\ INPUT DATA
}

BAROMETRIC PRESSURE $(\mathrm{mm} \mathrm{Hg})=$ 762

WATER TEMPERATURE ( C. $=\ldots \ldots \ldots \ldots \ldots$ 13

SATUROMETER READING $(\mathrm{mm} \mathrm{Hg})=$ 75

OXYGEN CONCENTRATION $(\mathrm{mg} / \mathrm{L})=$ 10.2

SALINITY $($ PPT $)=$ 0

RESULTS

BUNSEN SOLUBILITY COEFFICIENT 0.0357

WATER VAPOR PRESSURE $(\mathrm{mm} \mathrm{Hg})=$

TOTAL DISS. GAS PRESS. (mm Hg) 837

OXYGEN PRESSURE $(\mathrm{mm} \mathrm{Hg})=$ 151.9

NITROGEN PRESSURE $(\mathrm{mm} \mathrm{Hg})=$ 665.6

NITROGEN+ ARGON PRESS. $(\mathrm{mm} \mathrm{Hg})=\ldots$ 673.9

TOTAL HYPERB. PRESS. $(\mathrm{mm} \mathrm{Hg})=$ 75

OXYGEN HYPERB. PRESS. (mm Hg) = $-5.3$

OXYGEN + Ar HYPERB. PRESS. $(\mathrm{mm} \mathrm{Hg})=$ 80.4

TOTAL PERCENT SATURATION = 109.8

OXYGEN PERCENT SATURATION = 96.6 NITROGEN PERCENT SATURATION $=\ldots \ldots$ 113.5

RATIO OF OXYGEN \% / NITROGEN \%= ..

0.851 
Cook and Canton (1988) used Dawson's computer program for spot checks on a commercial fish farm. They expanded Dawson's (1986) work by using a spreadsheet for entering large quantities of data, and for subsequent graphical and statistical analysis.

Cook and Canton's (1988) spreadsheet program was developed with Symphony ${ }^{\mathrm{TM}}$ from Lotus Development Corporation. The equations required in the calculations were entered in the individual cells. Users can copy these cells with equations to other locations to perform a series of computations. An example of the spreadsheet is summarized and shown in Table 2.2.

Table 2.2

An example of Cook and Canton's spreadsheet used to calculate gas pressures and gas saturation.

\begin{tabular}{ccccccccc}
\hline & $\mathrm{A}$ & $\mathrm{B}$ & $\ldots \ldots$ & $\mathrm{F}$ & $\mathrm{G}$ & $\mathrm{H}$ & $\mathrm{I}$ & $\ldots \ldots$ \\
\hline & LOCATION & DATE & $\ldots \ldots$ & $\mathrm{BP}$ & $\Delta \mathrm{P}$ & $\mathrm{B}_{\mathrm{O}_{2}}$ & $\mathrm{P}_{\mathrm{H}_{2} \mathrm{O}}$ & $\ldots \ldots$ \\
& & & & $(\mathrm{mm} \mathrm{Hg})$ & $(\mathrm{mm} \mathrm{Hg})$ & $(\mathrm{mm} \mathrm{Hg})$ & $(\mathrm{mm} \mathrm{Hg})$ & \\
1 & Demo & $6 / 1 / 86$ & $\ldots \ldots$ & 680 & -54 & 0.036 & 10.52 & $\ldots \ldots$ \\
2 & Demo & $6 / 2 / 86$ & $\ldots \ldots$ & 763 & -33 & 0.036 & 11.24 & $\ldots \ldots$ \\
$:$ & $:$ & $:$ & $:$ & $:$ & $:$ & $:$ & $:$ & $:$ \\
$:$ & $:$ & $:$ & $:$ & $:$ & $:$ & $:$ & $:$ & $:$ \\
14 & Demo & $6 / 10 / 86$ & $\ldots \ldots$ & 768 & 67 & 0.033 & 14.54 & $\ldots \ldots$ \\
15 & Demo & $6 / 11 / 86$ & $\ldots \ldots$ & 730 & 89 & 0.032 & 15.48 & $\ldots \ldots$ \\
16 & Demo & $6 / 12 / 86$ & $\ldots \ldots$ & 767 & 145 & 0.033 & 15.00 & $\ldots \ldots$
\end{tabular}

Fries (1994) developed a computer program called SAMCALC written in QuickBASIC 4.0 which is compiled in Microsoft BASIC 7.1 to calculate statistical parameters and perform analysis of fish culture. The computations that SAMCALC can perform include the calculations for chemical treatment, oxygen solubility, and conditions of fish.

In addition, to calculate quantitative parameters such as gas concentration and size of fish, growers sometimes need to decide the cultural strategies, i.e., which species of fish and how 
many fish are going to be raised, for the hatcheries at the very beginning of the simulation. Hammond and Lackey (1976) developed a program called CAtchable Trout Fishery Simulator (CATS) written with FORTRAN IV to simulate a fishery with different stocking ratio among rainbow, brook, and brown trout.

The required input from users in CATS (Hammond and Lackey, 1976) are stocking ratio of species, stocking frequency, fishing pressure, total number of fish, culturing duration, and catchability coefficient. These inputs are treated as elements from probability distributions instead of exact values so the generated results are also probability distributions.

Users also have to decide the variability of the input variables, i.e., constant, randomly generated or proportional to other parameters, and the restocking policy. If a variable is randomly generated, CATS provides a random number generator to determine if the variable is from a standard normal or a uniform distribution. CATS provides three options for the stocking frequency. The action for restocking can be based on the number of fish surviving, catch per fishing hour, or an arbitrary number of days.

From the probability distributions, CATS obtains daily values of fishing pressure and catchability coefficients, and calculates daily values of catch per fishing hour, catch for each species, and population of each species. Finally, CATS will examine if the restocking condition

has been reached, and decides whether to run another daily iterative cycle or add another group of fish.

\subsection{ESTIMATION OF THE AGE AND LENGTH DISTRIBUTIONS OF FISH}

In some situations, the ages and the lengths of individual fish in a group are not uniform; therefore, the age-length relationship must be derived. Isermann and Knight (2005) provide a computer program named AGEKEY to estimate fish population age structure and mean lengths 
at any age. AGEKEY was written using the SAS programming language. It analyzes age-length keys of a group of fish from a set of data of an aged subsample collected from this group. These data are input in columnar format, and must include at least three parameters (columns) which are fish length, sex of fish and age of fish. From AGEKEY, users can obtain the age frequency and mean lengths at any age for the whole group of fish. 


\section{CHAPTER 3 SOFTWARE AND MODELS USED IN THE PROGRAM}

Calculations performed by this program are based mainly on information provided in the book: Flowing Water Fish Culture (Soderberg, 1994).

\subsection{EXCEL VBA}

For the purpose of this project, a software tool that has the ability to do the complicated computations, and also provides a convenient environment for user-defined functions and interface settings was selected. Visual Basic for Application in Microsoft Excel ${ }^{\mathrm{TM}}$ is an ideal language tool which conforms to the requirements described above and is used to develop the program.

\subsection{DESIGN AND SIMULATION OF A RACEWAY}

Raceways, which are linear units and generally rectangular in shape, are commonly used for intensive fish culture in the United States. The movement of water in raceways approximates a plug flow pattern where all elements of water have the same horizontal velocity. Water enters at one end and leaves at the opposite end of a raceway, and thus exhibits a water-quality gradient from the inlet to the outlet (Soderburg, 1994).

As the quantitative information of the flowing water system is available, and the conditions of a flowing water farm are more predictable than a fixed or a recirculating system, raceways are selected as the simulating units in the program. A simple illustration of raceways, and the parameters used for simulation in the program are shown in Figure 3.1. 


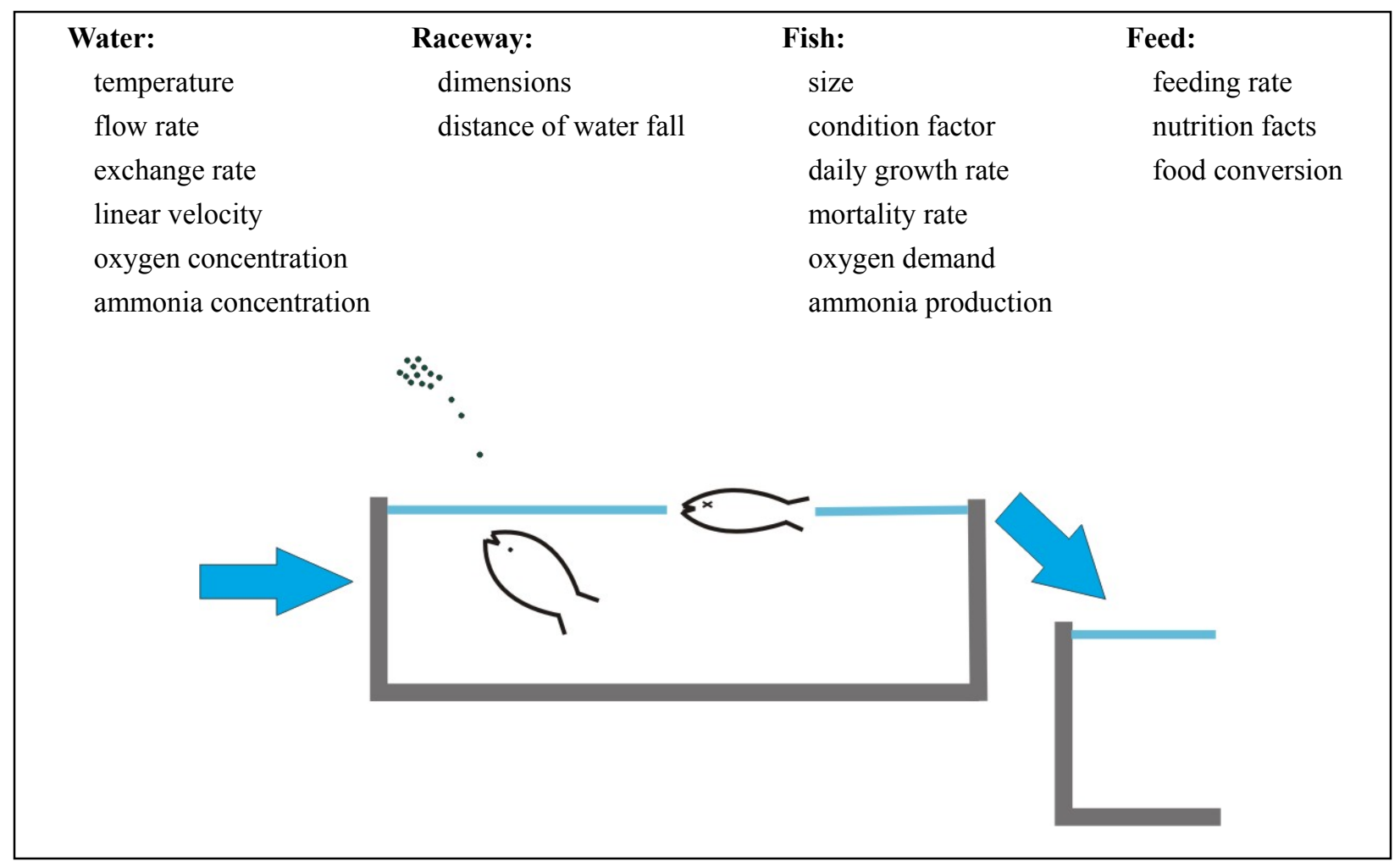

Figure 3.1 Simple Illustration of Raceways

Relationships between water flow rate, number of water exchanges, and the volume of a raceway that are used to explain the process of raceway design are given by Soderburg (1994). If water flow rate and water exchange rate are set, the volume of a raceway can be obtained from Equation (3.1):

$$
V=\frac{60 Q}{7.48 E}
$$

where $V$ is the volume of a raceway $\left(\mathrm{ft}^{3}\right), Q$ is the water flow rate $(\mathrm{gpm})$, and $E$ is the water exchange rate $\left(\mathrm{hr}^{-1}\right)$. 
Accordingly, the length and width of the raceway are:

$$
\begin{aligned}
& \alpha=\frac{3600 u}{E} \\
& \beta=\frac{V}{\alpha \gamma}
\end{aligned}
$$

where $\alpha$ is the length of a raceway (ft), $u$ is water velocity ( $\mathrm{ft} / \mathrm{s}), \beta$ is the width of a raceway (ft), and $\gamma$ is the depth of a raceway (ft). Similarly, if the dimensions of a raceway are known, water exchange rate and water velocity can be found from Equations (3.1-3.3) above. Soderburg (1994) recommends an exchange rate of 4 times per hour and a linear velocity of $0.1 \mathrm{ft} / \mathrm{s}$ for carrying the solids in the water out of the raceway.

\subsection{CONDITION FACTORS FOR FISH}

Haskell (1959) proposed a relationship between the length and the weight of the fish:

$$
W_{i}=K L_{i}{ }^{3}
$$

where $W_{i}$ is the average weight of one head of fish on the $i$ th day, $L_{i}$ is the length of one head of fish on the $i$ th day, and $K$ is a shape factor or "condition factor" for a specific species of fish.

This expression assumes that the shape of the fish remains constant as it grows, and only size changes while it is growing (Haskell, 1959). However, the condition factor may change as the fish grows. In reality, the value of the condition factor varies with different species of fish, environmental circumstances, and the size of fish. Nevertheless, since fish in the same hatchery experience the same conditions, a constant value of condition factor for a specific size of fish can be used in an intensive, fish-rearing system. We correlate the values of condition factors for

different sizes of rainbow trout provided by Klontz (1991) and obtain Equation (3.5) as a function of fish weight:

$$
K=10^{0.0179 \ln (W)-3.3408}
$$


Or, the condition factor can be represented as a function of fish length:

$$
K=10^{0.0559 \ln (L)-3.4842}
$$

where $K$ is the condition factor $\left(\frac{\mathrm{lb}}{\mathrm{in}^{3}}\right), W$ is the weight of fish (lb), and $L$ is the length of fish (in). It was also found that the value of the condition factor for brook trout, brown trout, and rainbow trout is, on average, about the same (Haskell, 1959); hence, Equations (3.5-3.6) will be used to calculate the condition factor for these species of fish in the program.

The ratio of the number of fish lost per month (mortality rate) is assumed constant in the program, and the ratio lost per day is, therefore, the same for each day in a given month. Daily number of fish lost is calculated by multiplying the fish number for the previous day by the average daily mortality rate which is obtained by dividing the monthly mortality by 30 as shown in Equation (3.7):

$$
n_{i}=N_{i-1} \times \frac{M \%}{30}
$$

where $n_{i}$ is the number of fish lost on the $i$ th day, $N_{i-1}$ is the number of fish on the $(i-1)$ th day, and $M$ is the mortality expressed as the $\%$ of the fish population dying per month.

\subsection{FISH GROWTH RATE}

This program focuses on the rearing of four species of trout, namely rainbow (shasta), rainbow (kamloops), brook and brown trout. Klontz (1991) provides equations to predict the daily growth rates for these four types of fish:

rainbow trout (shasta)

$$
\begin{aligned}
2^{\circ} \mathrm{C}<T \leq 15^{\circ} \mathrm{C} & \Delta L=\frac{T(0.0885 T-0.2361)}{(T-2)} \\
15^{\circ} \mathrm{C}<T \leq 25^{\circ} \mathrm{C} & \Delta L=\frac{T(-0.0907 T+2.4611)}{(T-2)}
\end{aligned}
$$


rainbow trout (kamloops)

$$
\begin{aligned}
2{ }^{\circ} \mathrm{C}<T \leq 15^{\circ} \mathrm{C} & \Delta L=\frac{T(0.1021 T-0.2727)}{(T-2)} \\
15^{\circ} \mathrm{C}<T \leq 25^{\circ} \mathrm{C} & \Delta L=\frac{T(-0.1048 T+2.8414)}{(T-2)}
\end{aligned}
$$

brook trout

$$
\begin{aligned}
2{ }^{\circ} \mathrm{C}<T \leq 14^{\circ} \mathrm{C} & \Delta L=\frac{T(0.0784 T-0.1471)}{(T-1)} \\
14^{\circ} \mathrm{C}<T \leq 25^{\circ} \mathrm{C} & \Delta L=\frac{T(-0.0784 T+2.0475)}{(T-1)}
\end{aligned}
$$

brown trout

$$
\begin{aligned}
2^{\circ} \mathrm{C}<T \leq 15^{\circ} \mathrm{C} & \Delta L=\frac{T(0.0643 T-0.1718)}{(T-2)} \\
15^{\circ} \mathrm{C}<T \leq 25^{\circ} \mathrm{C} & \Delta L=\frac{T(-0.066 T+1.79)}{(T-2)}
\end{aligned}
$$

where $\Delta L$ is the daily growth rate of fish (mm/day), and $T$ is the water temperature $\left({ }^{\circ} \mathrm{C}\right)$. It should be noticed that if $\Delta L$ is negative, $\Delta L$ is assumed to be 0. Plots of the daily growth rates of these four types of fish versus water temperature are shown in Figure 3.2.

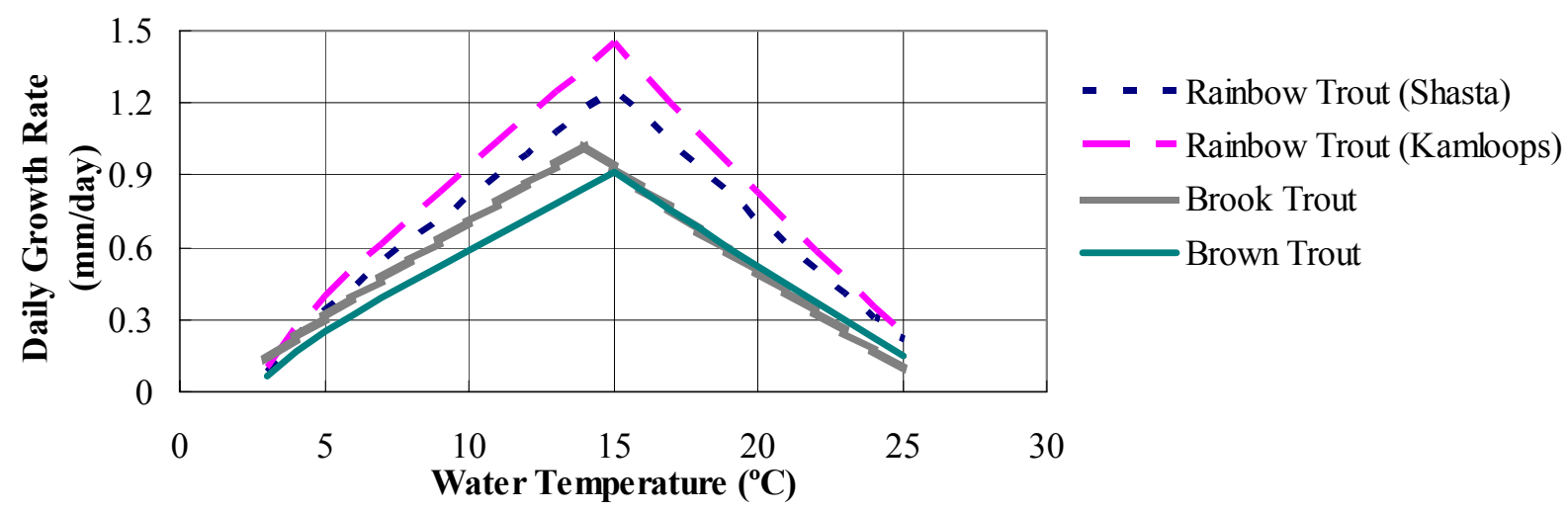

Figure 3.2 Plots of Daily Growth Rate versus Water Temperature 


\subsection{NUTRITION}

\subsubsection{FOOD CONVERSION}

Trout require 1750 Calories per pound of weight gain, and obtain 3.9, 8.0, and 1.6 Calories from each gram of protein, fat and carbohydrate, respectively (Soderburg, 1994). Therefore, food conversion (ratio of food amount fed to fish weight gain) can be predicted if the nutrition content of the food is known. The anticipated food conversion can be calculated directly from the Calorie content of food:

$$
F C=\frac{1750}{C a l}
$$

where $F C$ is food conversion $\left(\frac{\text { food amount fed }}{\text { weight of fish gain }}\right)$, and $\mathrm{Cal}$ is the Calorie content per pound of the food. Otherwise, the Calorie content can be estimated from the nutrition facts (protein, fat, and carbohydrate content) of food:

$$
\mathrm{Cal}=\frac{39 \mathrm{Pro}+80 \mathrm{Fat}+16 \mathrm{Carb}}{2.2}
$$

where Pro, Fat, and Carb are the percentage of protein, fat, and carbohydrate in the food by weight, respectively. The anticipated food conversion can then be calculated by substituting the value obtained from Equation (3.17) into Equation (3.16) (Soderburg, 1994).

When the value of food conversion has been derived, the daily weight gain of fish is calculated as,

$$
\Delta W_{i}=\frac{\sigma_{i}}{F C}
$$

where $\sigma_{i}$ is the food amount applied to one fish in the raceway, and $\Delta W_{i}$ is the weight gain per fish. The total weight gain for all fish in the raceway is simply the product of the weight gain per fish and the total number of fish in the raceway. 


\subsubsection{FEEDING RATE}

Haskell (1959) assumed that the rate of increase of fish length is constant at the same water temperature and applied the concept of differential growth rate to derive a feeding equation:

$$
F_{i}=\frac{300(F C)(\Delta L)}{L_{i}}
$$

where $F_{i}$ is the feeding rate on the $i$ th day which represents the ratio of amount of food required to the weight of fish expressed as a percentage (\%). Consequently, food required per day for all fish in the raceway is:

$$
\sigma_{i}=\frac{\left(F_{i}\right)\left(W_{t o t, i}\right)}{100}
$$

where $W_{t o t, i}$ is the total weight of fish in the raceway on the $i$ th day.

\subsection{OXYGEN DEMAND}

\subsubsection{OXYGEN SOLUBILITY IN WATER}

Soderburg (1994) suggested a regression expression to predict the saturated oxygen concentration in water:

$$
C e_{S L}=14.161-0.3943 T+0.0077147 T^{2}-0.0000646 T^{3}
$$

where $C_{S L}$ is the saturated oxygen concentration in water at sea level (mg/L). Equation (3.21) represents the saturated concentration of oxygen at an air pressure of $1 \mathrm{~atm}$, i.e., the elevation is sea level. However, the lower the pressure of a gas, the less the gas dissolves in water. Therefore, Equation (3.21) must be corrected by a pressure factor for elevations different from sea level.

A direct way to calculate the correction factor is by reading the barometric pressure, and computing the fraction.

$$
\text { COR }=\frac{P}{760}
$$

where $C O R$ is the correction factor, and $P$ is the atmosphere pressure at the location of the 
raceway (mm Hg). From Equations (3.22), the equilibrium concentration of oxygen in water, modified for the elevation of the raceway, is:

$$
C e^{\prime}=(C O R)\left(C e_{S L}\right)
$$

where $C e^{\prime}$ is the saturated concentration of oxygen in water $(\mathrm{mg} / \mathrm{L})$.

\subsubsection{CONCENTRATION OF DISSOLVED SOLIDS}

Solubility of oxygen in water is also affected by the concentration of dissolved solids. A convenient equation has been derived to calculate the reduction in the equilibrium oxygen concentration due to salinity (Soderburg, 1994):

$$
D s=S\left(0.0841-0.00256 T+0.0000374 T^{2}\right)
$$

where $D s$ is the reduction in $C e^{\prime}$ due to salinity $(\mathrm{mg} / \mathrm{L})$, and $S$ is the salinity in parts per thousand (ppt). Thus, the final equilibrium oxygen concentration in water becomes:

$$
C e=C e^{\prime}-D s
$$

Substituting Equations (3.21-3.23) and obtaining:

$$
C e=(C O R)\left(C e_{S L}\right)-D s
$$

where $C e$ is the saturated oxygen concentration in water $(\mathrm{mg} / \mathrm{L})$.

\subsubsection{OXYGEN CONSUMPTION RATE OF FISH}

While respiring, fish consume dissolved oxygen in the water, and release carbon dioxide (Soderburg, 1994). Therefore, the concentration of dissolved oxygen in water drops. Since oxygen is essential for the health and the growth of fish, estimation of the depleted and remaining amount of oxygen in the water is an important issue.

Several expressions for oxygen consumption rate of cultured fish have been derived. Willoughby (1968) suggested that the amount of food fed was related to the metabolic rate of fish, and hence affected the oxygen consumption rate of fish. Therefore, the relationship between 
the amount of oxygen in the influent and effluent water flow of the raceway, the volume of water, and the amount of food fed can be expressed as follows:

$$
\sigma=0.0545 Q\left(O_{\text {in }}-O_{\text {out }}\right)
$$

where $\sigma$ is the food amount fed per day (lb), $Q$ is the water flow rate (gpm), and $O_{\text {in }}$ and $O_{\text {out }}$ are the amount of oxygen in the influent and effluent flow of water to the raceway $(\mathrm{mg} / \mathrm{L})$, respectively.

Soderburg (1994) applied Haskell's (1959) feeding Equations (3.19) and (3.27) and obtained an equation for the oxygen consumption rate of fish as,

$$
O c_{i}=91.5523 F_{i}
$$

where $F_{i}$ is the feeding rate on the $i$ th day which represents the ratio of amount of food required to the weight of fish expressed as a percentage (\%). $O c_{i}$ is the oxygen consumption rate $\left(\frac{\mathrm{mg}}{\mathrm{kg} \text { fish } \cdot \text { hour }}\right)$ on the $i$ th day. Multiplying $O c_{i}$ obtained from Equation (3.28) by the total weight of fish, and then dividing it by the volume of water flowing through the raceway in one hour, will give the change in the oxygen concentration over the raceway tank.

$$
\overline{O c_{i}}=\frac{\left(O_{c_{i}}\right)\left(W_{t o t, i}\right)}{227.16 Q}
$$

where $\overline{O c_{i}}$ is the oxygen consumption rate over the raceway on the $i$ th day $(\mathrm{mg} / \mathrm{L}), W_{t o t, i}$ is the total weight of fish in the raceway on the $i$ th day $(\mathrm{kg})$. Since the raceway is assumed to be at steady state, the oxygen concentration in the effluent water flow of the raceway is the oxygen concentration in the influent flow minus the consumption of oxygen on the $i$ th day,

$$
O_{i n, i}-\overline{O c_{i}}=O_{o u t, i}
$$

The ratio of the effluent oxygen concentration to the saturated oxygen concentration expressed as 
a percentage is

$$
\theta_{i}=\frac{100\left(O_{\text {out }, i}\right)}{C e}
$$

The minimum recommended value of $\theta_{i}$ is 60 .

\subsubsection{PRODUCTION OF AMMONIA}

Ammonia is the principal by-product of fish metabolism of protein contained in food. "Aqueous ammonia occurs in two molecular forms and the equilibrium between them is determined by $\mathrm{pH}$, and to a lesser extent, temperature: $\mathrm{NH} \Leftrightarrow \mathrm{NH}_{4}^{+}$” (Soderberg, 1994) The total ammonia nitrogen $\left(\mathrm{NH}_{3}-\mathrm{N}\right.$ and $\left.\mathrm{NH}_{4}^{+}-\mathrm{N}\right)$ production rate from food is:

$$
A=\frac{56 \operatorname{Pro}}{100}
$$

where $A$ is the total ammonia nitrogen production rate $(\mathrm{mg} / \mathrm{kg}$ of food). Total ammonia nitrogen concentration is the total ammonia nitrogen production in one day divided by the volume of water flowing through the raceway in one day:

$$
\operatorname{TAN}_{i}(m g / L)=\frac{1000(A)\left(\sigma_{i}\right)}{5451.84 Q}
$$

where $T A N_{i}$ is the total ammonia nitrogen concentration $(\mathrm{mg} / \mathrm{L})$ on the $i$ th day, and $\sigma_{i}$ is the food amount fed on the $i$ th day $(\mathrm{kg})$. However, the un-ionized ammonia $\left(\mathrm{NH}_{3}\right)$ is much more toxic to fish than is $\mathrm{NH}_{4}{ }^{+}$(Soderburg, 1994), hence the knowledge of the concentration of $\mathrm{NH}_{3}$ in water is necessary.

Soderburg (1994) suggested an equation to calculate the acid dissociation constant which is expressed as the negative log for ammonia:

$$
p K a=0.09018+\frac{2729.92}{T+273.15}
$$


and the ratio of $\mathrm{NH}_{3}$ to the total ammonia nitrogen concentration can be obtained from:

$$
f=\frac{C_{N H_{3}}}{T A N}=\frac{1}{10^{p K a-p H}+1}
$$

where $C_{N_{3}}$ is the concentration of $\mathrm{NH}_{3}(\mathrm{mg} / \mathrm{L})$, and $p H$ is the $\mathrm{pH}$ value of water. Thus, the concentration of $\mathrm{NH}_{3}$ in water is the total ammonia nitrogen concentration (TAN) multiplied by $f$.

$$
C_{N_{3}}=(T A N)(f)
$$

The ratio of the concentration of $\mathrm{NH}_{3}$ production to the maximum allowable concentration of $\mathrm{NH}_{3}$ expressed as a percentage is:

$$
\pi_{i}=\frac{100 C_{N H_{3, i}}}{M_{N H_{3}}}
$$

where $M_{N_{3}}$ is the maximum allowable concentration of $\mathrm{NH}_{3}$. A value of $\pi_{i}$ greater than 100 indicates that $C_{N H_{3, i}}$ is beyond the maximum allowable concentration of $\mathrm{NH}_{3}$, and an undesirable situation resulting in reduced growth, disease, and risk of death of fish may occur. Therefore, some action such as removing some fish from the raceway is suggested to maintain optimal conditions in the raceway.

\subsection{PROCEDURE FOR CALCULATIONS PERFORMED IN THE PROGRAM}

Growth of fish is influenced by various factors. Klontz (1991) defined two types of trout growth model, Growth Rate Potential and Allowable Growth Rate, to forecast the size of fish. The Growth Rate Potential (GRP) is solely affected by water temperature; therefore, it assumes that a growth rate of fish at a specific water temperature is the maximum rate that can be achieved at this temperature.

The Allowable Growth Rate (AGR) takes the whole environment into consideration; therefore, it is affected by several factors such as water temperature, oxygen availability, water 
osmolarity, feed quality, and feed quantity, etc. The AGR and the GRP are equal under ideal conditions (Klontz, 1991).

Since, in practice, fish growth rate is not only influenced by water temperature, the allowable growth rate model is adopted to predict the daily growth rate of trout in the program. The following assumptions have been made:

Daily growth rate of fish is influenced by three factors:

- Feed quantity - amount of food fed

- Feed quality - nutritional content of food

- Water temperature

Food is supplied to fish everyday.

$>$ The quantity and quality of food provided in a given day will affect the instantaneous weight gain of fish.

Since the feed in a given day affects the conditions of the fish on the next day, and the conditions of fish further influence other parameters such as amount of dissolved oxygen and ammonia, the simulations in the program are "day-based", i.e., the simulation program calculates the parameters of the raceway and fish on a day-to-day basis and provides output on a monthly basis. The detailed explanations of the different calculations are described in the next chapter. 


\section{CHAPTER 4 PROGRAM USAGE AND SIMULATION DESCRIPTION}

\subsection{SINGLE-RACEWAY PROGRAM}

The conditions of a single raceway containing one cohort of fish are simulated in the single-raceway program. From the simulated results, users can see when the fish density or oxygen concentration in the exit of the raceway reaches a critical level for healthy fish production. In addition, actions such as removing some fish are suggested by the software to prevent an undesirable condition in the tank.

\subsubsection{ACTIVATION OF THE PROGRAM}

The program is built within an EXCEL worksheet. A user can access this program by clicking the button displayed in the first worksheet in the EXCEL file as shown in Figure 4.1:

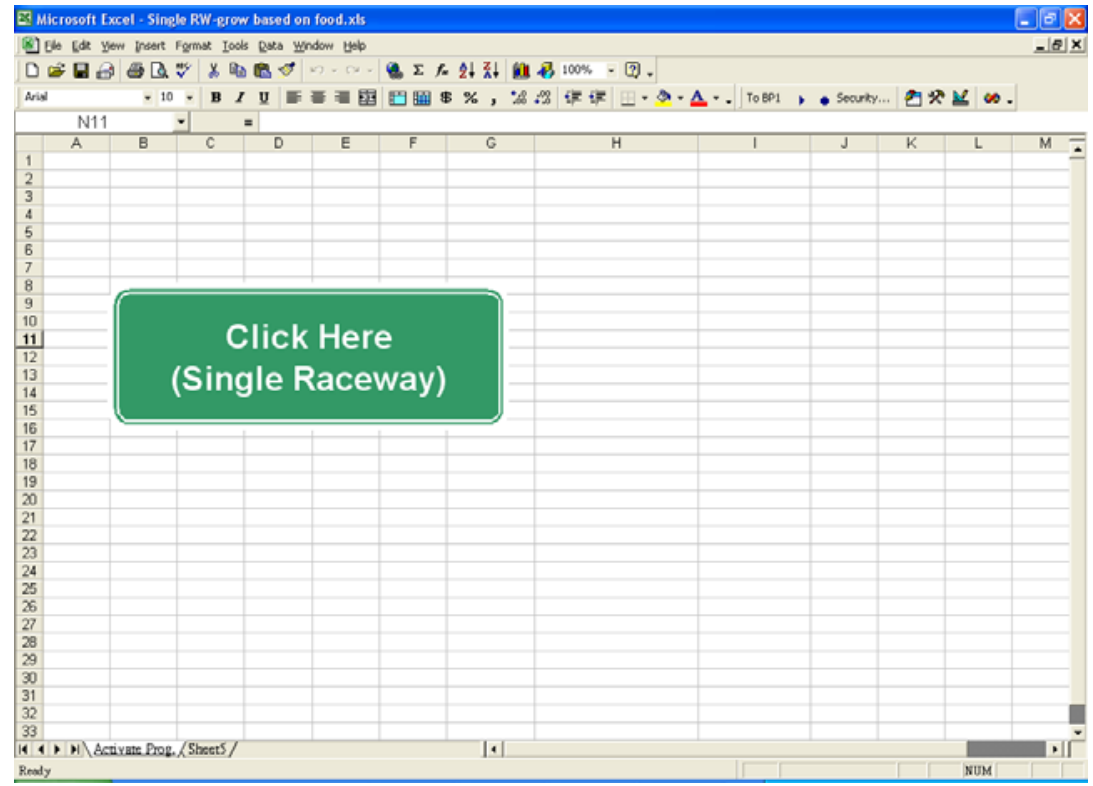

Figure 4.1 Activation of the Program 


\subsubsection{MAIN FORM}

The first form, shown as Figure 4.2, requires a user to set the location of the raceway that is going to be simulated, the species of fish that is going to be cultured in this raceway, and the start date to raise fish. Afterwards, a user can follow the numbered buttons underneath to continue the simulation.

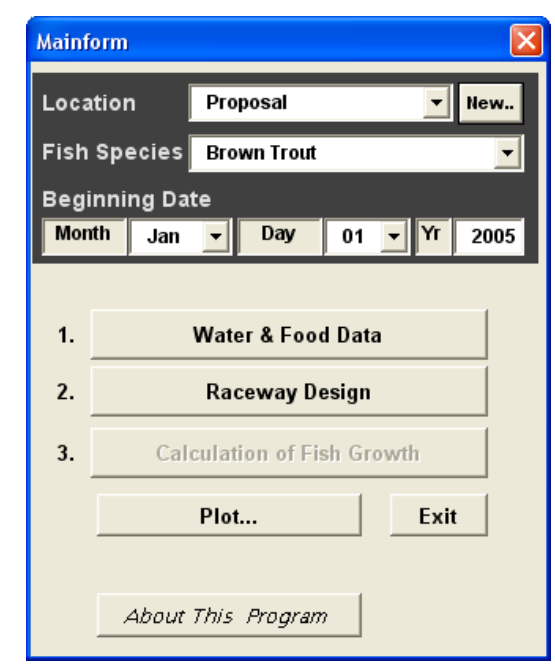

Figure 4.2 Main Form used to set the location and the species of trout

\subsubsection{WATER AND FOOD DATA FORM}

General background information is required before the performance of the raceway can be simulated. In the "Water \& Food Data" form, a user is asked to provide some basic information. There are two pages of forms requiring input. The first page contains columns for average monthly water temperature and water flow rate, and the second page requests information on food. 


\subsubsection{WATER TEMPERATURE AND WATER FLOW RATE}

The program provides two modes for setting water temperature, i.e., constant or monthly variations. Since the growth rate and thus the metabolic rate of fish vary with the water temperature, the oxygen consumption rate and the ammonia production rate increase when the temperature is suitable for fish growth. Consequently a higher water flow rate is better for maintaining good water conditions. Therefore, the variation in water flow rate is designed depending on the mode of water temperature so that the user can adjust the water flow rate according to the temperature input. For example, if a monthly changed water temperature system is selected, the water flow rate can also be varied monthly. If the water temperature is constant, the flow rate is correspondingly set to be constant.

However, sometimes the water temperature is constant but the water flow changes due to the natural hydrologic cycle. In such a situation, users can enter a constant value for all water temperatures while different values for water flow rates.

Upon entering the value of water temperature, the corresponding theoretical daily growth rate will be immediately displayed. The theoretical daily growth rate is calculated from Equations (3.8-3.15) depending on the species selected. For example, assuming the species of fish to be raised is brown trout, and the whole system is at a constant water temperature of $13{ }^{\circ} \mathrm{C}$, from Equation (3.14):

$$
\Delta L=\frac{13[(0.0643)(13)-0.1718]}{(13-2)}=0.7848 \mathrm{~mm} / \mathrm{day}=0.0309 \mathrm{in} / \mathrm{day}
$$

This value is shown in Figure 4.3. 


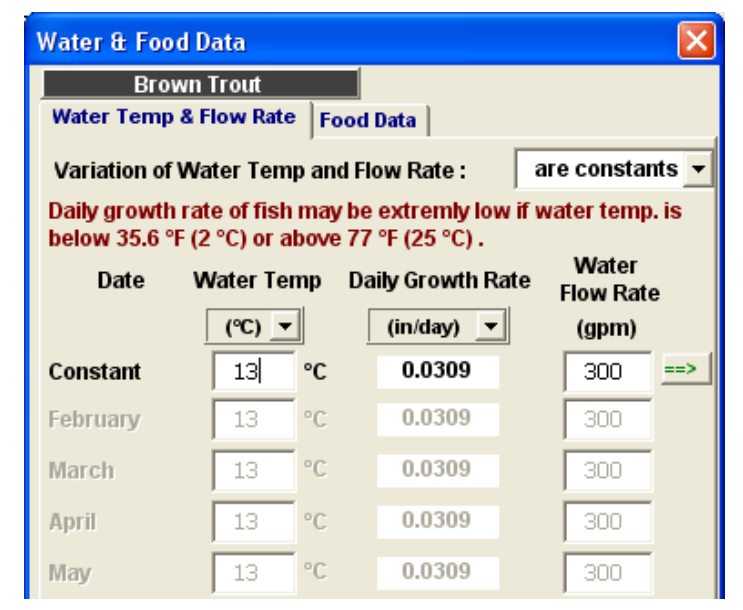

Figure 4.3 Water \& Food Data - Input form for water and food data

\subsubsection{FOOD DATA}

As shown in Figure 4.4, there are three choices with different sets of parameters required to be input on the second page in the Water \& Food Data form. A user can select one of them according to the information available on food. For example, the following input are assumed:

Target Feed Conversion:

Expected Food Amount Fed:

Calorie Content ( $\mathrm{Cal})$ :

Protein (Pro):

Price of Food $\left(P_{\text {food }}\right)$ :
Depend on food

$90 \%$ of food Required for Optimal Fish Growth

$1200 \mathrm{Cal} / \mathrm{lb}$ food

$45 \%$ of Food $(\mathrm{Wt})$

$0.35 \$ / 1 b$ 


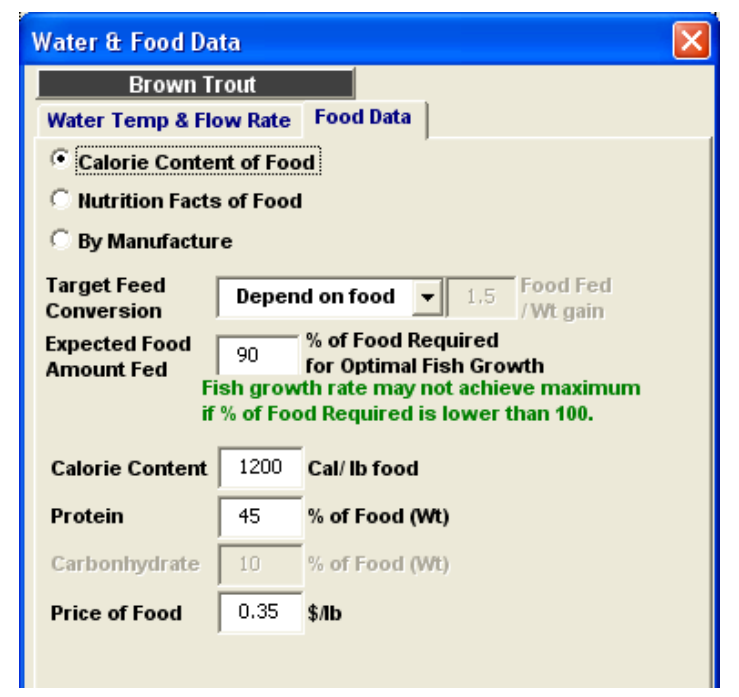

Figure 4.4 Input form for Food Data

After the input is finished, the program will distinguish which set of parameters the user entered, and perform the appropriate calculations. Since the Calorie content of the food was provided in the form in Figure 4.4, the only required calculation is to compute the food conversion from Equation (3.16):

$$
F C=\frac{1750}{1200}=1.5
$$

Sequentially, the program will save all of the inputs and selections in this form and also the results of calculations that have been done, including the daily growth rate of fish on the first page.

\subsubsection{RACEWAY DESIGN FORM}

The dimensions of a raceway, water exchange times per hour, and velocity of water flow can be designed or simulated in this form, Figure 4.5. 


\begin{tabular}{|c|c|c|c|c|c|c|c|c|}
\hline \multicolumn{4}{|c|}{ Raceway Design } & \multicolumn{5}{|c|}{ Results of Simulation } \\
\hline \multicolumn{4}{|c|}{ Brown Trout } & \multicolumn{5}{|c|}{ Results of Calculation } \\
\hline \multirow{3}{*}{$\begin{array}{l}\text { Location } \\
\text { Beginning } \\
\text { Date }\end{array}$} & \multicolumn{3}{|c|}{ Proposal } & \multirow{2}{*}{\multicolumn{5}{|c|}{$\begin{array}{l}{ }^{\star} 0.1 \mathrm{ft} / \mathrm{s} \text { of water velocity is recommended } \\
\text { to carry solids out from a raceway. } \\
\text { ^Minimum recommended exchanges per } \\
\text { hour is } 4 \text {. }\end{array}$}} \\
\hline & & $\operatorname{Jan} / \mathbf{1} / \mathbf{0}$ & & & & & & \\
\hline \multirow{4}{*}{\multicolumn{4}{|c|}{$\begin{array}{l}\text { - Design of New Raceway } \\
C \text { Simulation of Raceway }\end{array}$}} & \multirow{2}{*}{\multicolumn{3}{|c|}{$\begin{array}{l}\text { Volume of One Tank } \\
\text { Width of Raceway }\end{array}$}} & \multicolumn{2}{|c|}{$\mathrm{ft}^{\wedge} \mathbf{3}$} \\
\hline & & & & & & & 2.230 & \\
\hline & & & & Length & of One $T$ & ank & 45 & \\
\hline \multicolumn{3}{|c|}{ - Basic Raceway Data } & & \multirow{2}{*}{ Date } & \multirow{2}{*}{$\begin{array}{l}\text { Water } \\
\text { Temp } \\
\left({ }^{\circ} \mathrm{C}\right)\end{array}$} & \multirow{2}{*}{$\begin{array}{l}\text { Water } \\
\text { Flow Rate } \\
\text { (gpm) }\end{array}$} & \multirow{2}{*}{$\begin{array}{c}\text { Water } \\
\text { Exchange } \\
\text { (times/hr) }\end{array}$} & \multirow{2}{*}{$\begin{array}{l}\text { Water } \\
\text { Velocity } \\
\text { (ft/s) }\end{array}$} \\
\hline Length of Tan & & 45 & ft & & & & & \\
\hline Width of Tank & & 2,230 & ft & 1 Jan & 13 & 300 & 8 & 0.1 \\
\hline Depth of Tank & & 3 & ft & 2 Feb & 13 & 300 & 8 & 0.1 \\
\hline \multirow{2}{*}{\multicolumn{3}{|c|}{ - Water Data }} & & 3 Mar & 13 & 300 & 8 & 0.1 \\
\hline & & & \multirow{5}{*}{$\begin{array}{l}\text { ft/s } \\
\text { times } \\
\text { hour } \\
\text { gpm }\end{array}$} & $4 \mathrm{Apr}$ & 13 & 300 & 8 & 0.1 \\
\hline \multirow{4}{*}{$\begin{array}{l}\text { Velocity of Wat } \\
\text { Water Exchang } \\
\text { Max Water Flov } \\
\text { Rate Input }\end{array}$} & & 0.1 & & 5 May & 13 & 300 & 8 & 0.1 \\
\hline & & 8 & & 6 Jun & 13 & 300 & 8 & 0.1 \\
\hline & & 300 & & 7 Jul & 13 & 300 & 8 & 0.1 \\
\hline & & 500 & & 8 Aug & 13 & 300 & 8 & 0.1 \\
\hline \multirow[b]{3}{*}{ Previous } & \multirow[b]{3}{*}{ OK } & \multirow{4}{*}{ Next } & \multirow{4}{*}{ Exit } & 9 Sep & 13 & 300 & 8 & 0.1 \\
\hline & & & & 10 Oct & 13 & 300 & 8 & 0.1 \\
\hline & & & & 11 Hov & 13 & 300 & 8 & 0.1 \\
\hline Print & & & & $12 \mathrm{Dec}$ & 13 & 300 & 8 & 0.1 \\
\hline
\end{tabular}

Figure 4.5 Design of New Raceway

\subsubsection{DESIGN OF NEW RACEWAY}

The required input for the design of a new raceway is the depth of tank, velocity of water, and number of water exchanges. The program will then simulate the dimensions of a tank according to the data entered. For example, if a user entered the following parameters:

$\begin{array}{ll}\text { Water Flow Rate }(Q): & 300 \mathrm{gpm} \\ \text { Depth of Tank }(\gamma): & 3 \mathrm{ft} \\ \text { Velocity of Water }(\mathrm{u}): & 0.1 \mathrm{ft} / \mathrm{s} \\ \text { Water Exchange }(E): & 8 \mathrm{hr}^{-1}\end{array}$


After the "OK" button is pressed, the program will perform the following calculations from Equations (3.1-3.3), and obtain the values of volume, length, and width of a tank that conform to the input data.

$$
\begin{aligned}
& V=\frac{(60)(300)}{(7.48)(8)}=300.8 \mathrm{ft}^{3} \\
& \alpha=\frac{(3600)(0.1)}{8}=45 \mathrm{ft} \\
& \beta=\frac{300.8}{(45)(3)}=2.23 \mathrm{ft}
\end{aligned}
$$

\subsubsection{SIMULATION OF RACEWAY}

This "Simulation of Raceway" form is for a raceway that is already built and is shown in Figure 4.6. The program will simulate the number of water exchanges per hour and water

\begin{tabular}{|c|c|c|c|c|c|c|c|}
\hline \multicolumn{3}{|l|}{ Raceway Design } & \multicolumn{5}{|c|}{ Results of Simulation } \\
\hline \multicolumn{3}{|c|}{ Brown Trout } & \multicolumn{5}{|c|}{ Results of Calculation } \\
\hline \multirow[t]{2}{*}{$\begin{array}{l}\text { Location } \\
\text { Beginning } \\
\text { Date }\end{array}$} & \multicolumn{2}{|l|}{ Jan/1/05 } & \multicolumn{5}{|c|}{$\begin{array}{l}{ }^{\star} 0.1 \mathrm{ft} / \mathrm{s} \text { of water velocity is recommended } \\
\text { to carry solids out from a raceway. } \\
{ }^{\star} \text { Minimum recommended exchanges per } \\
\text { hour is } 4 \text {. }\end{array}$} \\
\hline & & & \multicolumn{3}{|c|}{ Volume of One Tank } & 300 & $\mathrm{ft}^{\wedge} \mathbf{3}$ \\
\hline \multirow{3}{*}{\multicolumn{3}{|c|}{$\begin{array}{l}\text { Design of New Raceway } \\
\text { Simulation of Raceway } \\
\text { Basic Raceway Data }\end{array}$}} & \multirow{2}{*}{\multicolumn{3}{|c|}{$\begin{array}{l}\text { Width of Raceway } \\
\text { Length of One Tank }\end{array}$}} & \multirow{2}{*}{\multicolumn{2}{|c|}{$\begin{array}{l}\text { ft } \\
\text { ft }\end{array}$}} \\
\hline & & & & & & & \\
\hline & & - Basic Raceway Data & \multirow[t]{2}{*}{ Date } & \multirow{2}{*}{$\begin{array}{l}\text { Water } \\
\text { Temp } \\
\left({ }^{\circ} \mathrm{C}\right)\end{array}$} & \multirow{2}{*}{$\begin{array}{l}\text { Water } \\
\text { Flow Rate } \\
\text { (gpm) }\end{array}$} & \multirow{2}{*}{$\begin{array}{c}\text { Water } \\
\text { Exchange } \\
\text { (times/hr) }\end{array}$} & \multirow{2}{*}{$\begin{array}{c}\text { Water } \\
\text { Velocity } \\
\text { (ft/s) }\end{array}$} \\
\hline Length of Tank & 25 & $\mathrm{ft}$ & & & & & \\
\hline Width of Tank & 4 & ft & 1 Jan & 13 & $\mathbf{3 0 0}$ & 8.0 & 0.06 \\
\hline Depth of Tank & 3 & ft & 2 Feb & 13 & $\mathbf{3 0 0}$ & $\mathbf{8 . 0}$ & 0.06 \\
\hline \multirow{2}{*}{\multicolumn{2}{|c|}{ - Water Data }} & & 3 Mar & 13 & 300 & 8.0 & 0.06 \\
\hline & & & 4 Apr & 13 & 300 & 8.0 & 0.06 \\
\hline \multirow{4}{*}{$\begin{array}{l}\text { Velocity of Water } \\
\text { Water Exchange } \\
\text { Max Water Flow } \\
\text { Rate Input }\end{array}$} & 0.1 & $\mathrm{ft} / \mathrm{s}$ & 5 May & 13 & 300 & 8.0 & 0.06 \\
\hline & 8 & times & 6 Jun & 13 & 300 & $\mathbf{8 . 0}$ & 0.06 \\
\hline & \multirow{2}{*}{300} & \multirow{2}{*}{ gpm } & $7 \mathrm{Jul}$ & 13 & $\mathbf{3 0 0}$ & $\mathbf{8 . 0}$ & 0.06 \\
\hline & & & 8 Aug & 13 & $\mathbf{3 0 0}$ & 8.0 & 0.06 \\
\hline \multirow{3}{*}{ Previous } & \multirow{4}{*}{ Hext } & \multirow{4}{*}{ Exit } & 9 Sep & 13 & 300 & $\mathbf{8 . 0}$ & 0.06 \\
\hline & & & 10 oct & 13 & $\mathbf{3 0 0}$ & $\mathbf{8 . 0}$ & 0.06 \\
\hline & & & 11 Hov & 13 & 300 & 8.0 & 0.06 \\
\hline Print & & & $12 \mathrm{Dec}$ & 13 & 300 & 8.0 & 0.06 \\
\hline
\end{tabular}
velocity according to the dimensions of the existing raceway and water flow rate set previously in the "Water \& Food Data Form".

Figure 4.6 Simulation of Raceway 
For example, if the dimensions of an existing raceway are:

$\begin{array}{ll}\text { Length of Tank }(\alpha): & 25 \mathrm{ft} \\ \text { Width of Tank }(\beta): & 4 \mathrm{ft} \\ \text { Depth of Tank }(\gamma): & 3 \mathrm{ft}\end{array}$

From Equations (3.1-3.3), the following parameters are calculated:

$$
\begin{aligned}
& V=25 \times 4 \times 3=300 \mathrm{ft}^{3} \\
& E=\frac{(60)(300)}{(7.48)(300)}=8 \frac{\text { times }}{\text { hour }} \\
& u=\frac{(25)(8)}{3600}=0.06 \frac{\mathrm{ft}}{\mathrm{s}}
\end{aligned}
$$

From these procedures, a user will obtain the simulation of a raceway.

If the derived exchange rate and velocity are below the recommended values, $4 \mathrm{hr}^{-1}$ and 0.1 $\mathrm{ft} / \mathrm{s}$, by Soderburg (1994), then they will be displayed in red on the form as a reminder that they are less than the recommended minimum values. See Figure 4.6 for water velocity.

\subsubsection{CALCULATION OF FISH GROWTH}

After acquiring the background data for the raceway, simulations of fish growth, periodic and accumulated food amount required, gas conditions in the water and revenue can be calculated in this form.

The first page on the input form contains columns for fish and gas data inputs, and the second page is for the schedule for removal of fish by a user in order to sell the fish or for other management reasons.

\subsubsection{FISH AND GAS DATA}

A user is prompted to enter size, number and mortality of fish, and the cost of fingerlings in the Fish Data section of the form shown in Figure 4.7. The initial length/weight is the size of fish on the day that fish are added to the raceway. Input of the target length/weight is optional. If this 
input is selected, the program will simulate the number of days required and the date for fish to achieve this target condition from the initial size.

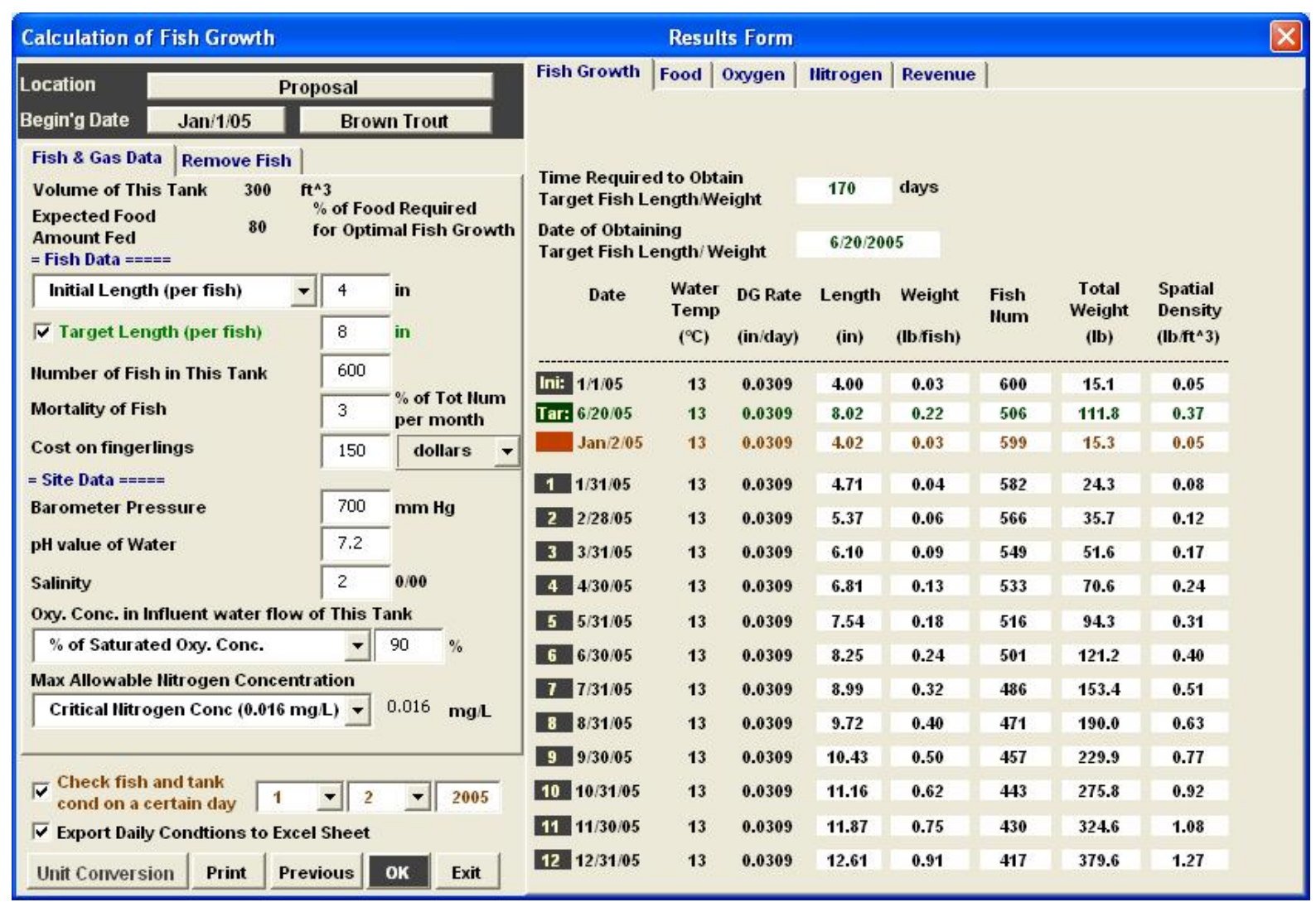

Figure 4.7 Simulation of Fish Growth

When the "OK" button is pressed, the program will perform the simulations and save all the data input and results obtained from this form.

The conditions of fish and water quality on the last day of every month in the following year from the beginning day will be displayed on the right side of the form. If a user wants to check the conditions of the system on another day, selection of the "Check fish and tank cond on a certain day" box on the bottom will accomplish this.

The data set and derived parameters from the "Calculation of Fish Growth" form are summarized in Table 4.1. 


\section{Table 4.1 Summary of parameters from the "Calculation of Fish Growth" form}

- Parameters obtained previously:

Fish species:

Beginning date:

Water temperature $(T)$ :

Theoretical daily growth Rate $(\Delta L)$ :

Water flow rate $(Q)$ :

Food conversion $(F C)$ :

Protein (Pro):

Price of food $\left(P_{\text {food }}\right)$ :

Expected food amount fed:

Volume of raceway $(V)$ :

- Parameters set in the "Calculation of Fish Growth":

Fish Data:

Initial length (per fish) $\left(L_{l}\right)$ :

Target length (per fish):

Number of fish in this tank $\left(N_{l}\right)$ :

Mortality of fish $(M)$ :

Cost on fingerlings purchase $\left(P_{\text {flings }}\right)$ :

Gas Data:

Barometer Pressure $(P)$ :

$\mathrm{pH}$ value of water $(p H)$ :

Salinity $(S)$ :

Oxygen concentration in influent flow

( $\%$ of saturated oxygen concentration)

Maximum Allowable Nitrogen Concentration

(Critical Nitrogen Concentration, $\mathrm{M}_{\mathrm{NH}_{3}}$ )
Brown Trout

Jan/1, 2005

$13{ }^{\circ} \mathrm{C}$ (constant)

$0.0309 \mathrm{in} /$ day (constant)

300 gpm (constant)

$1.5 \frac{\text { food amount fed }}{\text { weight of fish gain }}$

$45 \%$ of food by weight

$0.35 \$ / 1 b$

$90 \%$ of food required for optimal fish growth

$300 \mathrm{ft}^{3}$

4 in

8 in

600

$3 \%$ of total number per month

150 dollars

$700 \mathrm{~mm} \mathrm{Hg}$

7.2

$3 \mathrm{ppt}$

90

$0.016 \mathrm{mg} / \mathrm{L}$ 
In the process of simulation, first the program computes background parameters that are independent of the growth of fish, i.e., the parameters which do not change day to day, such as saturated oxygen concentration, weight or length of fish on the beginning date, total ammonia nitrogen production rate $(T A N)$, acid dissociation constant $(p K a)$, and ratio of $\mathrm{NH}_{3}$ to the total ammonia nitrogen concentration $(f)$.

It should be noted that the program does not round off the values of parameters while doing calculations, but performs the simulations with variables that have at least 6 decimal places. The number of decimal places for a parameter is rounded only when it is recorded or exported to the result form. Therefore, the results derived in the following illustration of the calculation procedure will be displayed in the full (not rounded) format.

From Equation (3.21), the saturated oxygen concentration at sea level is:

$$
C e_{S L}=14.161-0.3943(13)+0.0077147(13)^{2}-0.0000646(13)^{3}=10.2 \mathrm{mg} / \mathrm{L}
$$

From Equations (3.22) and (3.24), the correction factor for oxygen concentration above sea level and the reduction in the oxygen concentration due to salinity are:

$$
\begin{aligned}
& C O R=\frac{700}{760}=0.921 \\
& D s=2\left[0.0841-0.00256(13)+0.0000374(13)^{2}\right]=0.1143 \mathrm{mg} / \mathrm{L}
\end{aligned}
$$

Thus, the saturated oxygen concentration in the water at the location of the raceway can be obtained from Equation (3.26):

$$
C e=(0.921)(10.2)-0.1143=9.2799 \mathrm{mg} / \mathrm{L}
$$

and the oxygen concentration in the influent water flow to the raceway is:

$$
O_{i n}=(9.2799)(90 \%)=8.35 \mathrm{mg} / \mathrm{L}
$$

From Equations (3.32), (3.34) and (3.35), the factors related to the production rate of the un-ionized form of ammonia are calculated, as: 


$$
\begin{aligned}
& A=(56)(45 \%)=25.2 \frac{g \text { of total ammonia production }}{\mathrm{kg} \text { of food }} \\
& p K a=0.09018+\frac{2729.92}{13+273.15}=9.6304 \\
& f=\frac{1}{10^{9.6304-7.2}+1}=3.6982 \times 10^{-3}
\end{aligned}
$$

From Equations (3.6) and (3.4), weight of fish on the first day (initial weight):

$$
\begin{aligned}
& K=10^{0.0559 \ln (4)-3.4842}=0.000392 \\
& W_{I}=(0.000392)\left(4^{3}\right)=0.0251 \mathrm{lb}
\end{aligned}
$$

Total weight of fish in the raceway on the first day:

$$
W_{t o t, 1}=(0.0251)(600)=15.0532 \mathrm{lb}
$$

Next, the program simulates the food amount required, size of fish and water quality, etc., day to day from the beginning date, Jan/1, 2005.

- First day ( Jan/1, 2005)

From Equation (3.19), the feeding rate on the first day is:

$$
F_{1}=\frac{(300)(1.5)(0.0309)}{4}=3.4763
$$

However, the percentage of expected food amount required was set as $90 \%$ of that required for optimal fish growth. Therefore, the practical feeding rate becomes:

$$
F_{1}=(3.4763)(90 \%)=3.1287
$$

From Equation (3.20) total food amount fed to fish is :

$$
\sigma_{1}=\frac{(3.1287)(15.0532)}{100}=0.471 \mathrm{lb}
$$

and the spacial density of fish in the raceway, the cost for food, and the cumulative cost for food and fingerlings on the first day are:

$$
D_{l}=\frac{15.0532}{300}=0.0502 \mathrm{lb} / \mathrm{ft}^{3}
$$




$$
\begin{aligned}
& C_{\text {food, }, 1}=\left(\sigma_{1}\right)\left(P_{\text {food }}\right)=(0.471)(0.35)=\$ 0.16 \\
& C_{a c c u, 1}=C_{\text {food, }, 1}+P_{\text {flings }}=0.16+150=\$ 150.16
\end{aligned}
$$

From Equations (3.28-3.31), the oxygen concentration of the effluent water flow from the raceway is obtained:

$$
\begin{aligned}
& O c_{1}=(91.5523)(3.1287)=286.4397 \frac{\mathrm{mg}}{\mathrm{kg} \text { of fish-hour }} \\
& \overline{O c}_{1}=\frac{(286.4397)\left(\frac{15.0532}{2.2}\right)}{(227.16)(300)}=0.0288 \mathrm{mg} / \mathrm{L} \\
& O_{\text {out }, 1}=8.35-0.0288=8.32 \mathrm{mg} / \mathrm{L} \\
& \theta_{1}=\frac{(100)(8.32)}{9.2799}=89.66
\end{aligned}
$$

Calculation of the concentration of un-ionized ammonia from Equations (3.33), (3.36) and (3.37):

$$
\begin{aligned}
& \operatorname{TAN}_{1}=\frac{1000(25.2)\left(\frac{0.471}{2.2}\right)}{(5451.84)(300)}=3.2986 \times 10^{-3} \mathrm{mg} / \mathrm{L} \\
& C_{N H_{3}, l}=\left(3.2986 \times 10^{-3}\right)\left(3.6982 \times 10^{-3}\right)=1.22 \times 10^{-5} \mathrm{mg} / \mathrm{L} \\
& \pi_{1}=\frac{(100)\left(1.22 \times 10^{-5}\right)}{0.016}=0.08 \%
\end{aligned}
$$

- Second day ( Jan/2, 2005)

The food conversion of $1.5 \frac{\text { food amount fed }}{\text { weight of fish gain }}$ was derived from the previous calculation. The total weight gain for all fish in the raceway due to the food amount fed on the first day can be calculated from Equation (3.18):

$$
\Delta W_{2}=\frac{\sigma_{1}}{F C}=\frac{0.471}{1.5}=0.314 \mathrm{lb}
$$

The number of fish lost on the second day is calculated from Equation (3.7): 


$$
\begin{aligned}
& n_{2}=N_{1} \times \frac{M \%}{30}=600 \times \frac{3 \%}{30}=0.6 \\
& N_{2}=N_{1}-n_{2}=600-0.6=599.4
\end{aligned}
$$

Thus, the total weight of fish in the raceway on the second day is:

$$
\begin{aligned}
& W_{t o t, 2}=W_{t o t, 1}+\Delta W_{2}-\left(n_{2}\right)\left(W_{1}\right)=15.0532+0.314-(0.6)(0.0251)=15.352 \mathrm{lb} \\
& W_{2}=\frac{W_{t o t, 2}}{N_{2}}=\frac{15.352}{599.4}=0.0256 \mathrm{lb} \\
& K=10^{0.0179 \ln (0.0256)-3.3408}=0.0003923 \\
& L_{2}=\left(\frac{W_{2}}{K}\right)^{1 / 3}=\left(\frac{0.0256}{0.0003923}\right)^{1 / 3}=4.026 \mathrm{in} \\
& D_{2}=\frac{15.352}{300}=0.0512 \mathrm{lb} / \mathrm{ft}^{3}
\end{aligned}
$$

Calculation of food amount required on the second day:

$$
\begin{aligned}
& F_{2}=\frac{(300)(1.5)(0.0309)}{4.026}(90 \%)=3.1084 \\
& \sigma_{2}=\frac{(15.352)(3.1084)}{100}=0.477 \mathrm{lb} \\
& C_{f o o d, 2}=\left(\sigma_{2}\right)\left(P_{\text {food }}\right)=(0.477)(0.35)=\$ 0.17 \\
& C_{a c c u, 2}=C_{a c c u, 1}+C_{f o o d, 2}=150.16+0.17=\$ 150.33
\end{aligned}
$$

Calculation of water conditions on the second day:

$$
\begin{aligned}
& O_{c, 2}=(91.5523)(3.1084)=284.5812 \frac{\mathrm{mg}}{\mathrm{kg} \text { of fish } \text {-hour }} \\
& \overline{O c_{2}}=\frac{(284.5812) \frac{15.352}{2.2}}{(227.16)(300)}=0.0291 \mathrm{mg} / \mathrm{L} \\
& O_{\text {out }, 2}=8.35-0.0291=8.32 \mathrm{mg} / \mathrm{L} \\
& \theta_{2}=\frac{(100)(8.32)}{9.2799}=89.66 \\
& T A N_{2}=\frac{(1000)(25.2)\left(\frac{0.477}{2.2}\right)}{(5451.84)(300)}=3.341 \times 10^{-3} \mathrm{mg} / \mathrm{L}
\end{aligned}
$$




$$
\begin{aligned}
& C_{\mathrm{NH}_{3}, 2}=\left(3.341 \times 10^{-3}\right)\left(3.6982 \times 10^{-3}\right)=1.23 \times 10^{-5} \mathrm{mg} / \mathrm{L} \\
& \pi_{2}=\frac{(100)\left(1.23 \times 10^{-5}\right)}{0.016}=0.08 \%
\end{aligned}
$$

After finishing the calculations on the second day, the program will simulate the conditions of the system on the third and subsequent days.

For the date that a user sets on the "Check fish and tank cond on a certain day", the program will record the information obtained on this day, and display the data in the result section of the form. In addition, when the fish length reaches the Target Length set by a user, the program will record and display this date and the parameters that have been accumulated from the start day.

\subsubsection{WORKSHEET WITH DAILY CONDITIONS RECORDED}

The program provides a worksheet for daily tracking as shown in Figure 4.8. This worksheet records daily conditions of a rearing system derived from the simulation, such as fish length,

\begin{tabular}{|c|c|c|c|c|c|c|c|c|c|c|c|}
\hline \multicolumn{12}{|c|}{$\Delta$ Microsoft Excel - Proposal.xIs } \\
\hline \multicolumn{2}{|c|}{ :점 File Edit } & View & sert Forn & Iools & Data & Help & & & & & \multirow[b]{2}{*}{ - $\mathbf{B} I$} \\
\hline \multicolumn{5}{|c|}{ 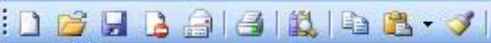 } & \multicolumn{5}{|c|}{ ") Arial } & - 10 & \\
\hline & $\mathrm{S} 22$ & $\checkmark$ & $f_{x}$ & & & & & & & & \\
\hline & $\mathrm{A}$ & $\mathrm{B}$ & C & D & $E$ & $\mathrm{~F}$ & G & $\mathrm{H}$ & 1 & $\mathrm{~J}$ & $\mathrm{~K}$ \\
\hline 1 & Date & $\begin{array}{l}\text { Water } \\
\text { Temp } \\
\left(\left({ }^{\circ} \mathrm{C}\right)\right)\end{array}$ & $\begin{array}{c}\text { DGR } \\
\text { (in/day) }\end{array}$ & $\begin{array}{l}\text { Fish } \\
\text { Length } \\
\text { (in) }\end{array}$ & $\begin{array}{c}\text { Fish } \\
\text { Weight } \\
\text { (lb/fish) }\end{array}$ & $\begin{array}{l}\text { Number } \\
\text { of Fish }\end{array}$ & $\begin{array}{c}\text { Total } \\
\text { Fish } \\
\text { Weight } \\
\text { (lb) }\end{array}$ & $\begin{array}{c}\text { Density } \\
\left(\mathrm{lb} / \mathrm{ft}^{3}\right)\end{array}$ & $\begin{array}{c}\text { Food } \\
\text { Conversion }\end{array}$ & $\begin{array}{c}\text { Feeding } \\
\text { Rate } \\
(\% \\
\text { BW/day) }\end{array}$ & $\begin{array}{l}\text { Food } \\
\text { Amount } \\
\text { Required } \\
\text { (lb/day) }\end{array}$ \\
\hline 2 & $1 / 1 / 05$ & 13 & 0.0309 & 4 & 0.03 & 600 & 15.05307 & 0.05 & 1.5 & 2.78 & 0.4 \\
\hline 3 & $1 / 2 / 05$ & 13 & 0.0309 & 4.023767 & 0.03 & 599 & 15.3 & 0.05 & 1.5 & 2.76 & 0.4 \\
\hline 4 & $1 / 3 / 05$ & 13 & 0.0309 & 4.047344 & 0.03 & 599 & 15.6 & 0.05 & 1.5 & 2.75 & 0.4 \\
\hline 5 & $1 / 4 / 05$ & 13 & 0.0309 & 4.070923 & 0.03 & 598 & 15.9 & 0.05 & 1.5 & 2.73 & 0.4 \\
\hline 6 & $1 / 5 / 05$ & 13 & 0.0309 & 4.094502 & 0.03 & 598 & 16.1 & 0.05 & 1.5 & 2.72 & 0.4 \\
\hline 7 & $1 / 6 / 05$ & 13 & 0.0309 & 4.118082 & 0.03 & 597 & 16.4 & 0.05 & 1.5 & 2.7 & 0.4 \\
\hline 8 & $1 / 7 / 05$ & 13 & 0.0309 & 4.141663 & 0.03 & 596 & 16.7 & 0.06 & 1.5 & 2.69 & 0.4 \\
\hline 9 & $1 / 8 / 05$ & 13 & 0.0309 & 4.165244 & 0.03 & 596 & 17 & 0.06 & 1.5 & 2.67 & 0.5 \\
\hline 10 & $1 / 9 / 05$ & 13 & 0.0309 & 4.188827 & 0.03 & 595 & 17.2 & 0.06 & 1.5 & 2.66 & 0.5 \\
\hline 11 & $1 / 10 / 05$ & 13 & 0.0309 & 4.21241 & 0.03 & 595 & 17.5 & 0.06 & 1.5 & 2.64 & 0.5 \\
\hline 12 & $1 / 11 / 05$ & 13 & 0.0309 & 4.235994 & 0.03 & 594 & 17.8 & 0.06 & 1.5 & 2.63 & 0.5 \\
\hline 13 & $1 / 12 / 05$ & 13 & 0.0309 & 4.259579 & 0.03 & 593 & 18.1 & 0.06 & 1.5 & 2.61 & 0.5 \\
\hline 14 & $1 / 13 / 05$ & 13 & 0.0309 & 4.283164 & 0.03 & 593 & 18.4 & 0.06 & 1.5 & 2.6 & 0.5 \\
\hline 15 & $1 / 14 / 05$ & 13 & 0.0309 & 4.30675 & 0.03 & 592 & 18.7 & 0.06 & 1.5 & 2.58 & 0.5 \\
\hline 16 & $1 / 15 / 05$ & 13 & 0.0309 & 4.330338 & 0.03 & 592 & 19 & 0.06 & 1.5 & 2.57 & 0.5 \\
\hline 17 & $1 / 16 / 05$ & 13 & 0.0309 & 4.353925 & 0.03 & 591 & 19.3 & 0.06 & 1.5 & 2.55 & 0.5 \\
\hline 18 & $1 / 17 / 05$ & 13 & 0.0309 & 4.377514 & 0.03 & 590 & 19.6 & 0.07 & 1.5 & 2.54 & 0.5 \\
\hline
\end{tabular}
food amount required per day, and oxygen concentration in the effluent water flow, etc.

Figure 4.8 Worksheet with daily conditions recorded 


\subsubsection{REMOVAL OF FISH}

When the amount of oxygen in the water is insufficient, or a user wants to harvest some fish, a fish removal action is required. The single-raceway program provides a simulation to predict the conditions in the hatchery system when an amount of fish is removed.

Following the example above and the simulated conditions of fish on September 30, 2005 are given as follows:

$$
\begin{aligned}
& W_{273}=0.5031 \mathrm{lb} \\
& N_{273}=457.0504 \\
& W_{t o t, 273}=229.9409 \mathrm{lb}
\end{aligned}
$$

If $200 \mathrm{lb}$ of fish are removed from the raceway on September 30, 2005, the total weight and the number of fish remaining in the raceway on September 30 becomes:

$$
\begin{aligned}
& W_{t o t, 273}=229.9409-200=29.9409 \mathrm{lb} \\
& N_{273}=457.0504-\frac{200}{0.5031}=60
\end{aligned}
$$

From Figure 4.9, it can be seen that an amount of fish is removed on September 30 from the sharp reduction in fish number, total weight and density from August to September, as shown in the circle. 


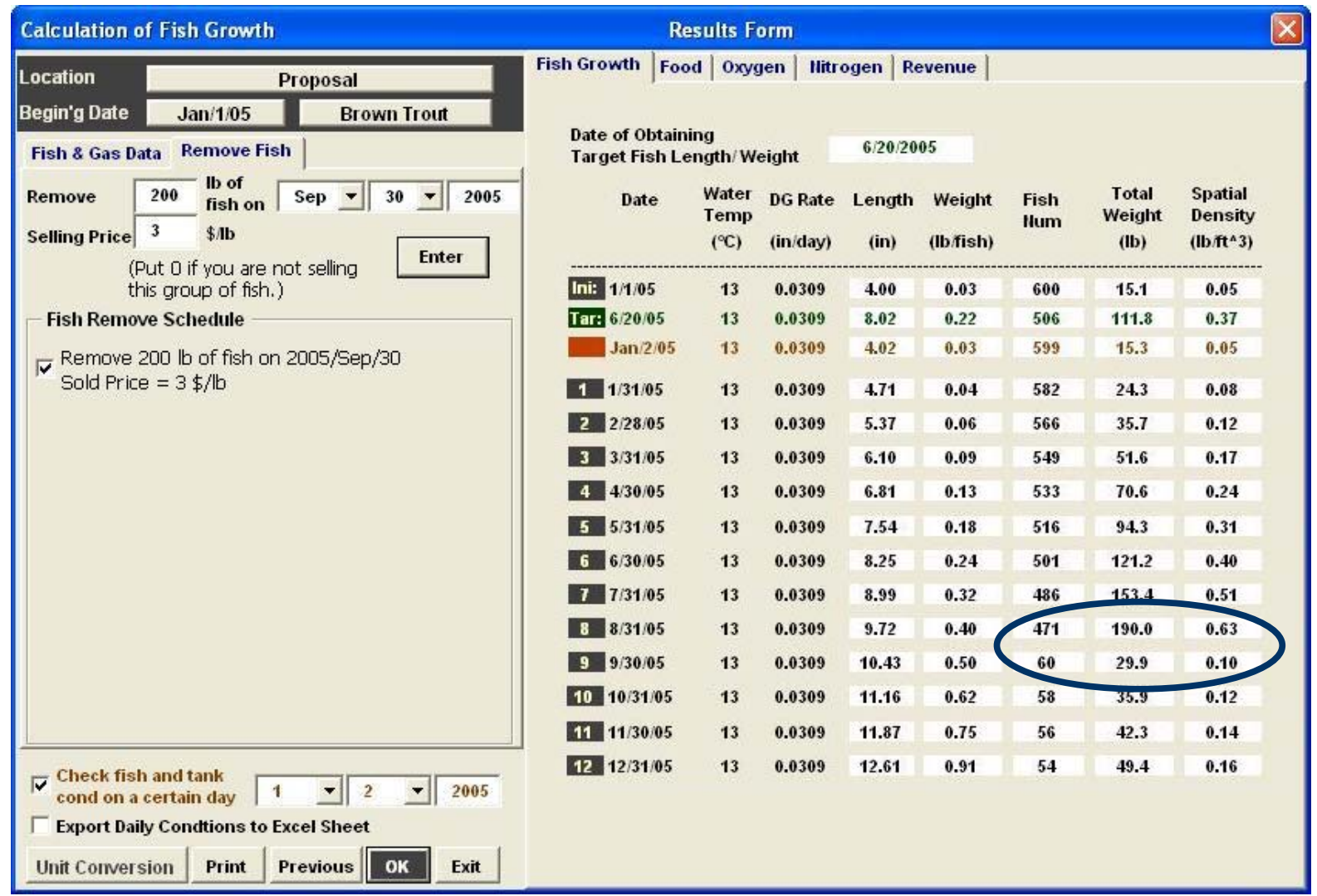

Figure 4.9 Simulation of Removal of Fish

The calculation process for water conditions is the same as that described above. It should be noted that the average weight of fish (weight per fish) on September 30 was not recalculated, because removal of fish from a raceway does not affect the growth rate of fish but it does affect the oxygen and nitrogen concentrations in water.

\subsubsection{PLOT AND PRINT FUNCTIONS}

After the simulations have been completed, the program provides charts of various parameters such as fish length, food amount required, and percentage of effluent oxygen concentration to saturated oxygen concentration versus time. These charts give the user a quick idea of how a raceway behaves/will behave and when a "risky" situation occurs. An example of a plot of effluent oxygen concentration versus time is displayed in Figure 4.10. 
Moreover, although a worksheet with daily conditions of the system is provided, it is sometimes cumbersome to use a spreadsheet with so much information. Therefore, print-outs of all the forms that appeared in the program are available for users. While operating the "Raceway Design" or the "Calculation of Fish Growth" form, a user can click the "Print" button on the bottom of the form, and then the activated form will be printed out including other pages in the input parts of the form.

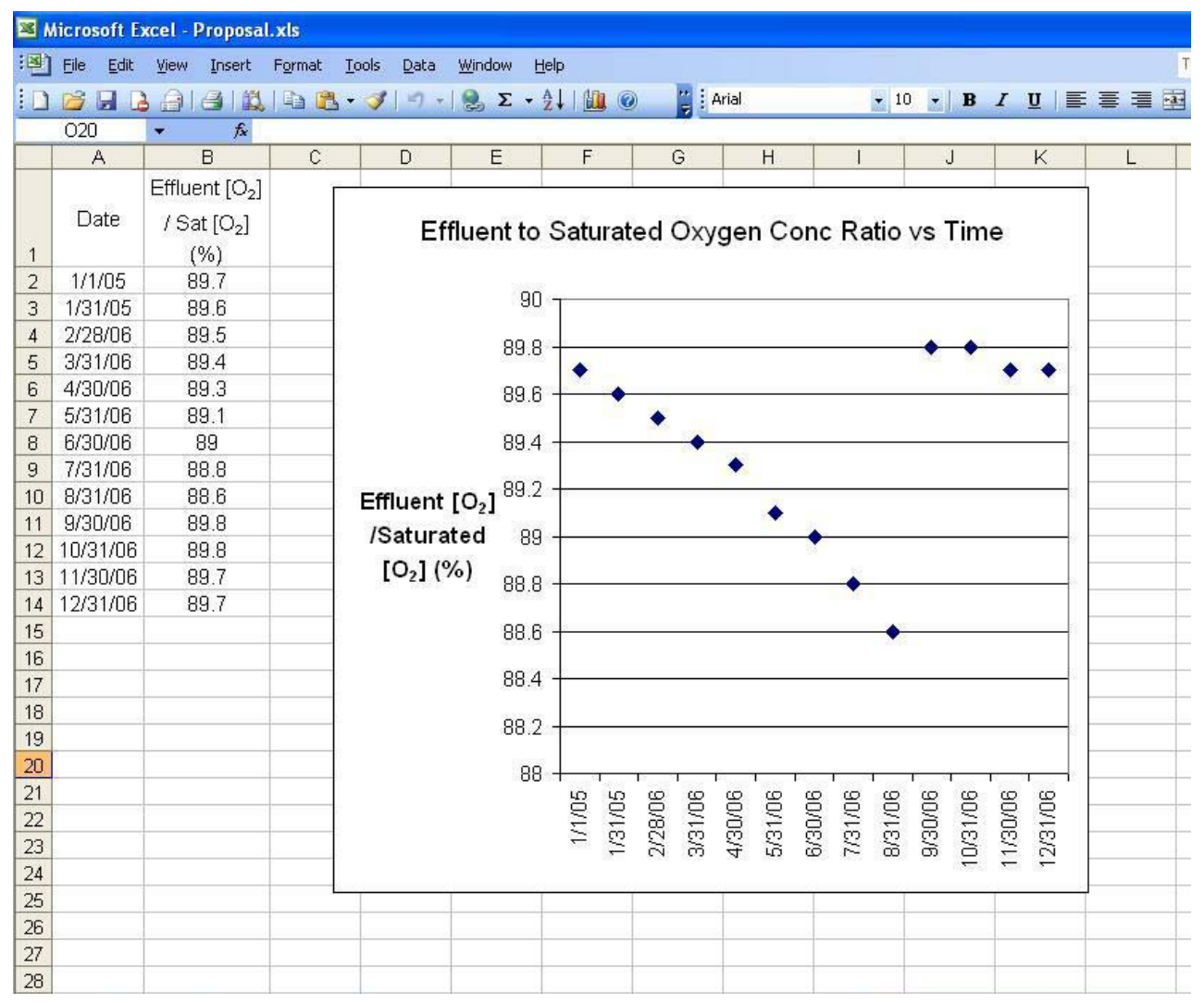

Figure 4.10 Plot of Effluent Oxygen Concentration vs. Time 


\subsection{MULTIPLE-RACEWAY PROGRAM}

\subsubsection{ADDITIONAL CONSIDERATIONS IN MULTIPLE-RACEWAY PROGRAM}

In the single-raceway program, only one raceway can be simulated at a time. However, there are usually at least 3 raceways in a practical fish-rearing farm. Thus, a program that can predict the conditions of all of the raceways in a farm will be more helpful.

There are some additional issues that do not exist in the single-raceway program but must be considered in the multiple one:

- Change in Gas Concentration in Influent Water Flow

From the illustration of calculation procedures given previously, it can be seen that the oxygen concentration in the influent water flow does not change so long as the water temperature is constant. This is because that the tank simulated in the single-raceway program is assumed to be the first tank to which water flows. Likewise, for a single-tank simulation, the inlet ammonia concentration in the water is fixed. However, this is not the case in a multiple-raceway system. For example, the ammonia concentration in the effluent water flow of the first tank is that in the influent flow to the second tank. Since the size and the number of fish change everyday, the effluent ammonia amount also changes day to day, so the influent ammonia content in the water fed to downstream tanks in the system will change accordingly.

\section{- Gravity Aeration}

In most multi-raceway systems, raceways in a run are usually located at different elevations, i.e., the tank in the back is higher than the tank in the front to allow for the gravity flow of water (Soderburg, 1994). Using this arrangement, water can be aerated naturally without much additional expense. This design, the oxygenation of water using a gravity weir, is implemented in the multi-raceway program. Input boxes for the height of water fall between adjacent raceways 
in a run have been added, as shown in the circle in Figure 4.11.

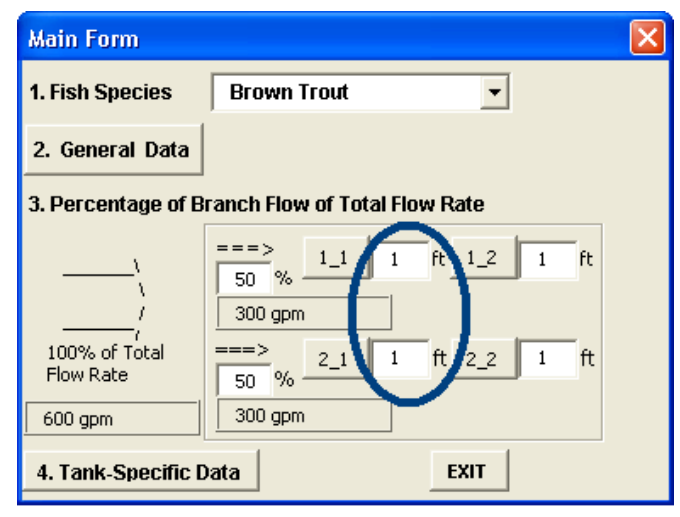

Figure 4.11 Illustration of settings of the distance of water fall

Equation (4.1) was correlated using the data provided by Klontz (1991) to calculate the increased amount of oxygen in water falling through a specific distance.

$$
\theta_{\text {aer }}=\frac{\theta}{100}+10^{\left(-0.00024091 \theta^{2}+0.015452 \theta-1.013+0.4087 \log (d)\right)}
$$

where $\theta_{\text {aer }}$ is the ratio of oxygen concentration to the saturated concentration after gravity aeration, $\theta$ is the ratio of oxygen concentration to the saturated concentration before gravity aeration expressed in percentage, and $d$ is the distance that the water falls ( $\mathrm{ft}$ ).

For example, if the oxygen concentration in the effluent stream of Tank $1 \_1$ in Figure 4.11 is $70 \%$ of saturation, after $1 \mathrm{ft}$ of water fall, from Equation (4.1), the oxygen concentration becomes:

$$
\theta_{\text {aer }}=\frac{70}{100}+10\left(-0.00024091(70)^{2}+0.015452(70)-1.013+0.4087 \log (1)\right)=0.7773
$$

Therefore, the amount of oxygen in the influent stream of Tank 1_2 in Figure 4.11 is $77.73 \%$ of saturation. 
- Addition and Movement of Fish

In the single-raceway program, fish are allowed to be added to a raceway only once. However, in practice, a user may harvest fish, and add a new cohort to a raceway several times during a year. Also, he or she may move an amount of fish from a raceway to another, or split fish among two production units due to management or economic concerns. This function is available in the multiple-raceway program. As shown in Figure 4.12, users can add, move, or remove fish from a raceway several times during a year.

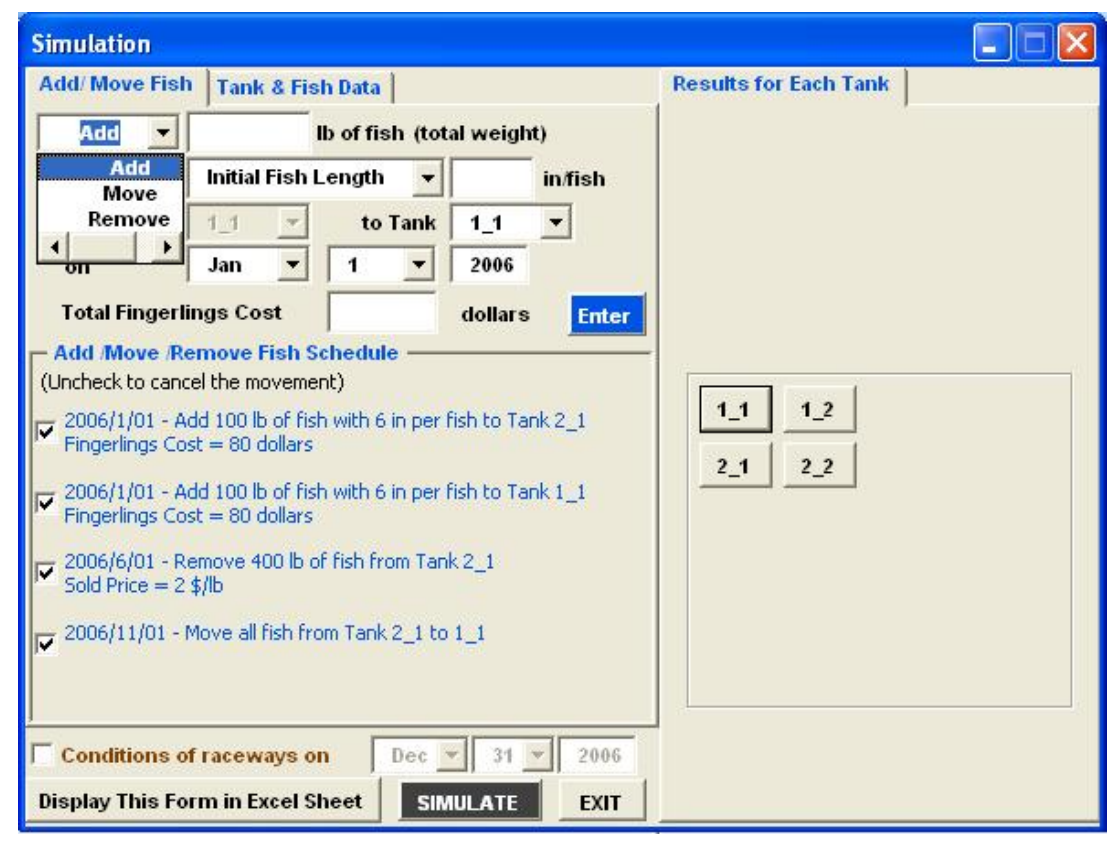

Figure 4.12 Addition, Movement and Removal of Fish

\section{- Mixing of Cohorts}

The single-raceway program is limited to simulate one cohort of fish being raised in a single raceway. However, growers sometimes place several groups of fish with different sizes in the same raceway. The multiple-raceway program can accomplish the simulation of different cohorts of fish in a given raceway. The procedure of calculation of the conditions in a raceway with 
multiple cohorts of fish is the same with the single cohort.

In the simulation of the gas contents in water, the program will calculate the oxygen demand and the ammonia production of each cohort in a raceway individually and then sum the values of all cohorts to compute the gas concentration in the effluent flow. For example, assuming that there are two cohorts in a raceway and the oxygen consumption rates over the raceway of cohort 1 and cohort 2 are $\overline{O c_{(c t 1)}}$ and $\overline{O c_{(c t 2)}}$, respectively, the oxygen concentration in the effluent flow will be

$$
O_{o u t}=O_{i n}-\left(\overline{O c_{(c t 1)}}+\overline{O c_{(c t 2)}}\right)
$$




\subsubsection{SIMULATION DESCRIPTION}

The logic of the simulation in the multiple-raceway program is basically same as that in the single-raceway program, except there is more than one raceway required to be simulated. The program first numbers the raceways as shown in Figure 4.13 in the simulation process. Next the program will read all of the actions that have been entered in the "Add/ Move/ Remove Fish Schedule" as shown in Figure 4.12 and sort the dates of these actions. Afterwards, similar with the single-raceway program, the program will perform the simulation day to day from the first day (2006/1/01 in Figure 4.12).

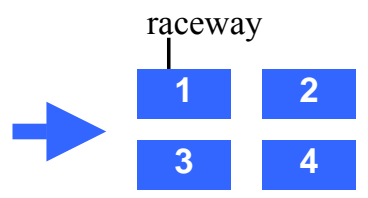

Figure 4.13 Numbered Raceways in the Multiple-raceway Program

While simulating for a specific day, the program performs the simulation for the raceways by number, i.e., raceway numbered 1 is the first to be simulated. If there are no fish in a raceway on that day, the program will simulate for the next raceway. Following the example shown in Figure 4.12 , on $2006 / 1 / 01$, the program will start simulations from raceway 1 , skip raceway 2 since it does not contain fish on 1/01, and then simulate raceway 3 (Tank 2_1). Also, raceway 4 (Tank 2_2) will not be simulated on 2006/1/01. When all of the raceways have been simulated for a day, the program will continue to calculate the conditions for the next day.

However, a problem occurs when some fish are moved from a high-numbered raceway to a low-numbered raceway. Assuming that $500 \mathrm{lb}$ of fish are moved from raceway 2 to raceway 1 on 2006/6/1, as shown in Figure 4.14, when the program is calculating the conditions of raceway 1 
on 2006/6/1, it does not possess the length and weight of a fish of this $500 \mathrm{lb}$ of fish from raceway 2 yet. Therefore, the food amount required and the gas concentration of water in raceway 1 cannot be obtained.

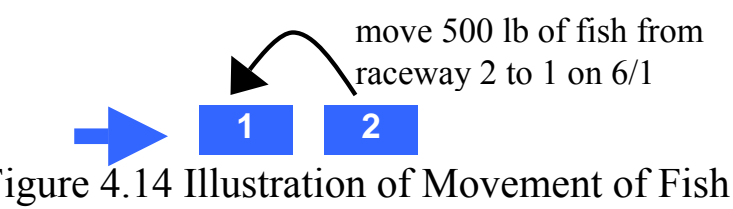

If the program passes raceway 1 and first simulates raceway 2 on $6 / 1$, the gas concentration of raceway 2 still cannot be calculated because the gas contents in the effluent water flow of raceway 1 are unknown. Therefore, on the day that fish are moved from one raceway to another, the program will first calculate the conditions of fish and the food amount required for the fish-removing raceway (raceway 2 in this case) and then go back to calculate all of the parameters including size of fish, food amount required, and gas conditions for the fish-receiving raceway (raceway 1). Finally, the program simulates the gas conditions for the large-numbered raceway. A simple illustration of this simulation procedure is shown in Figure 4.15. 


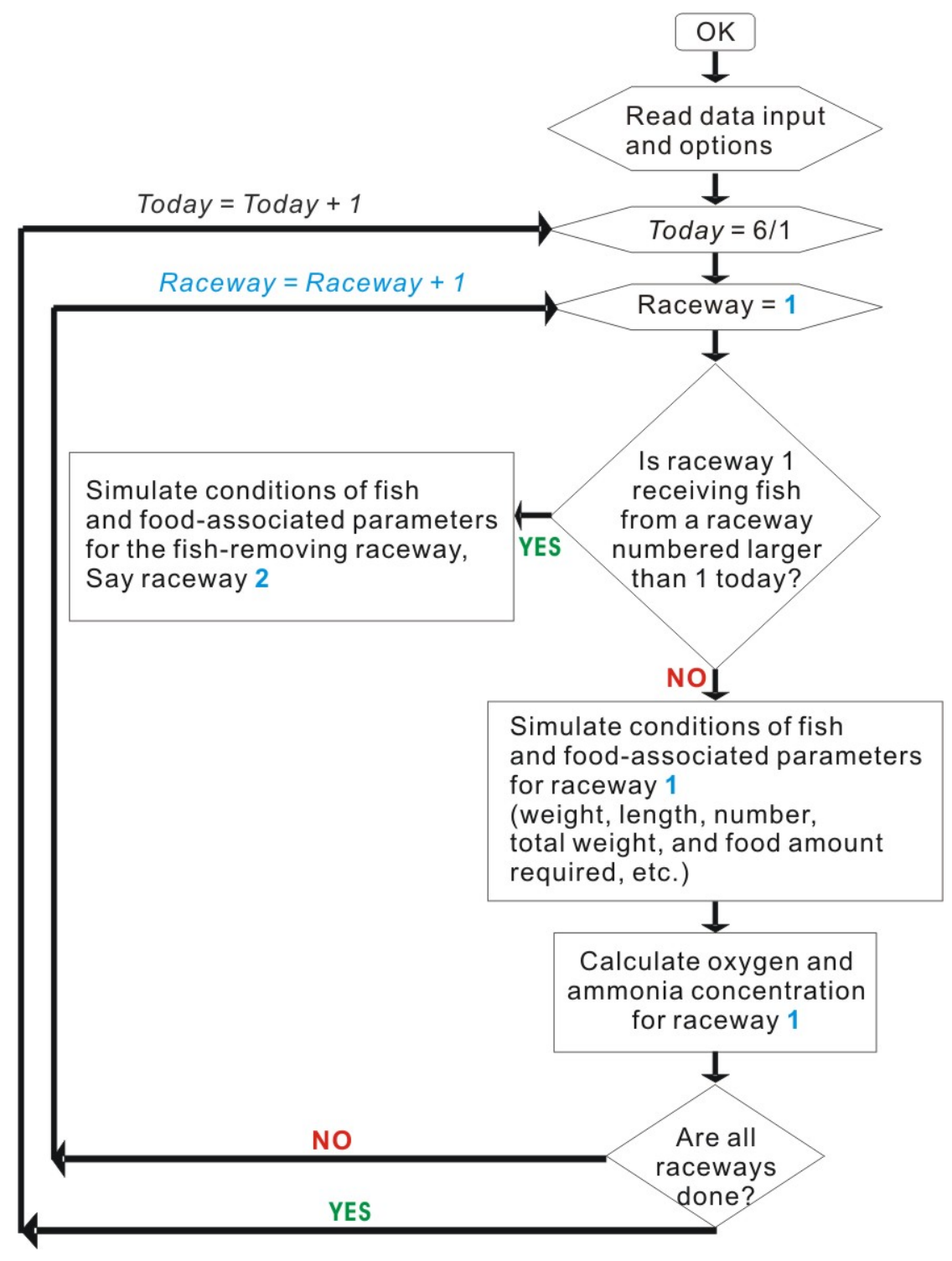

Figure 4.15 Flowchart of Process of Simulation in Multiple-Raceway Program 


\section{CHAPTER 5 CONCLUSION AND FUTURE WORK}

The multiple-raceway program provides an efficient way for users to manage their fish-rearing farms. There are some other issues that can be considered to make this program more practical and powerful.

- Change in Mortality Rate

Haskell (1959) suggested that the mortality rate changed with size of fish. In the current program, the mortality rate is assumed constant due to the limitation of the current information. The acquisition of a relationship between the mortality rate and the fish size, and applying it to the program are suggested. One of the advantages of applying the function of mortality rate and fish size is that the user will not need to input the information which is not easy to measure or obtain by a single user.

- $\mathrm{CO}_{2}$ Concentration in Water

$\mathrm{CO}_{2}$ production from the respiration of fish will affect the acidity of water, i.e., the $\mathrm{pH}$ value, the ammonia concentration, and the oxygen concentration will consequently change. The $\mathrm{CO}_{2}$ concentration should be considered in the future work.

- User-Defined Functions

The availability of user-defined functions can help the program users create simulations for other species of fish or change the equations for the original species in the program to improve the simulation results. 


\section{BIBLIOGRAPHY}

Cook, M. F. and Canton, S. P., 1988, Calculation of percent gas saturation in water by use of a spreadsheet, The Progressive Fish-Culturist, 50, 248-250

Dawson, V. K., 1986, Computer program calculation of gas supersaturation in water, The Progressive Fish-Culturist, 48, 248-250

Fries, J. N., 1994, SAMCALC: A computer program for fish culturists, The Progressive Fish-Culturist, 56, 62-64

Haskell, D. C., 1959, Trout growth in hatcheries, New York Fish and Game Journal, 6 (2), 204-237

Hammond, D. E. and Lackey, R.T., 1976, Analysis of Catchable Trout Fisheries Management by Computer Simulation, Transactions of the American Fisheries Society, 105 (1), 48-56

Isermann, D. A. and Knight, C. T., 2005, A Computer Program for Age-Length Keys Incorporating Age Assignment to Individual Fish, North American Journal of Fisheries Management, 25, 1153-1160

Klontz, G. W., 1991, A Manual for Rainbow Trout Production on the Family-Owned Farm, Nelson \& Sons, Inc, Murray, Utah

Soderberg, R. W., 1994, Flowing water fish culture, CRC Press LLC, Boca Raton, Florida Willoughby, H., 1968, A method for calculating carrying capacities of hatchery troughs and ponds, The Progressive Fish-Culturist, 30, 173-174 
Appendix: Software Manual

Raceway Design and Simulation System (RDSS)

\section{User's Guide}




\section{Table of Contents for Software Manual}

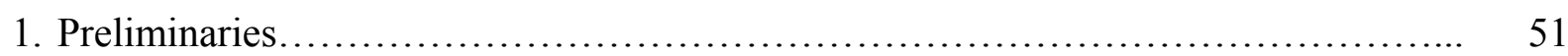

1.1 Introduction of RDSS ................................................ 51

1.2 Installation and Security Level Settings................................... 52

1.3 Some Tips about RDSS ................................................. 53

2. Quick Start................................................................... 54

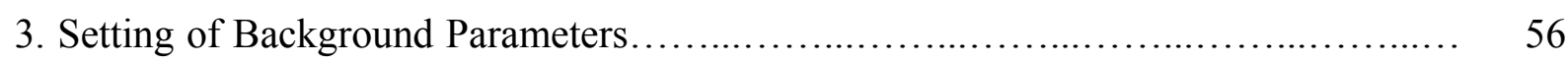

3.1 Fish Species.............................................................. 56

3.2 General Data.............................................................. 57

3.2.1 Water temperature and water flow rate............................... 57

3.2.2 Number of Raceways and Gas Data................................... 60

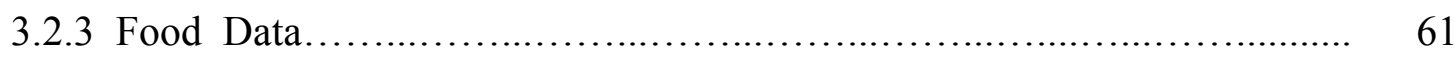

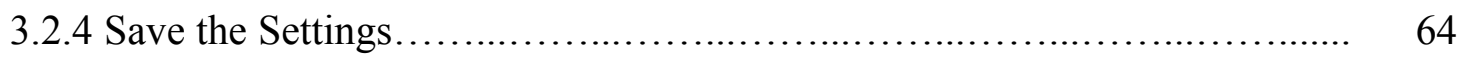

3.3 Branch Flow as a Percentage of Total Flow Rate............................... 65

4. Simulation.................................................................... 66

4.1 Placement of Fish.......................................................... 66

4.2 Settings of Tank Specific Data and Fish Data.................................. 69

4.3 Check Conditions of Raceways on a Specific Day........................... 70

4.4 Activate the Simulation................................................ 70 


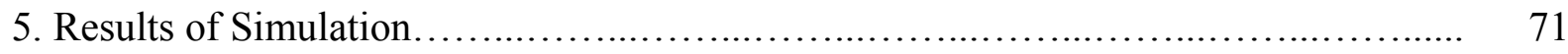

5.1 Detailed Information for Each Raceway ......................................... 71

5.1.1 Water Exchange Rate and Water Velocity ..................................... 72

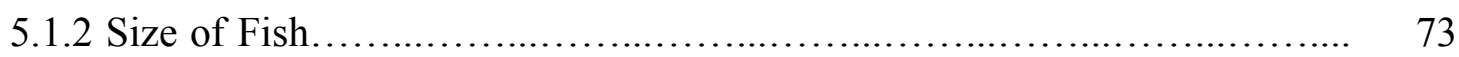

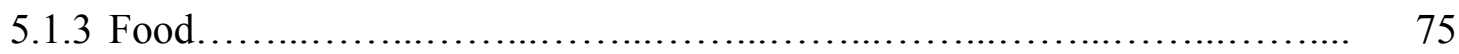

5.1.4 Oxygen Concentration in Water............................................. 79

5.1.5 Ammonia Concentration in Water......................................... 80

5.1.6 Food Cost and Revenue from Fish Sales....................................... 82

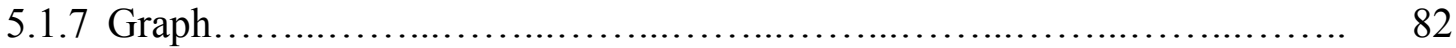

5.1.8 Screenshot of a Form........................................................... 83

5.2 Overview of the Conditions of the Whole System on a Specific Day.............. 84

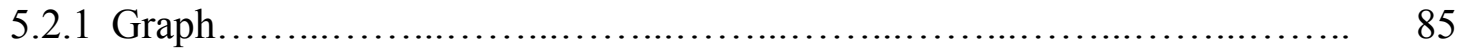

5.2.2 Screenshot of the Simulation form.............................................. 85

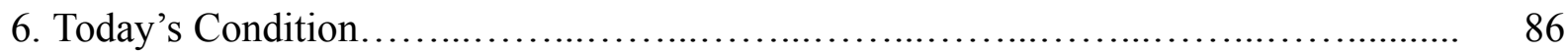

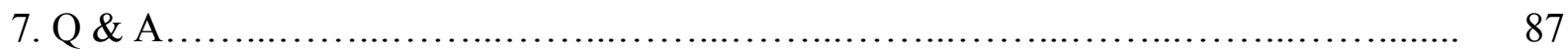

8. Error and Information Messages........................................................... 91

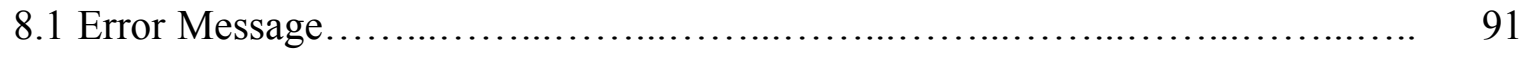

8.2 Information Message............................................................... 97

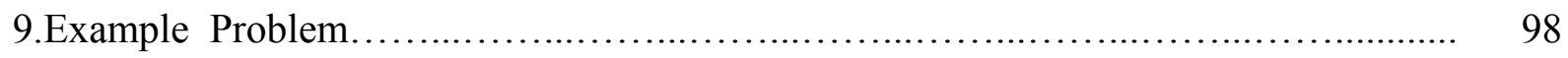




\section{Preliminaries}

\subsection{Introduction of RDSS}

RDSS (Raceway Design and Simulation System) is a built-in program in Microsoft Excel ${ }^{\mathrm{TM}}$. RDSS is a tool for evaluation of fish-rearing raceways. It includes:

- simulations of a system of multiple tanks arranged both in series and parallel arrangements

- allowances for the movement of fish at different times in different tanks

- $\quad$ simulations of multiple cohorts in a single raceway

- forecasts of size of fish, number of fish (due to mortality), and monthly food required

- forecasts of oxygen and ammonia concentration in water for each raceway

- an evaluation of monthly and accumulative cost for food, revenue from fish sale and cash flow

- charts of various parameters for each raceway and for the system to give an overview of the system during the following year

- displays of RDSS forms in $\mathrm{Excel}^{\mathrm{TM}}$ worksheets for printing and saving 


\subsection{Installation and Security Level Settings}

Step 1 Save the "RDSS" folder in your hard drive (for example, C: \My Documents).

Step 2 Open Microsoft Excel ${ }^{\mathrm{TM}}$. On the Tools menu, click Macro $=>$ Security... to check if the security level is at Medium.

- If the security level is High or Very High, change it to the Medium level, close Excel $^{\mathrm{TM}}$, and re-open it. Open RDSS.xls to start the simulation.

- If the security level is Medium or lower already, go ahead to open RDSS.xls.

- You will be warned about the macro viruses while RDSS is opening. Press Enable Macros to allow RDSS to function properly.

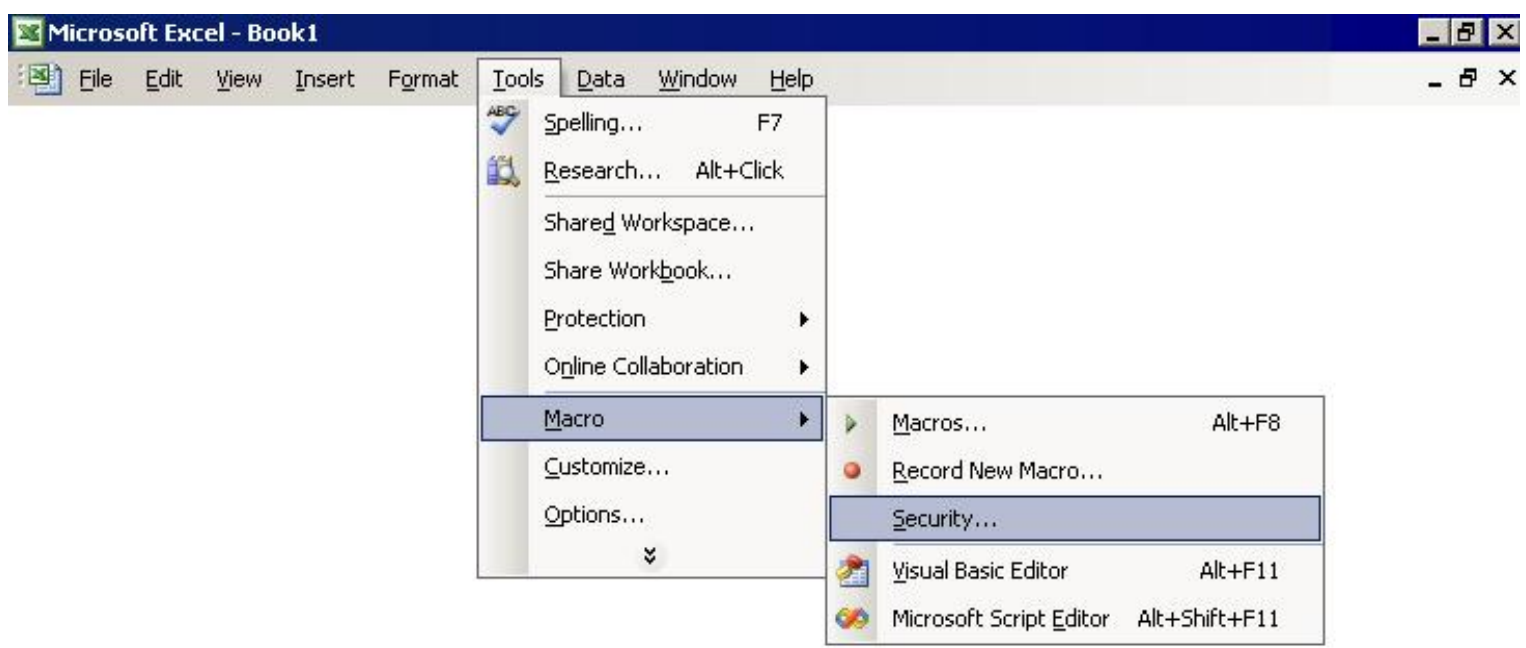

Figure A1 Setting of Security Level 


\subsection{Some Tips about RDSS}

- RDSS provides various options for background information settings. Once the data have been saved, you will not need to set them again for the simulations unless you want to change the background data.

- Some buttons and input columns contain immediate help messages to describe what the button/column is for. Rest your mouse on the button/column for a little while. The message will show up.

\section{Basic Operation}

- Close RDSS

Click Exit This Program on Main Form to close RDSS.

- For display and print of forms, click Display This Form in Excel Sheet on the left bottom of the form. The image of this form will be pasted into an Excel $^{\mathrm{TM}}$ worksheet.

- Exit a form

Click EXIT on the bottom of the form to exit it. 


\section{Quick Start}

Step 1 open RDSS.xls.

Step 2 Click Start Simulation to activate the program.

Step 3 Click 4 . Simulation on Main Form.

Step 4 Add an amount of fish with specific length or weight to a tank.

- For example, $300 \mathrm{lb}$ of 4" long fish were put in Tank 1_1 on February 1, 2006, and the total fingerlings cost was entered as \$200. Fill this information in the Add/Move Fish section, and then click Enter

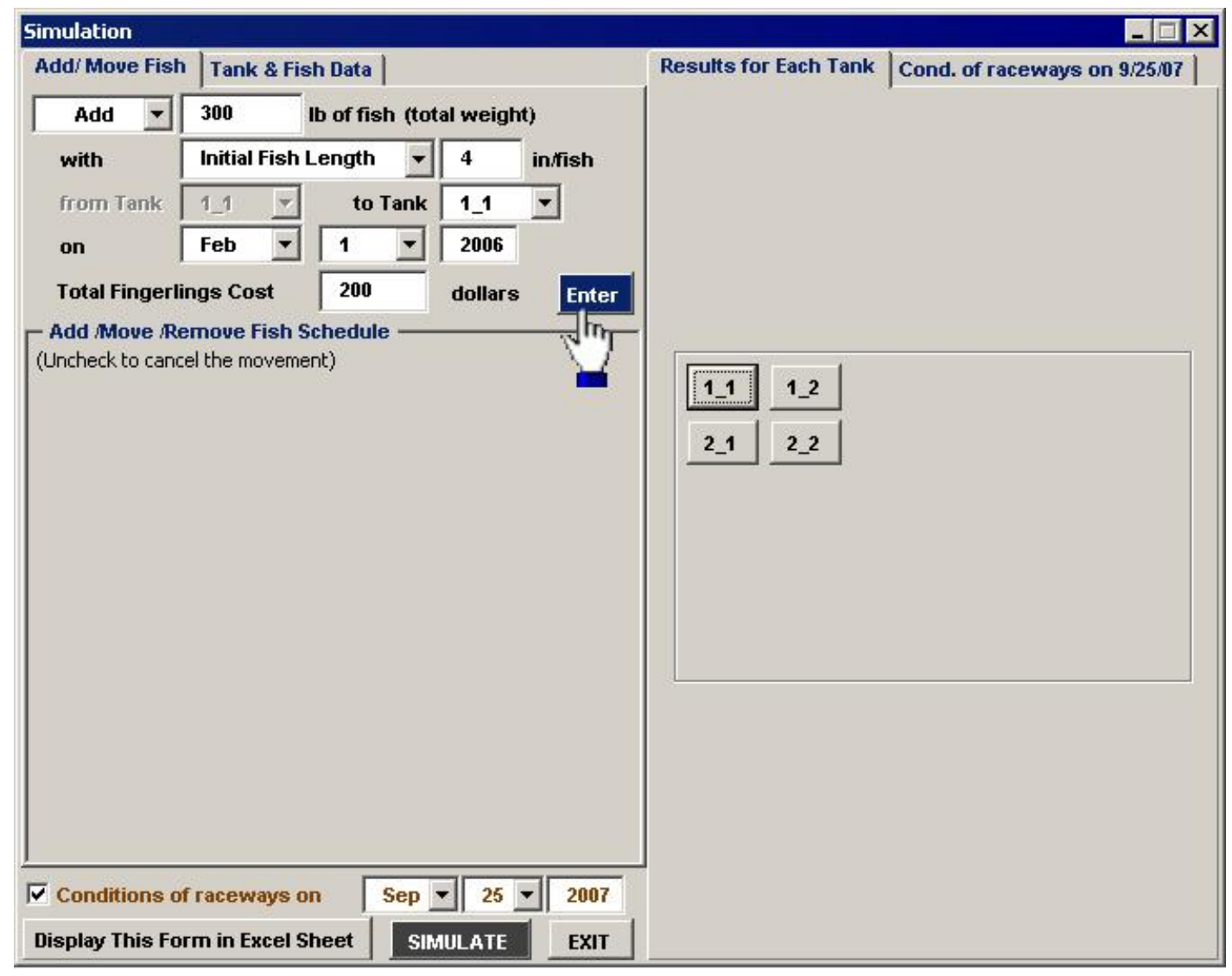

Figure A2 Addition of Fish in a Raceway 
- The data you just entered will be displayed in the Add /Move Remove Fish schedule frame to indicate that a "movement" has been made.

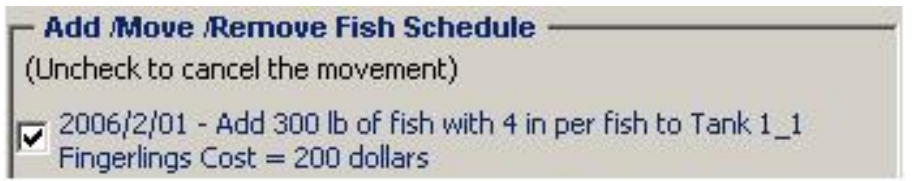

Figure A3 Add /Move /Remove Fish Schedule

Step 5 Repeat Step 4 to add more fish.

Step 6 If you wish to view the conditions of the raceway on a particular day, change the date at the bottom of the form (now showing Sep 25 2006) and leave the checkbox next to it checked.

Step 7 Click SIMULATE on the bottom of the Simulation form. When the caption on the right top shows "DONE!", you may click 1_1 (or other tank icons in which you have put fish) to view the simulation results for Tank 1_1.

Step 8 Click the Cond. of Raceways on 9/25/06 tab to view the conditions of each tank on September 25, 2006 (or the date you entered in Step 6). 


\section{Setting of Background Parameters}

\subsection{Fish Species}

RDSS provides four types of trout for simulation: Shasta rainbow trout, Kamloops rainbow trout, Brook trout, and Brown trout. Fish in all raceways in the system simulated by RDSS are assumed to be of the same species.

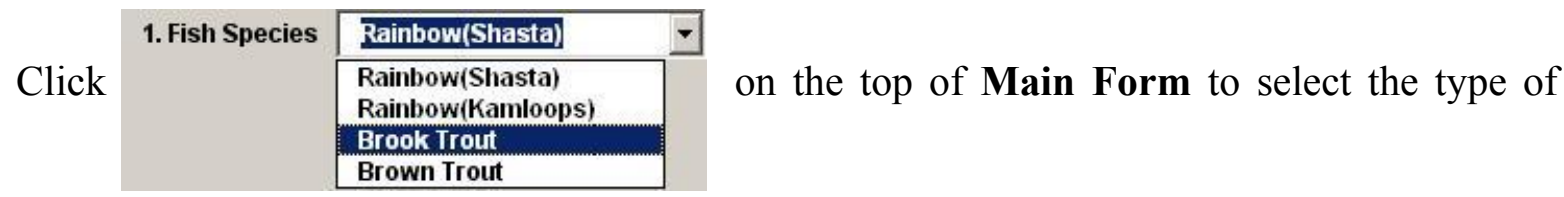

trout you want in the raceway. The program will immediately save the species of fish you just selected. 


\subsection{General Data}

Click 2. General Data on the Main Form to set/change the general parameters. The species of fish you have selected will be displayed on the left top label on the General Data form as shown in Figure A4.

3.2.1 Water temperature and water flow rate

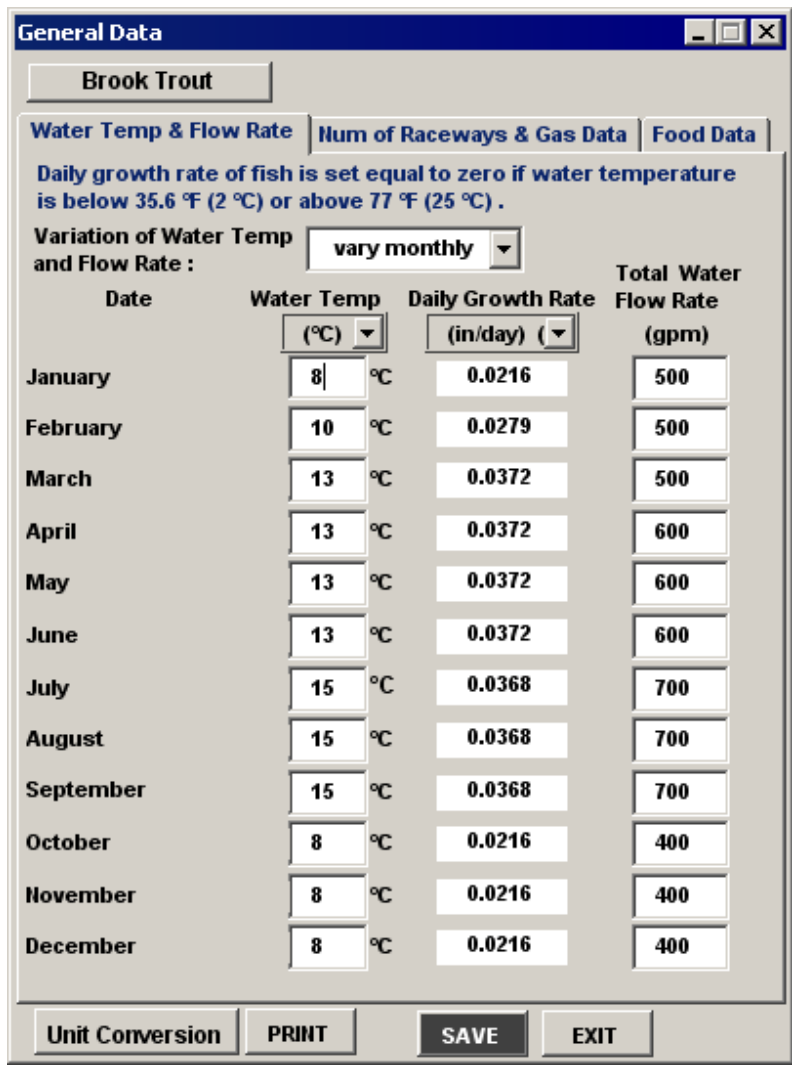

Figure A4 Setting of Water Temperature and Water Flow Rate

- Variation of Water Temp and Flow Rate

Water temperature and water flow rate can set to be constant or changed monthly in RDSS. Click Variation of Water Temp and Flow Rate :

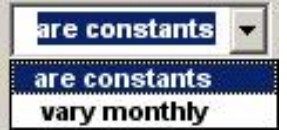
to set the variation of temperature and flow rate of the system you want to simulate. If a constant-temperature/flow rate is selected, the second to the twelfth boxes for temperatures and flow rates will be disabled. 
- Input of Water Temperature and Water Flow Rate

Enter the constant water temperature/flow rate or monthly average water temperatures/flow rates (according to the variation of temperature/flow rate you have set) in the Water Temp and Total Water Flow Rate columns shown in Figure A5 and Figure A6.

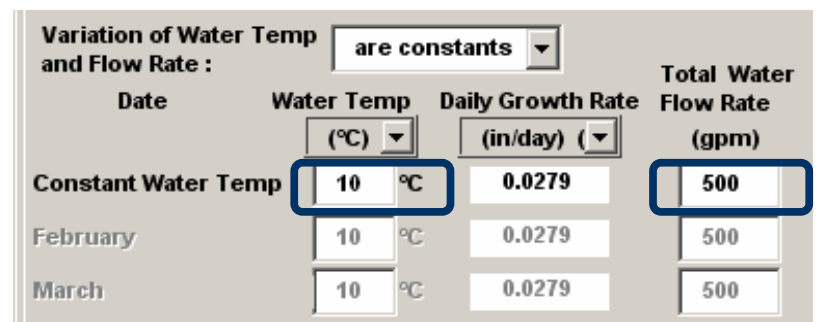

Figure A5

Constant Water Temperature and Flow Rate

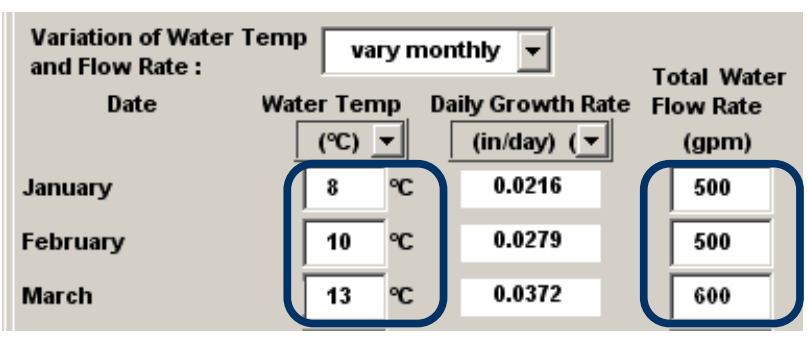

Figure A6

Monthly-Changed Water Temperature and Flow Rate

- Daily Growth Rate

Upon entering the value of water temperature, the corresponding theoretical daily growth rate will be immediately displayed in the column on the right side of the water temperature box.

- Units of Water Temperature

You can choose the units of water temperature to be Centigrade or Fahrenheit.

Click

While the unit of temperature is being changed, the theoretical daily growth rate will be immediately evaluated according to the unit selected and the value in the water temperature box.

Note:

* The numerical values in the water temperature box are not converted when the 
units are changed. They are simply units presented in the new units. For example, if the temperature is $10{ }^{\circ} \mathrm{C}$, and the theoretical growth rate is 0.0279 in/day originally, when the unit is changed from ${ }^{\circ} \mathrm{C}$ to ${ }^{\circ} \mathrm{F}$, the growth rate will become zero since $10^{\circ} \mathrm{F}$ is used to evaluate fish growth, which is zero for this temperature.

- Size Units for Fish

You can choose the units of length and weight of fish to be either English or metric.

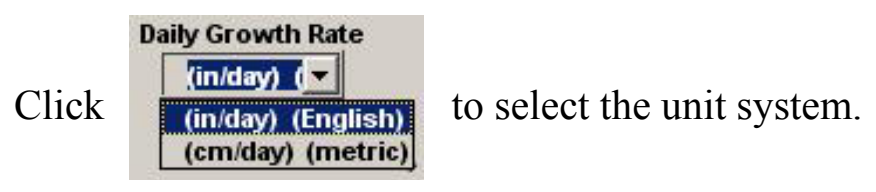

If English system is selected, the length and the weight of fish in the following simulations will be calculated and displayed in inches and pounds, respectively. On the other hand, the length and the weight of one fish will be calculated and displayed in centimeters and grams if the metric system is chosen.

While the unit system is being changed, the theoretical daily growth rate will be immediately evaluated according to the unit selected. For example, if the temperature is $10^{\circ} \mathrm{C}$ and the unit is changed from (in/day) (English) to (cm/day) (metric), the growth rate will be converted from $0.0279 \mathrm{in} /$ day to $0.0709 \mathrm{~cm} /$ day. 


\subsubsection{Number of Raceways and Gas Data}

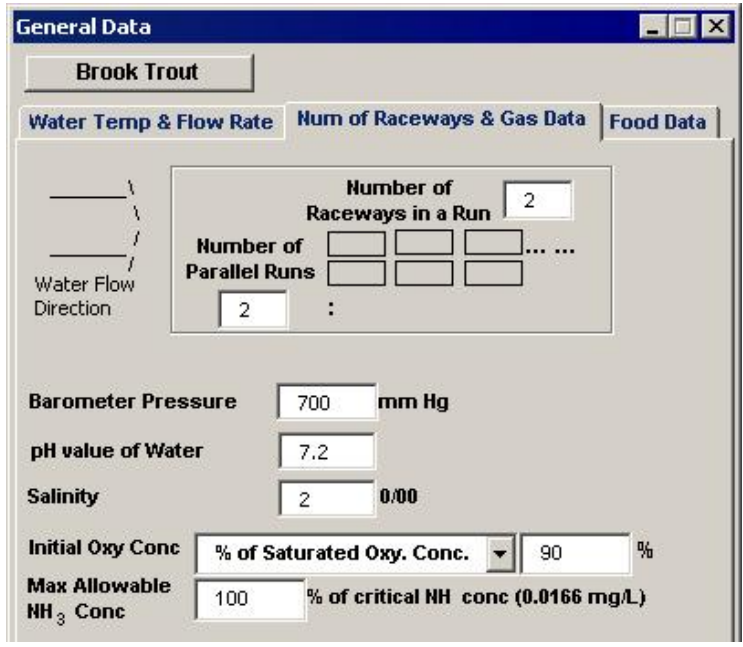

Figure A7 Setting of Number of Raceways and Gas Data

- Number of Raceways

The maximum number of raceways in a run is 10 and the maximum number of parallel runs is 5 . Neither of them can be zero.

\section{- Barometer Pressure}

The units for the required barometer pressure input are millimeters of mercury ( $\mathrm{mm}$ $\mathrm{Hg}$ ). If your barometer does not use this unit system, there are many websites providing the unit conversion calculation. You may enter the reading on your barometer to obtain the value in $\mathrm{mm} \mathrm{Hg}$ easily. The following websites are for your reference:

http://www.onlineconversion.com/

http://www.digitaldutch.com/unitconverter/ 
- Initial Oxygen Concentration

To set the initial oxygen concentration in the influent water of the whole fish-rearing system, click Initial Oxy Conc

$\begin{aligned} & \text { \% of Saturated Oxy. Conc. }>85 \\ & \text { \% of Saturated Oxy. Conc. }\end{aligned}$.
Customize...

- \% of Saturated Oxy. Conc. You are prompted to enter a percentage in the input box. RDSS will calculate the oxygen concentration in $\mathrm{mg} / \mathrm{L}$ in the initial influent water of the whole system according to the temperature, the barometer pressure, the salinity of water, and the percentage you have entered.

- Customize... You must enter the value of the oxygen concentration in $\mathrm{mg} / \mathrm{L}$ in the initial influent water for the whole system. In this case, the initial influent oxygen concentration will be constant regardless of the variation of the water temperature.

- Maximum Allowable Ammonia Concentration

To set the maximum allowable ammonia concentration in the raceways, enter a percentage value in $\begin{aligned} & \mathbf{M a x}_{\mathbf{H}} \text { Allowable } \\ & \mathbf{H} \mathbf{H}_{3} \text { Conc }\end{aligned}$

The critical $\mathrm{NH}_{3}$ concentration is $0.0166 \mathrm{mg} / \mathrm{L}$ which is suggested by Soderburg (1994). If you enter a percentage higher than 100, you permit a larger range of $\mathrm{NH}_{3}$ in your raceways. For example, if $\mathbf{1 2 0} \%$ of critical $\mathrm{NH}_{3}$ concentration is set, the maximum allowable $\mathrm{NH}_{3}$ content in a raceway will be

$$
(0.016)(120 \%)=0.02 \mathrm{mg} / \mathrm{L}
$$

Therefore, a $\mathrm{NH}_{3}$ concentration higher than $0.016 \mathrm{mg} / \mathrm{L}$ such as $0.019 \mathrm{mg} / \mathrm{L}$ will be acceptable in your raceways.

\subsubsection{Food Data}

RDSS provides three choices with different sets of parameters required to be input for food data. You can select one of them according to the information available on food. 


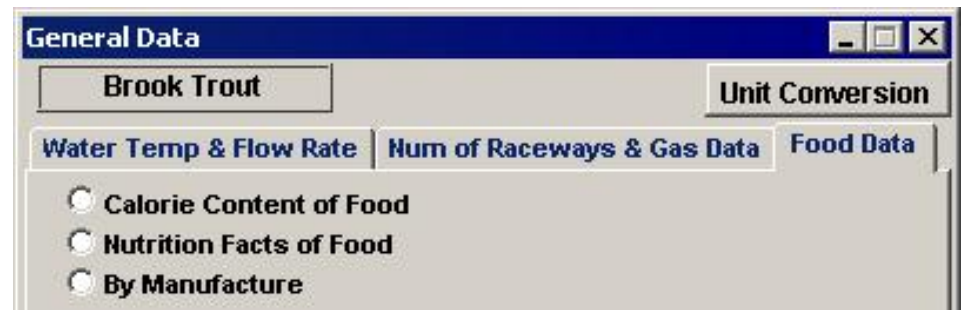

Figure A8 Three Choices for Setting of Food Data

Calorie Content of Food requires metabolic Calorie and protein content of food, you may ask your food vendor for this information.

- Hutrition Facts of Food requires protein, fat and carbohydrate content of food.

\section{Note:}

When you switch the options between Calorie Content of Food and Nutrition Facts of Food, the required information in the Calorie input box will change. Make sure the value in every input box is reasonable.

For example, as shown in Figure A9, when the option changes from Calorie Content of Food to Nutrition Facts of Food, the input box for the Calorie becomes the box for the fat content. The value of 1200 for the Calorie originally will be inappropriate for the fat content, and cause incorrect simulation results.

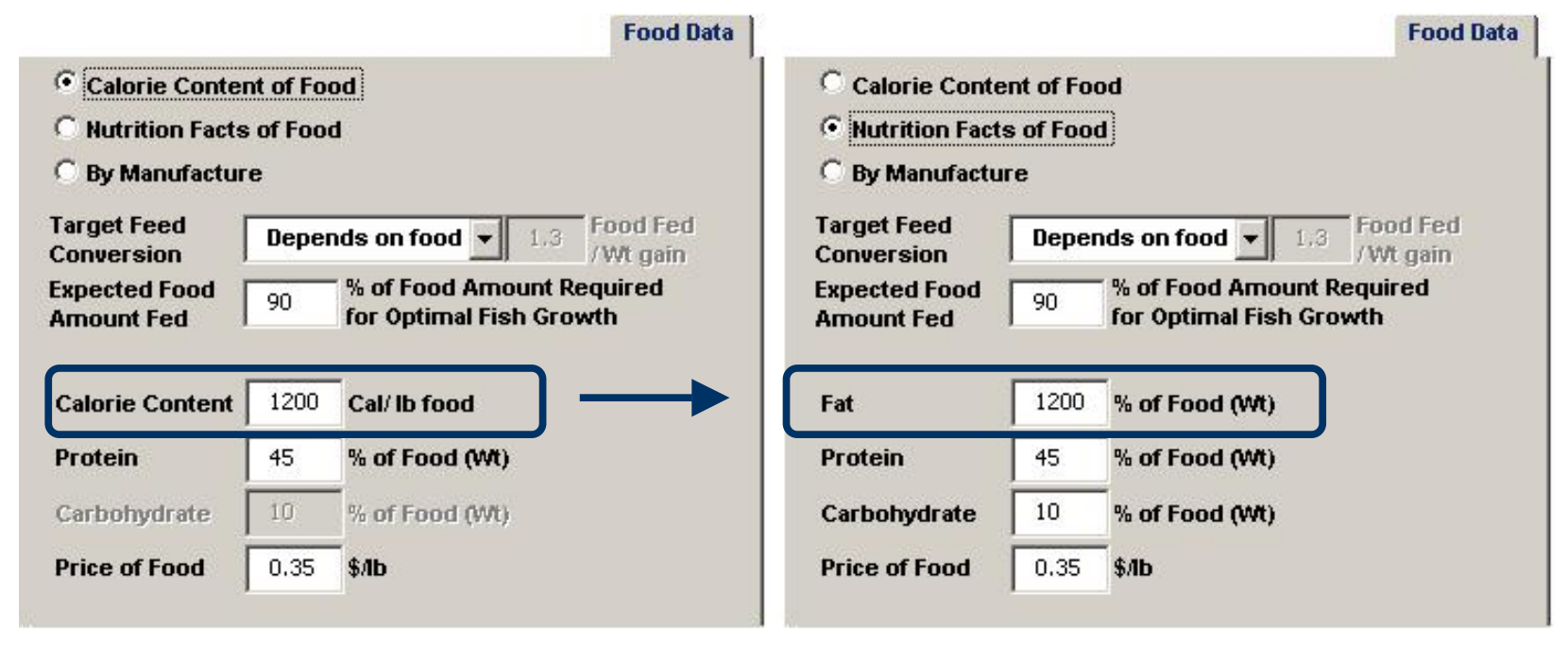

Figure A9 Setting of Food Data 


\section{By Manufacture}

Usually, food is provided with various types and nutrition facts for different size of fish to obtain the optimal growth. You can select a specific feed for a range of fish size in this By Manufacture option.

- Click a manufacture button shown in Figure A10, food of all categories for that manufacture will be selected or unselected.

- Alternatively, you can directly press a feed type button for each range of fish length shown as Figure A11. Only one feed can be selected in a category.

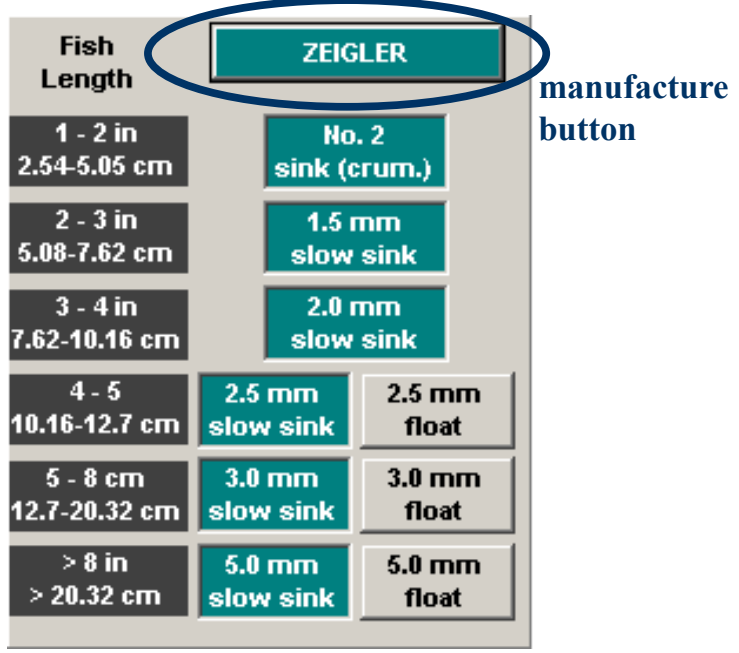

Figure A10 Selection of Food

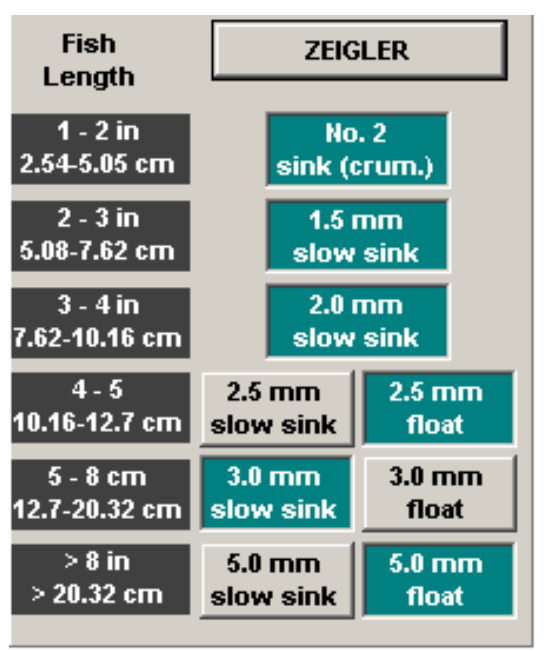

Figure A11 Selection of Food

\section{Note:}

* You must select a specific feed for every range of fish length. If your initial fish size is 3" long, just press any button for 1 - 2 in of fish; since, this feed type will not be used in the simulation.

- Target Feed Conversion

Target feed conversion is the ratio of the amount of food fed to the weight gain of fish. RDSS will use the target feed conversion you set to compute the increased 
weight of fish.

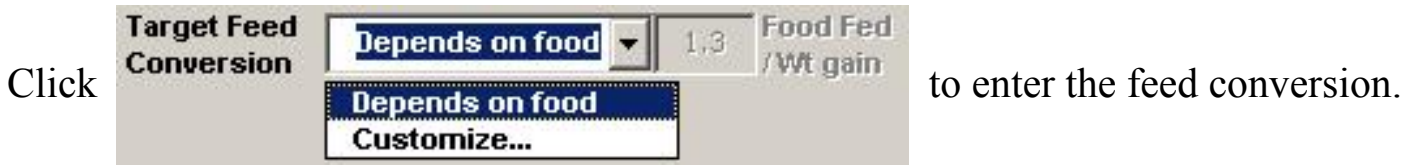

\section{- Depends on food}

RDSS will calculate the target feed conversion according to the nutrition facts you entered. You will not need to input the value of feed conversion if this item is selected.

- Customize...

RDSS will take the value of feed conversion you input to do the simulations regardless of the actual nutrition content of the food.

* You cannot customize the target feed conversion if the food is By Manufacture since the nutrition contents have been specifically fixed.

- Expected Food Amount Fed

You can adjust the amount of food you want to feed. Enter a percentage in $\begin{aligned} & \text { Expected Food } \\ & \text { Amount Fed }\end{aligned} \quad \begin{aligned} & \% 0 \text { of Food Amount Required } \\ & \text { for Optimal Fish Growth }\end{aligned}$. This value will affect the weight gain of fish.

For example, assuming that a fish would gain $1 \mathrm{oz}$ in a day when it was fed $100 \%$ of food amount required for optimal growth, then it would actually gain 0.9 oz if $90 \%$ of the optimal amount of food is fed.

\subsubsection{Save the Settings}

Click SAvE on the bottom of the General Data form to save all of the options and values you have set. 


\subsection{Branch Flow as a Percentage of Total Flow Rate}

- Water flow rate in Raceways

To adjust the water flow rate through a run, enter a percentage value in the box on Main Form shown in Figure A12.

The total water flow rate you have set in 2. General Data is shown in the list, and the corresponding water flow rate will be immediately displayed on the list below the percentage box.

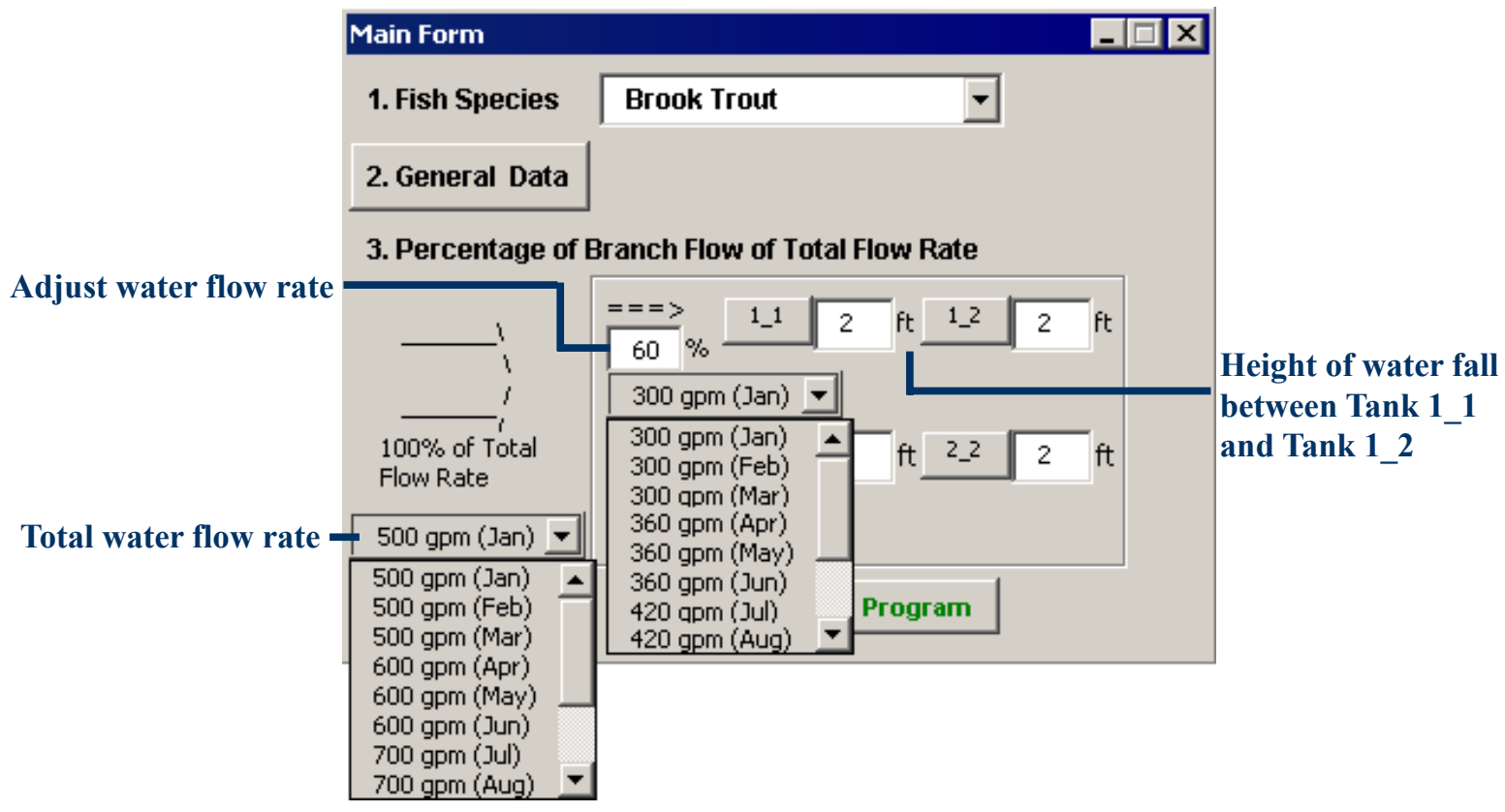

Figure A12 Setting of Water Flow Rate of Branch Flow and Height of Water Fall

- Height of Water Fall between Adjacent Raceways

Enter the height of water fall between adjacent raceways in a run shown in Figure A12. This value will affect the increase in oxygen concentration in the influent water to the next raceway. 


\section{Simulation}

\begin{tabular}{l|l|l} 
Click & 4. Simulation & on Main Form to perform the simulations.
\end{tabular}

\subsection{Placement of Fish}

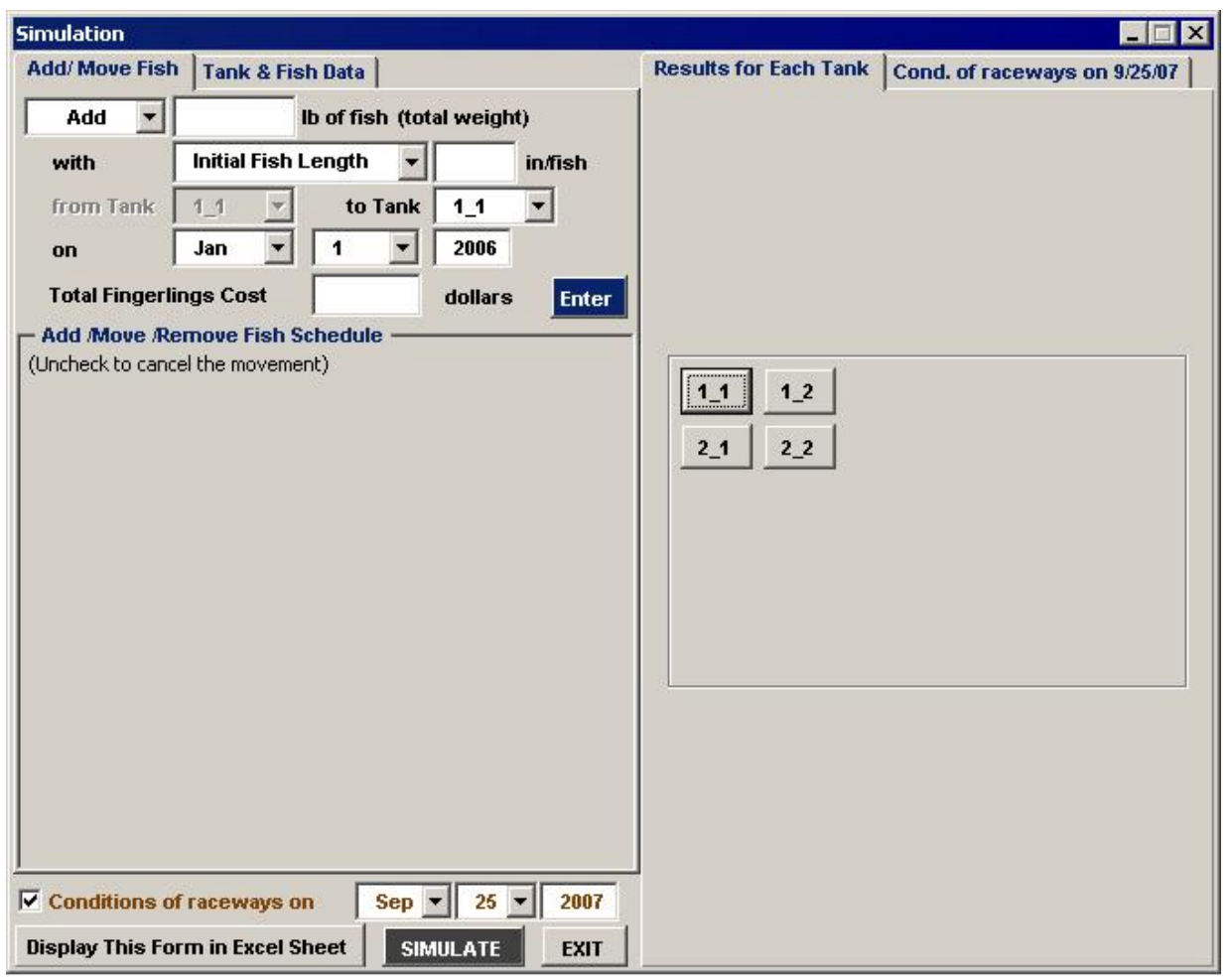

Figure A13 Simulation Form

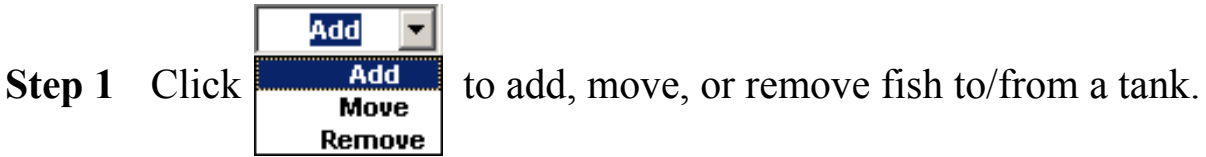

Add is for adding a certain amount of fish with known conditions to a tank. This group of fish is not from another tank in the system.

Move is for moving an amount of fish from one tank to another in the system

Remove is for removing a certain amount of fish out of the system.

Step 2 Set the total weight of fish you want to put or remove.

If you Add fish in Step 1, you must enter a specific value of total fish weight in 
Ib of fish (total weight). If you Move or Remove fish in Step 1, a drop button will show up as in Move 300 (1) of fish (total weight). You can choose to move all fish from the raceway, or enter a value in the box to move a specific amount of fish.

If you selected English unit system on the General Data form, the unit of the total weight of fish is in lb. If a metric system was selected, the unit of the total weight of fish is in $\mathrm{kg}$.

Step 3 Enter the initial size of fish in Initial Fish Length input the length or the weight of fish.

For English unit system, the unit of the initial length of fish is in in., and the initial weight of fish is in lb/fish. For a metric system, the length of fish is in cm, and the weight of fish is in $\mathrm{g} /$ fish.

* If you Move or Remove fish in Step 1, you will not need to input this initial value.

Step 4 Assign the tank in which you want to put in fish or remove fish from.

\begin{tabular}{|c|c|c|c|c|c|}
\hline \multirow[t]{5}{*}{ from Tank } & 1_1 & $\nabla$ & \multirow[t]{5}{*}{ to Tank } & 1_2 & $\nabla$ \\
\hline & \multicolumn{2}{|c|}{11} & & \multicolumn{2}{|l|}{11} \\
\hline & \multicolumn{2}{|c|}{$1 \_2$} & & \multicolumn{2}{|c|}{12} \\
\hline & \multicolumn{2}{|c|}{21} & & \multicolumn{2}{|c|}{21} \\
\hline & \multicolumn{2}{|c|}{$2{ }_{2}$} & & \multicolumn{2}{|l|}{22} \\
\hline
\end{tabular}

* If you Add fish in Step 1, the from Tank part will be disabled to remind that you do not need to assign any tank there. Likewise, the to Tank part will be disabled if you select Remove in Step 1.

Step 5 Set the date you want to perform this "movement" in on $\begin{array}{lll}\text { Jan } & \mathbf{1} & \mathbf{2} \\ \mathbf{2 0 0 7}\end{array}$

Step 6 For "Add", enter the cost of this group of fish in Total Fingerlings cost $\square$ dollars . For "Remove", enter the price of fish you are going to sell in Sold Price (per lb) $\square$ \$lb . 
* If you are not sure the cost or the price of fish, just leave this box empty or enter 0 .

Step 7 Click Enter . The data you just set will be displayed in the Add /Move Remove Fish schedule frame to indicate that a "movement" has been made.

* RDSS will not execute the movement if you do not press Enter.

Step 8 Repeat Step 1 to Step 7 to add other movements.

* If you want to cancel a movement, uncheck the item as shown in Figure A14. This item will become grey, and will not be considered in the simulations. On the contrary, check the item if you want to keep the movement.

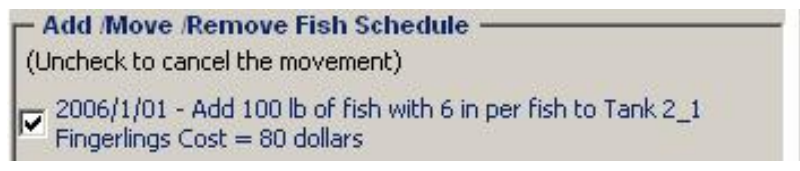

- Add Move Remove Fish Schedule

$\sqrt{ } 2006 / 1 / 01$ - Add $100 \mathrm{lb}$ of fish with 6 in per fish to Tank 2_1

Figure A14 Cancellation of a Movement

\section{Note:}

- Add Move Remove Fish Schedule (Uncheck to cancel the movement)

- 2006/1/01 - Add 100 lb of fish with 6 in per fish to Tank 2_1

* There is no need to put movements in order of date. RDSS will arrange the movements while simulating.

* While you are setting a movement, make sure that the logic is correct. For example, as shown in Figure A15, fish cannot be taken out of Tank 1_1 earlier than 3/1/2007 since there are no fish in it before this date.

$2007 / 2 / 10$ is earlier than $2007 / 3 / 01$.

Therefore, the circled item is wrong

- Add Move Remove Fish Schedule (Uncheck to cancel the movement) $\sqrt{\checkmark}$ 2007/3/01 - Add $500 \mathrm{lb}$ of fish with $1 \mathrm{lb}$ per fish to Tank 1_1 $\sqrt{\checkmark} 2007 / 2 / 10$ - Remove $800 \mathrm{lb}$ of fish from Tank 1_1

Figure A15 Wrong Movement 


\subsection{Settings of Tank Specific Data and Fish Data}

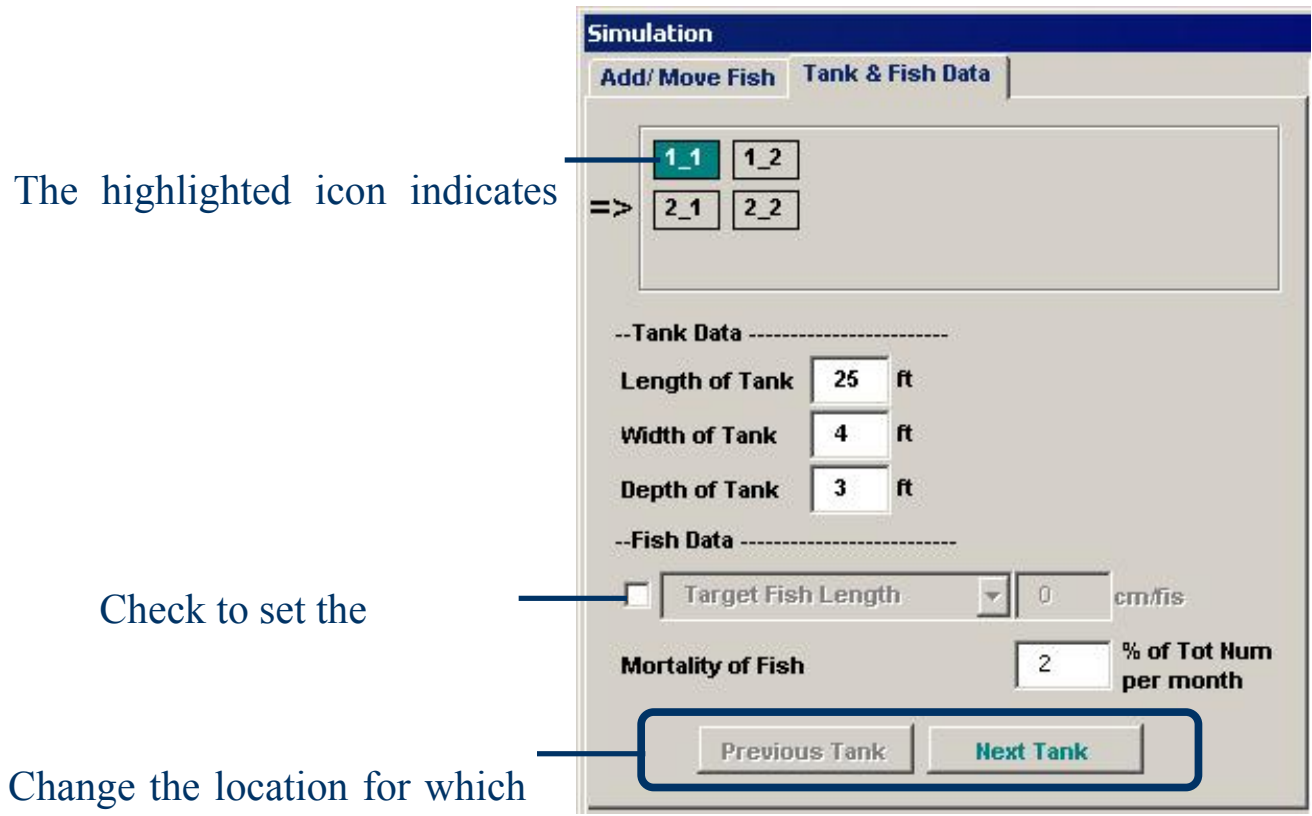

Figure A16 Settings of Tank Specific Data and Fish Data

- Enter Data for a Specific Raceway

Click Next Tank or Previous Tank to change the location you want to input data. The highlighted icon will also change accordingly as shown in Figure A17. The value you entered will be automatically saved.
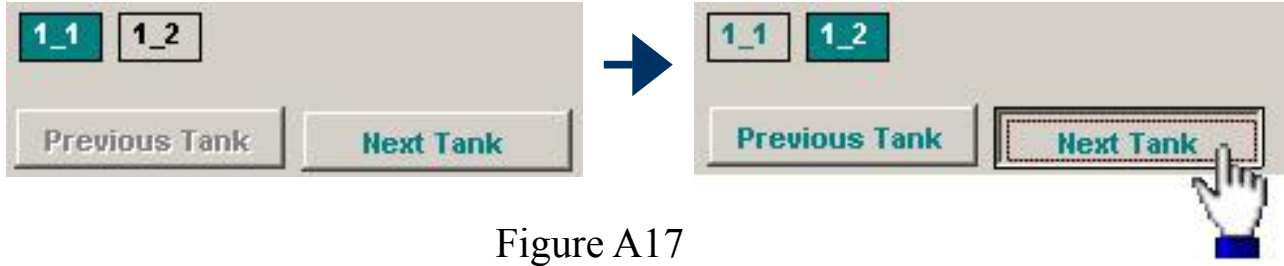

Set Data for a Specific Raceway

- Length, Width and Depth of Tank

The dimension of the tank you input will affect the water exchange rate (times $/ \mathrm{hr}$ ), the water velocity $(\mathrm{ft} / \mathrm{s})$, and the spatial density of fish $\left(\mathrm{lb} / \mathrm{ft}^{3}\right)$ in the tank. 
- Target Value

You can choose to set a target length/weight of fish or not. Check the box shown in Figure A16 to enter the target value. Similar to the setting of the initial condition of fish, you can enter the target value by the weight or the length of fish.

RDSS will estimate the number of days required to obtain the target size of fish from the initial size of fish you set.

- Mortality

Enter the percentage of fish lost per month in the Mortality of Fish column. RDSS will calculate the average number of fish lost per day from this value.

\subsection{Check Conditions of Raceways on a Specific Day}

RDSS will output the conditions of raceways on the end of every month during a year, such as $1 / 31,2 / 28$, etc. You can set a specific day such as $5 / 12$ to view the conditions of the system.

Check $\nabla$ Conditions of raceways on

\subsection{Activate the Simulation}

After all of the settings have been entered, press SIMULATE to run the program. 


\section{Results of Simulation}

As shown in Figure A18, by pressing SIMULATE, RDSS will run the program, and the caption on the right top of the Simulation form will show the date for which RDSS is estimating. The caption will show "DONE !" when the simulation is completed, and then you can press the highlighted icon below the caption to view the simulation results for that tank on a result form, or the Cond. of raceways on $\mathbf{x x x}$ tab on the right top to view the conditions of all raceways on the specific day.

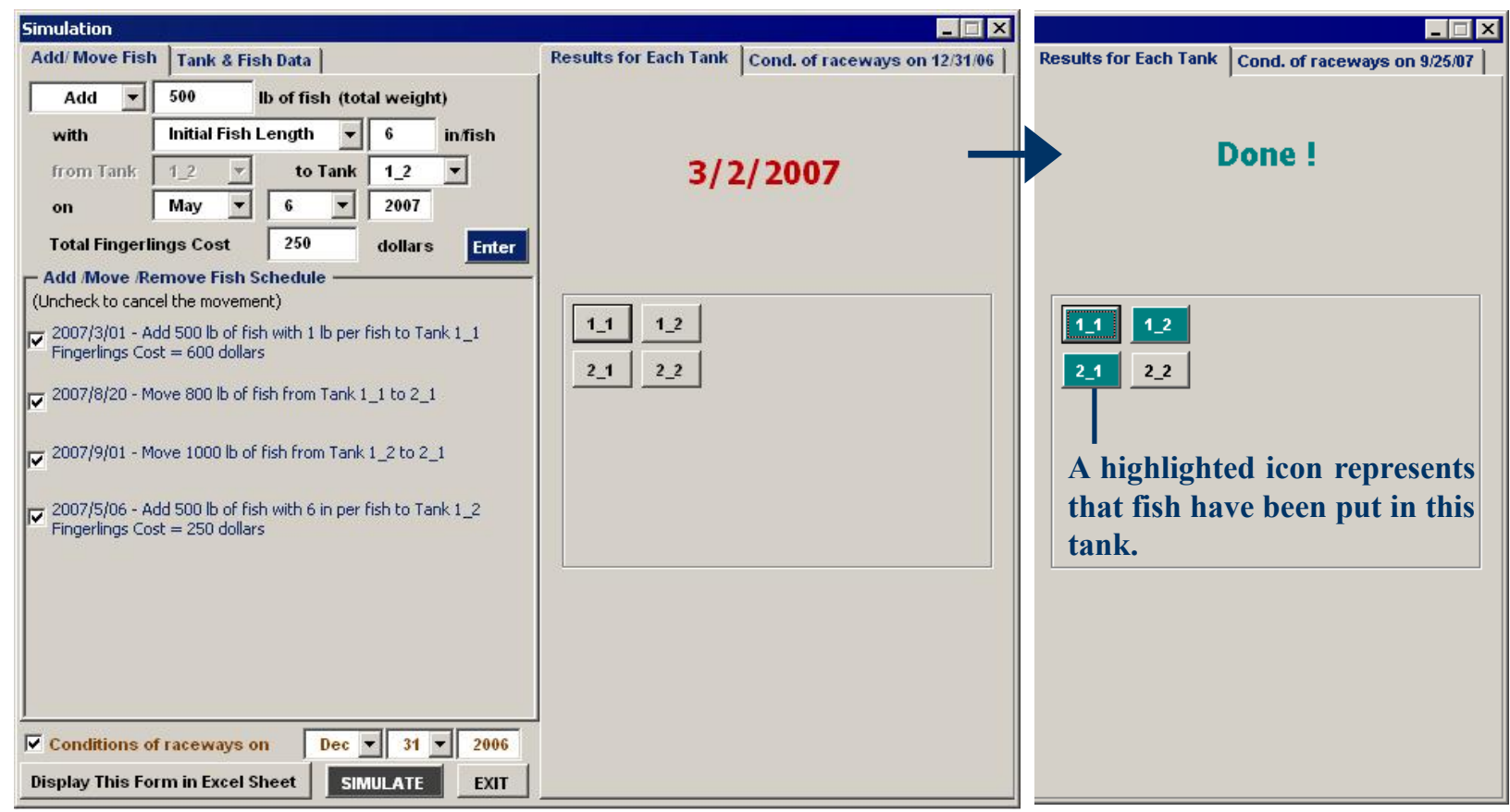

Figure A18 Simulation of Raceways

\subsection{Detailed Information for Each Raceway}

A form displaying the simulation results for a tank, as shown in Figure A19, will pop up when a highlighted icon (Figure A18) is pressed. The title bar of the form indicates the location of this tank, and the first day that the tank accommodates fish.

The buttons on the top of the form represent the cohorts of fish in this tank. You can 
press General to view the common data for the whole tank, and the cohort button to view the size of a specific group of fish.

The cohort with a lowercase $\mathrm{s}$ indicates that the size of this cohort is the smallest among all groups of fish in this tank. As shown in Figure A19, the length of fish in Cohort 2 is smaller than that of Cohort 1 in Tank 2 _.

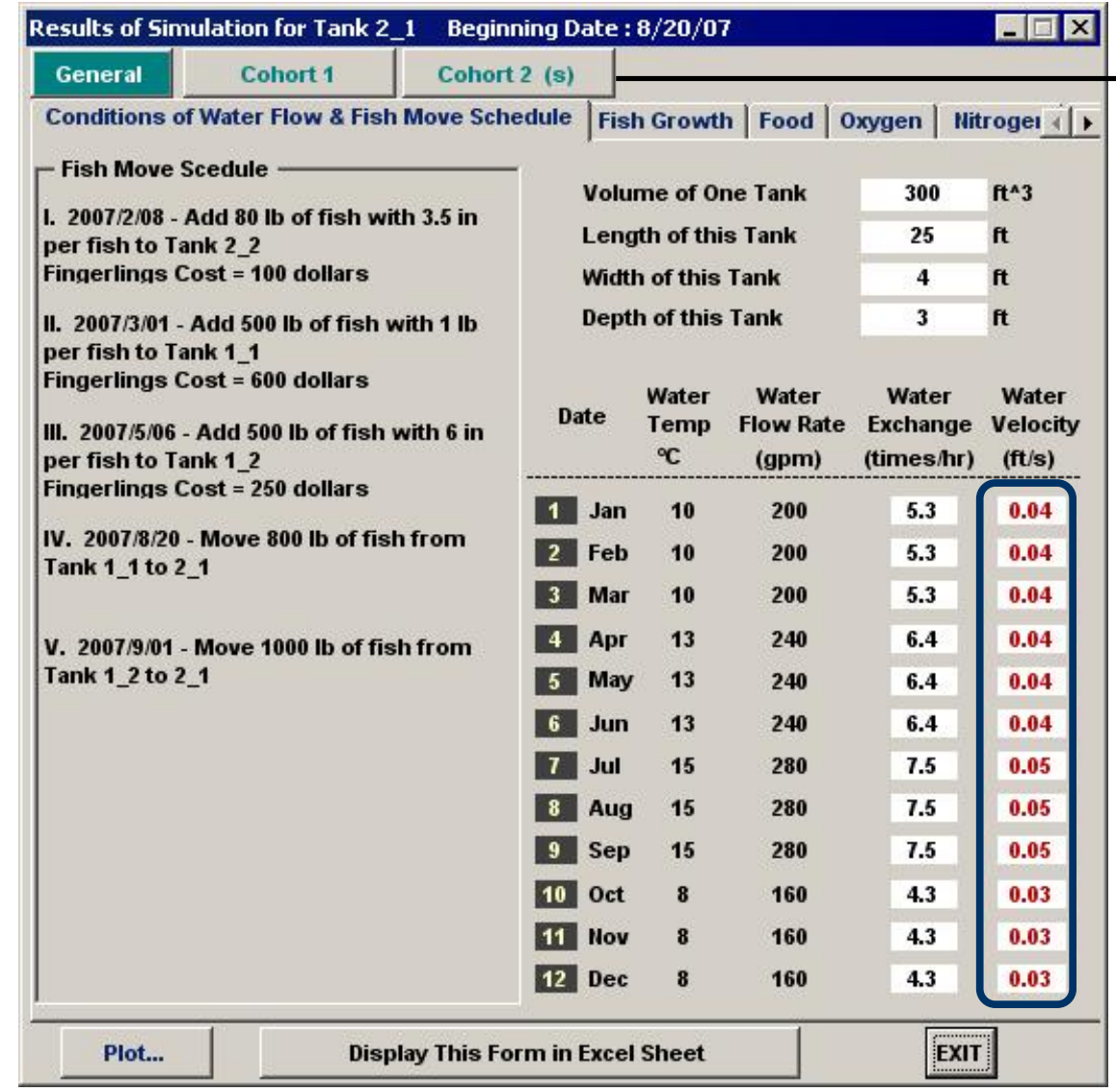

Press to view the size of the cohort of fish.

(s) represents that the size of Cohort 2 is the smallest.

When a velocity is below the recommended minimum value, $0.1 \mathrm{ft} / \mathrm{s}$, it will be displayed in red.

Figure A19 Conditions of Water Flow

\subsubsection{Water Exchange Rate and Water Velocity}

As shown in Figure A19, the left side of the first page displays all "movements" you have made for the whole system on the Simulation form, and the right side shows the water exchange rates and the water velocities.

Low water exchange rates and low water velocities cause solids depositing at the 
bottom of raceways. The recommended value for water exchange rate and water velocity are 4 times $/ \mathrm{hr}$ and $0.1 \mathrm{ft} / \mathrm{s}$, respectively (Soderburg, 1994). If the simulation result is below the recommended value, it will be shown in red to represent a potential problem in the raceway. The water flow rate or raceway dimensions should be adjusted to give water velocities or exchange rates above the recommended minimum values.

\subsubsection{Size of Fish}

The Fish Growth page lists the length and the weight of a cohort of fish at the end of each month during a year. The spatial density is the average fish weight per unit volume of a raceway.

\section{Target Condition}

If you have assigned a target weight/length for the fish, say $2 \mathrm{lb}$ per fish, for a specific tank on the Simulation form, the date that fish reach the target condition, from the initial size, will be displayed as in Figure A20.

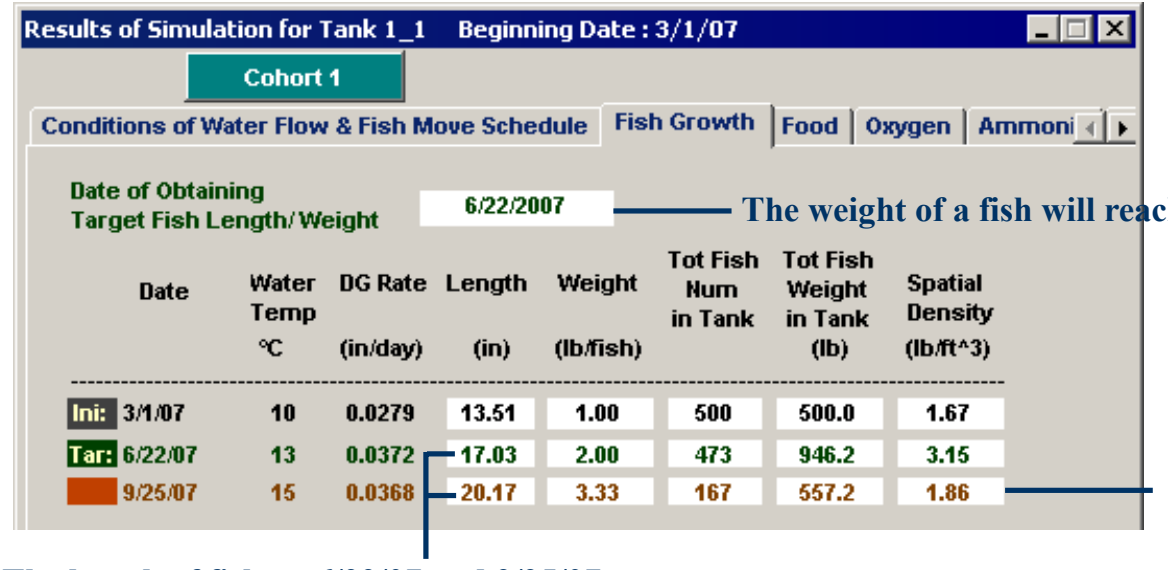

The conditions of fish on the specific day $(9 / 25 / 07)$.

The length of fish on $6 / 22 / 07$ and 9/25/07 are 17.03 in and 20.17 in, respectively.

Figure A20 Conditions on a Specific Day 
* If you enter a target value smaller than the initial size of fish, for example, the target length of fish is set as 8 in., but the initial length is 10 in., the Date of Obtaining Target Fish Length/Weight label will display "Target is less than Initial" as shown in Figure A21 to remind you that there was a mistake in this input.

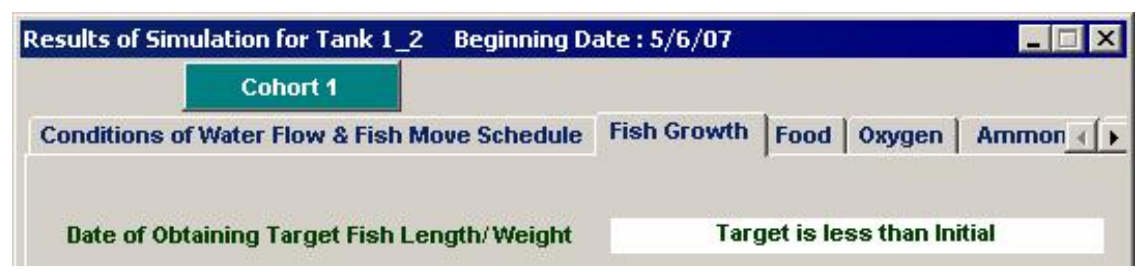

Figure A21 Situation of an Inappropriate Input of Target Size

Size of Fish on a Specific Day

The conditions of fish on the day you set on the Simulation form will be displayed as shown in Figure A20.

* See Figure A22. If you have set a specific day but no results are displayed for it, it means that the day you set is earlier than the stocking date for this tank, so there are no fish in the tank at this requested time.

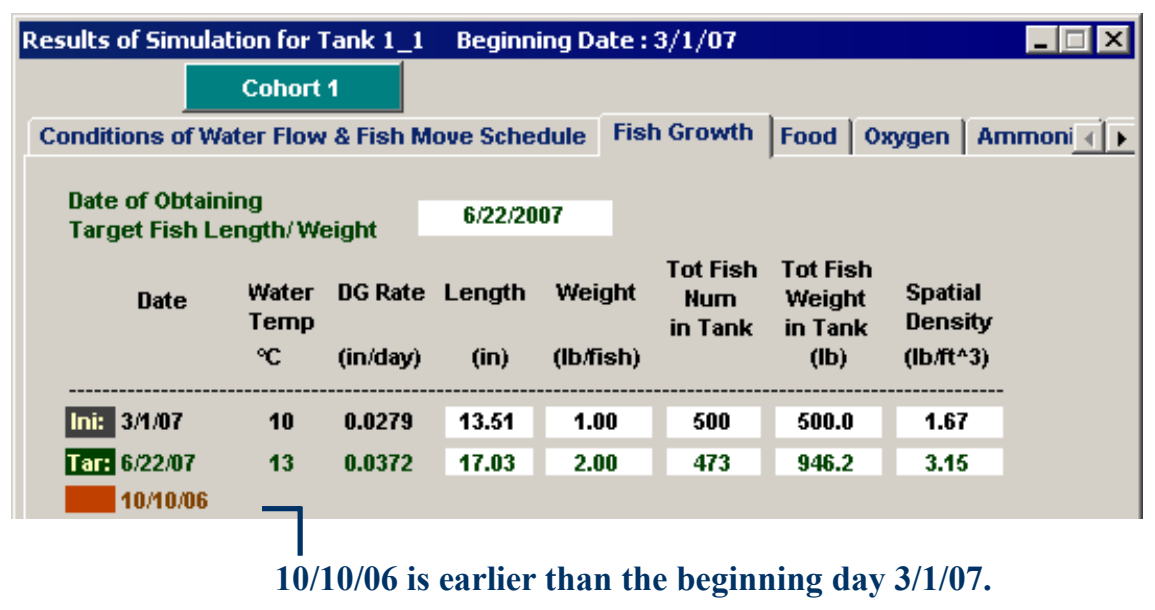

Figure A22 Situation when the conditions of a specific is unavailable 


\section{Note:}

* All simulation results concerned with the day on which fish achieve the target size will be shown in green, and the results on the specific day will be shown in orange for a quick and distinct view.

\subsubsection{Food}

Food with Constant Nutrition Contents

If you select Calorie Content of Food or Nutrition Facts of Food on the General Data form, the nutrition contents of food will be assumed to be constant. RDSS will simulate the monthly food amount required and display it on the Food page.

From Figure A23 and Figure A24, we can see the difference of Target Feed Conversion between Depends on food and Customize.... 


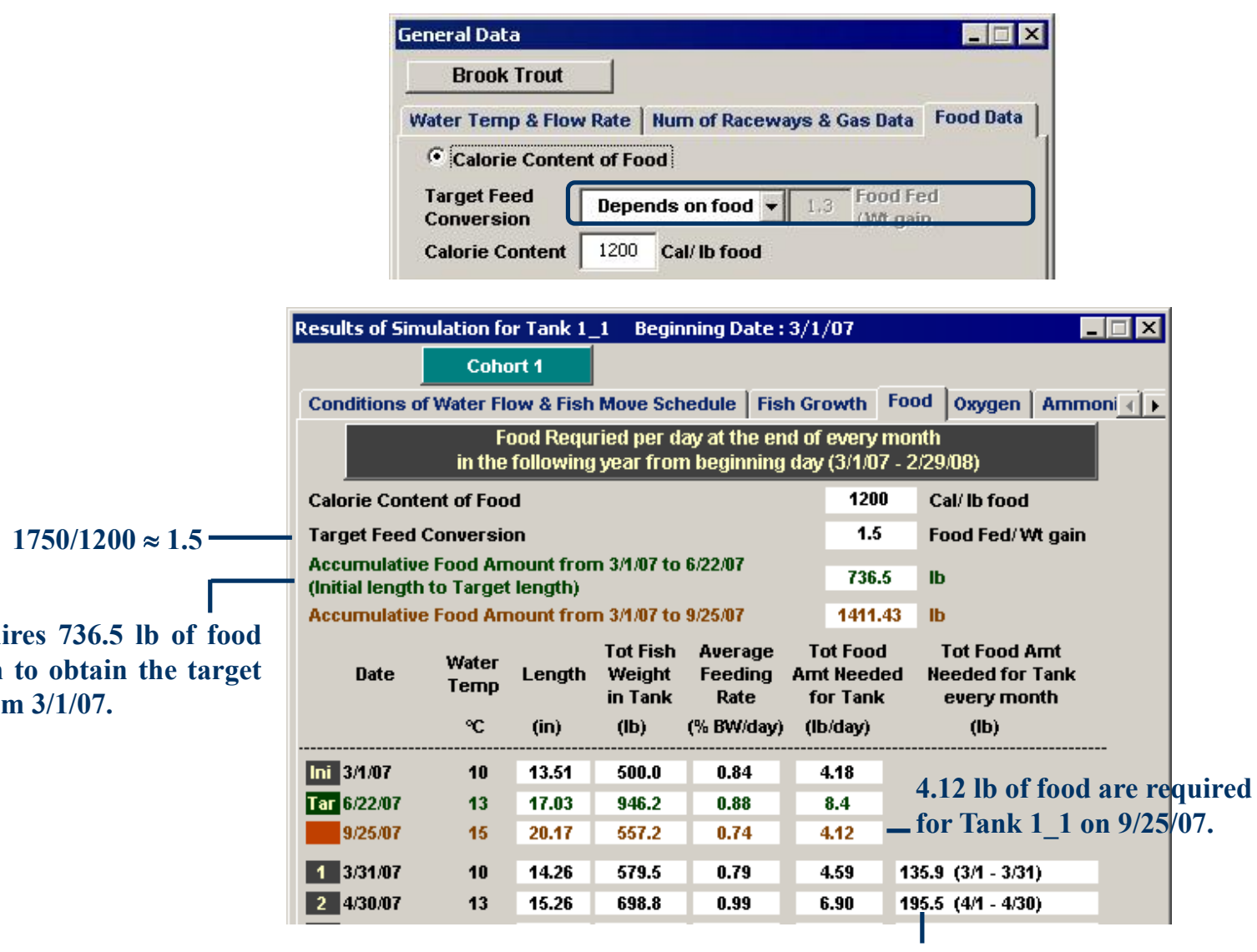

It requires $736.5 \mathrm{lb}$ of food for fish to obtain the target size from $3 / 1 / 07$.

Figure A23

$195.5 \mathrm{lb}$ of food are required for Tank 1_1 in April.

Feed Conversion depending on Food

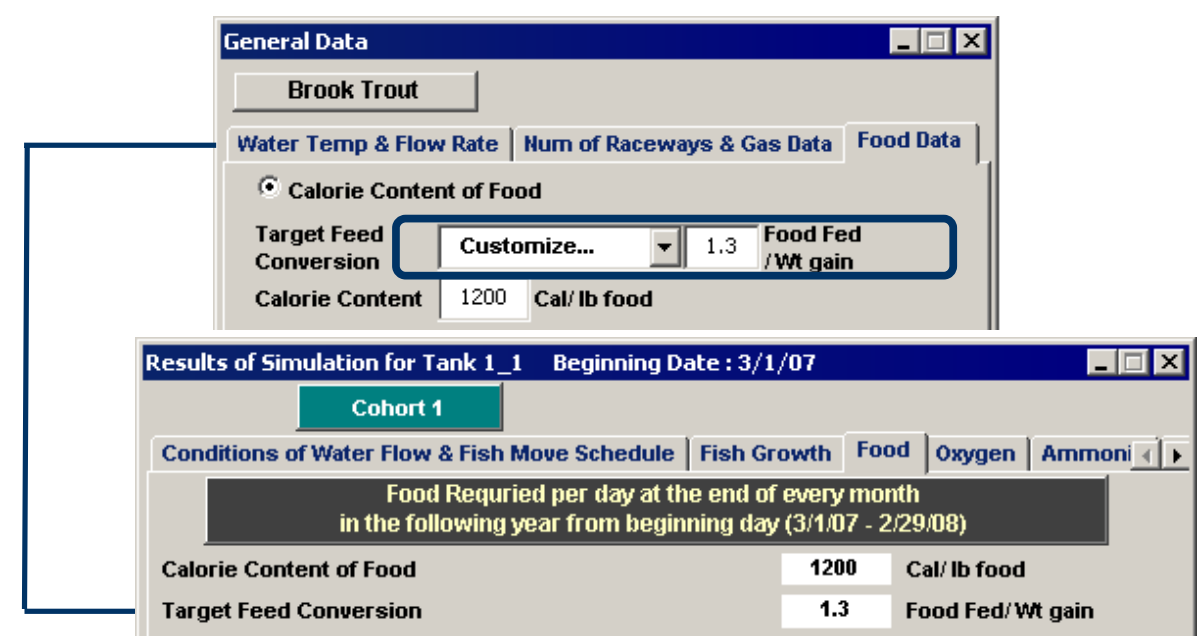

Figure A24

Customized Feed Conversion 
Food with Different Nutrition Contents Depending on Fish Size

If you select By Manufacture on the General Data form, the type of food will depend on the size of fish. There are three pages, Food-1, Food-2, and Food-3, of simulation results concerning food.

Food-1 lists the amount of food required a day and the average feeding rate on the end of each month, as shown in Figure A25.

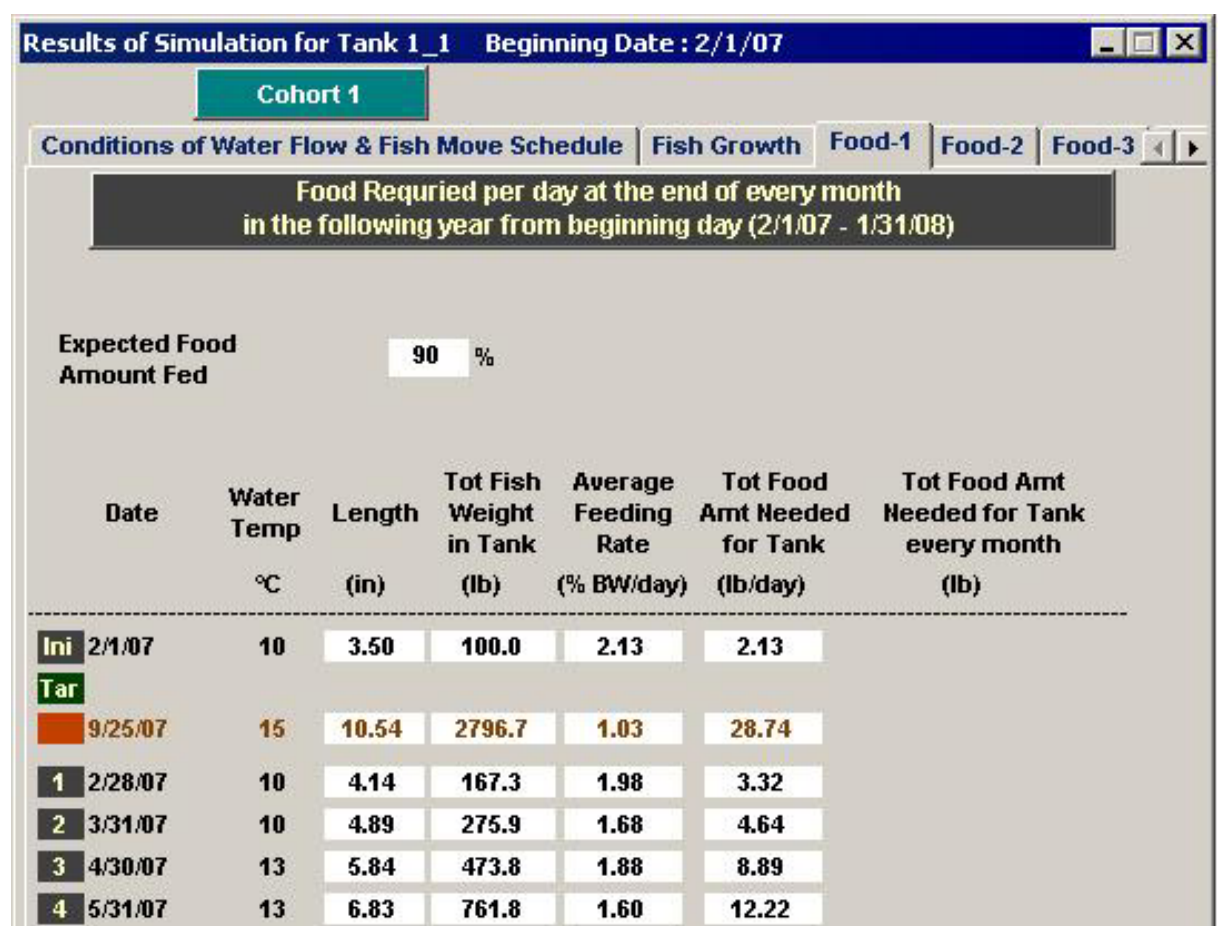

Figure A25 Food Required on the End of Each Month

Food-2 displays the detailed type of feed required in every month. For example, from Figure A26, we can see that $33.4 \mathrm{lb}$ of food (2.5 mm - Slow Sink - Zeigler) and $132 \mathrm{lb}$ of food $\left(3.0 \mathrm{~mm}\right.$ - Slow Sink - Zeigler) are required for Tank $2 \_2$ in April, wherein the $2.5 \mathrm{~mm}$ food is for $4 / 1$ to $4 / 7$, and the 3.0 food $\mathrm{mm}$ is for $4 / 8$ to $4 / 30$. The feeding rate on $4 / 1$ is $2.28 \% \mathrm{BW} /$ day, and $2.19 \% \mathrm{BW} /$ day on $4 / 7$. 


\subsubsection{Oxygen Concentration in Water}

As shown in Figure A28, the Oxygen sheet displays the conditions of oxygen in the water at the end of every month.

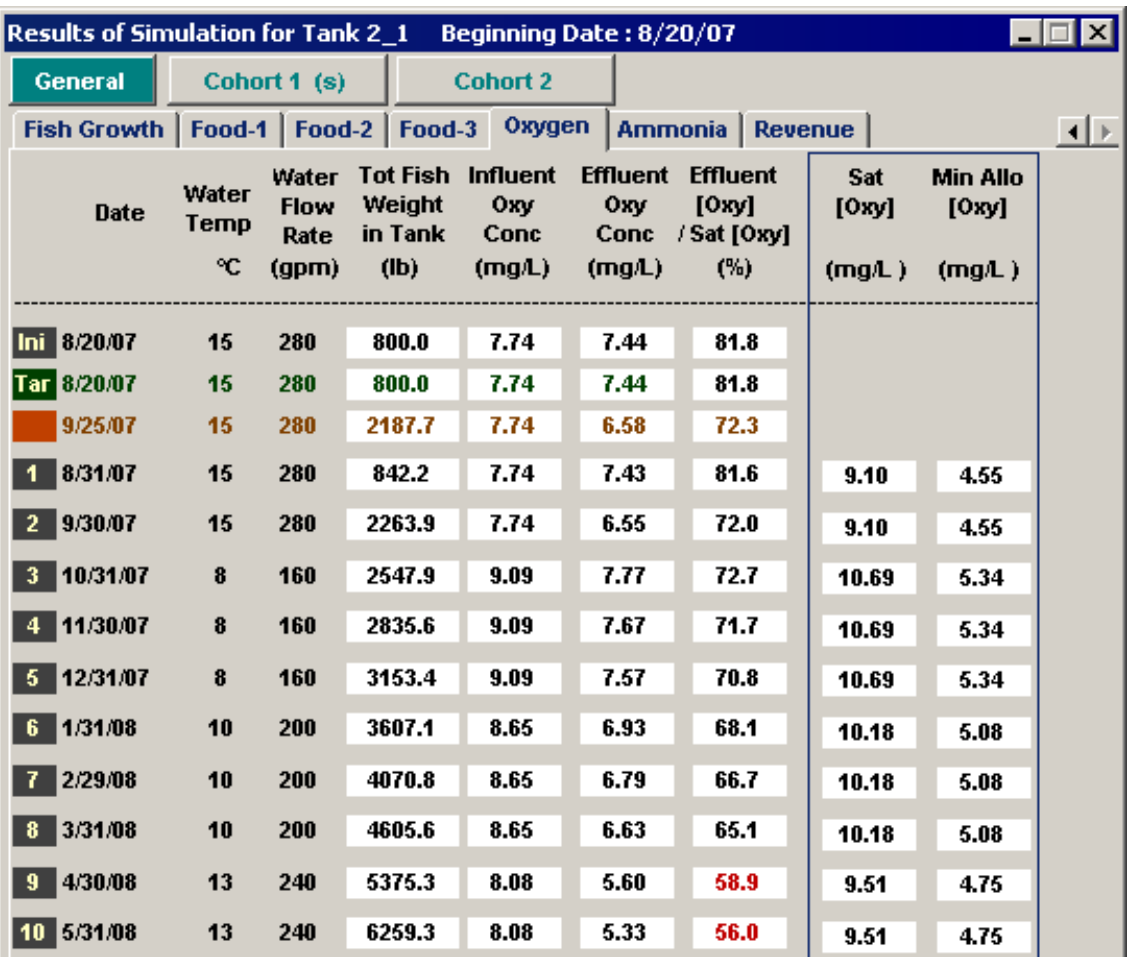

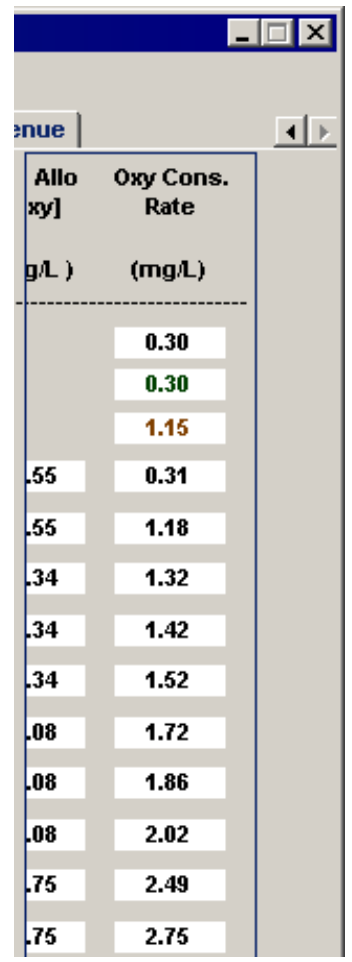

Figure A28 Oxygen Concentration

\section{- Influent Oxy Conc}

As shown in Figure A28, Influent Oxy Conc is the oxygen concentration in the influent water of the tank. For the first tank to which water flows in the raceway, such as Tank 1_1 and Tank 2_1, the influent oxygen concentration is found according to the saturated oxygen concentration at the specific water temperature, the barometer pressure, the salinity of water, and the percentage that were set in the Initial Oxy Conc box on the General Form (page 61).

The influent oxygen concentration of a downstream tank depends on the effluent oxygen concentration from the upstream tank, and the height of water fall you have 
entered on the Main Form (page 65).

\section{- Effluent Oxy Conc}

The effluent oxygen concentration of a tank is calculated using the influent oxygen concentration minus the oxygen consumed by the fish. If the effluent oxygen concentration is lower than $60 \%$ of the saturation value, it will be displayed in red (as shown for April and May 2008 in Figure A26).

\section{- Min Allo [Oxy]}

The minimum allowable oxygen concentration is the critical oxygen amount that can support fish life.

\subsubsection{Ammonia Concentration in Water}

As shown in Figure A29, the Ammonia sheet displays the ammonia concentration conditions at the end of each month.

\begin{tabular}{|c|c|c|c|c|c|c|c|c|}
\hline \multicolumn{7}{|c|}{ Results of Simulation for Tank 2_1 Beginning Date : 8/20/07 } & \multirow{2}{*}{\multicolumn{2}{|c|}{$-\square \mathrm{a}$}} \\
\hline \multirow{2}{*}{$\frac{\text { General }}{\text { Fish Growth }}$} & \multicolumn{2}{|c|}{ Cohort 1 (s) } & \multicolumn{2}{|c|}{ Cohort 2} & \multirow[b]{2}{*}{ Ammonia } & \multirow[b]{2}{*}{ Revenue | } & & \\
\hline & Food-1 & Food-2 & Food-3 & Oxygen & & & \multicolumn{2}{|r|}{$1 \mid$} \\
\hline Date & $\begin{array}{c}\text { Water } \\
\text { Temp } \\
{ }^{\circ} \mathrm{C}\end{array}$ & $\begin{array}{l}\text { Water } \\
\text { Flow } \\
\text { Rate } \\
\text { (gpm) }\end{array}$ & $\begin{array}{l}\text { Tot Fish } \\
\text { Weight } \\
\text { in Tank } \\
\text { (lb) }\end{array}$ & $\begin{array}{l}\text { Effluent } \\
\text { [Amon] } \\
\text { ( mgls) }\end{array}$ & $\begin{array}{c}\text { Effluent } \\
\text { [Amon] } \\
\text { /Crit [Amon] } \\
(\%)\end{array}$ & $\begin{array}{c}\text { Critical } \\
\text { [Amon] } \\
\text { / Effluent } \\
\text { [Amon] }\end{array}$ & $\begin{array}{l}\text { Effluent } \\
\text { [TAN] } \\
\text { (mgL) }\end{array}$ & \\
\hline Ini $8 / 20: 07$ & 15 & 280 & 800.0 & $1.38 E-04$ & 0.9 & & 0.03 & \\
\hline Tar 8/20/07 & 15 & 280 & 800.0 & 1.38E-04 & 0.9 & & 0.03 & \\
\hline $9 / 25 / 07$ & 15 & 280 & 2187.7 & 5.33E-04 & 3.3 & & 0.12 & \\
\hline $18 / 31 / 07$ & 15 & 280 & 842.2 & 1.42E-04 & 0.9 & $>20$ & 0.03 & \\
\hline $29 / 30 / 07$ & 15 & 280 & 2263.9 & 5.46E-04 & 3.4 & $>20$ & 0.13 & \\
\hline \begin{tabular}{l|l}
3 & $10 / 31 / 07$
\end{tabular} & 8 & 160 & 2547.9 & 3.54E-04 & 2.2 & $>20$ & 0.14 & \\
\hline 4 11/30/07 & 8 & 160 & 2835.6 & 3.80E-04 & 2.4 & $>20$ & 0.15 & \\
\hline 5 12/31/07 & 8 & 160 & 3153.4 & 4.08E-04 & 2.6 & $>20$ & 0.16 & \\
\hline \begin{tabular}{l|l}
6 & $1 / 31 / 08$
\end{tabular} & 10 & 200 & 3607.1 & 5.40E-04 & 3.4 & $>20$ & 0.18 & \\
\hline $72 / 29 / 08$ & 10 & 200 & 4070.8 & 5.86E-04 & 3.7 & $>20$ & 0.20 & \\
\hline \begin{tabular}{l|l}
8 & $3 / 31 / 08$
\end{tabular} & 10 & 200 & 4605.6 & 6.35E-04 & 4.0 & $>20$ & 0.22 & \\
\hline \begin{tabular}{l|l}
$9 / 30 / 08$
\end{tabular} & 13 & 240 & 5375.3 & 9.86E-04 & 6.2 & 16.2 & 0.27 & \\
\hline
\end{tabular}

Figure A29 Ammonia Concentration 


\section{- Effluent [Amon]}

Effluent [Amon] is the concentration of the unionized form of ammonia, $\mathrm{NH}_{3}$, in the effluent water of the tank.

- Effluent [Amon] / Crit [Amon] is the ratio of the concentration of $\mathrm{NH}_{3}$ to the critical concentration of $\mathrm{NH}_{3}$ expressed in percentage. This critical concentration of $\mathrm{NH}_{3}$ is the value that was set in the Max Allowable $\mathbf{N H}_{3}$ Conc box on the General Data form (page 61).

A value of Effluent [Amon] / Crit [Amon] larger than 100 means that the effluent $\mathrm{NH}_{3}$ is beyond the critical amount of $\mathrm{NH}_{3}$ and will be displayed in red as a warning.

- Crit [Amon] / Effluent [Amon] is the ratio of the critical concentration of $\mathrm{NH}_{3}$ to the Effluent $\mathrm{NH}_{3}$. It can be interpreted as the maximum allowable times of water use.

- Effluent [TAN] is the concentrations of total ammonia nitrogen, $\mathrm{NH}_{3}$ and $\mathrm{NH}_{4}{ }_{4}^{+}$, in the effluent water of the tank what are limits if any. 


\subsubsection{Food Cost and Revenue from Fish Sales}

As shown in Figure A30, the Revenue sheet displays the costs of food and fingerlings, and the income from fish sales in each month. The monthly and annual balances are also displayed.

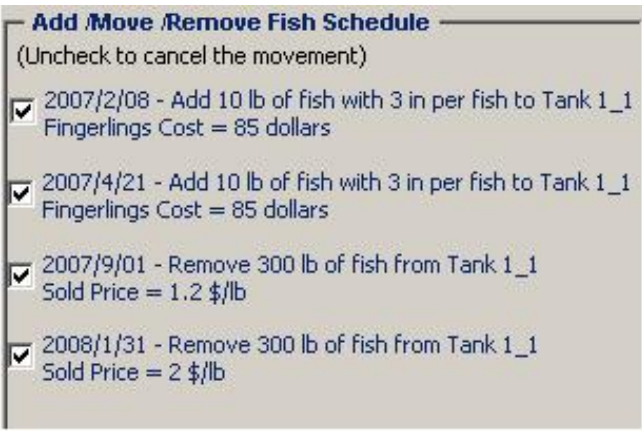

\begin{tabular}{|c|c|c|c|c|c|c|}
\hline \multicolumn{3}{|c|}{ Results of Simulation for Tank 1} & \multicolumn{2}{|c|}{ Beginning Date : $2 / 8 / 07$} & \multicolumn{2}{|r|}{$-1 \square x$} \\
\hline \multirow{2}{*}{$\begin{array}{c}\text { General } \\
\text { Fish Growth }\end{array}$} & \multicolumn{2}{|c|}{ Cohort 1 (s) } & Cohort 2 & & & \multirow[b]{2}{*}{ 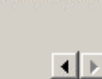 } \\
\hline & \begin{tabular}{|l|} 
| Food \\
\end{tabular} & Oxygen | & Ulitrogen $\operatorname{Rev}$ & enue & & \\
\hline \multicolumn{2}{|l|}{ Date } & $\begin{array}{l}\text { Food Amt } \\
\text { Needed } \\
\text { (Ib) }\end{array}$ & $\begin{array}{l}\text { Food Cost } \\
\text { (\$) }\end{array}$ & $\begin{array}{l}\text { Fingerlings } \\
\text { Cost } \\
\text { (\$) }\end{array}$ & $\begin{array}{l}\text { Income from } \\
\text { Fish Sale } \\
\text { (\$) }\end{array}$ & $\begin{array}{l}\text { Cash } \\
\text { Flow } \\
\text { (\$) }\end{array}$ \\
\hline \multicolumn{2}{|c|}{$1 / 2 / 8-2 / 28 / 07$} & 9.2 & (3.22) & (85.00) & & (88.22) \\
\hline \multicolumn{2}{|c|}{$23 / 1-3 / 31 / 07$} & 19.4 & (6.79) & & & (6.79) \\
\hline \multicolumn{2}{|c|}{ 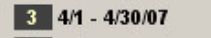 } & 43.1 & (15.09) & (85.00) & & (100.09) \\
\hline \multicolumn{2}{|c|}{\begin{tabular}{l|l|l|}
4 & $5 / 1$ & $-5 / 31 / 07$ \\
\end{tabular}} & 81.0 & (28.35) & & & (28.35) \\
\hline \multicolumn{2}{|c|}{\begin{tabular}{|l|l|}
5 & $6 / 1-6 / 30 / 07$ \\
\end{tabular}} & 111.6 & (39.06) & & & (39.06) \\
\hline \multicolumn{2}{|c|}{\begin{tabular}{|l|l|}
6 & $7 / 1$ \\
\end{tabular}} & 153.6 & (53.76) & & & (53.76) \\
\hline \multicolumn{2}{|c|}{ 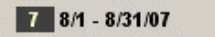 } & 198.8 & (69.58) & & & (69.58) \\
\hline \multicolumn{2}{|c|}{\begin{tabular}{|l|l|}
8 & $9 / 1$ \\
\end{tabular}} & 67.6 & (23.66) & & 360.00 & 336.34 \\
\hline \multicolumn{2}{|c|}{$910 / 1-10 / 31 / 07$} & 47.9 & (16.77) & & & (16.77) \\
\hline \multirow{2}{*}{\multicolumn{2}{|c|}{ 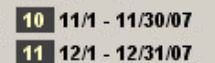 }} & 51.3 & (17.96) & & & (17.96) \\
\hline & & 58.4 & (20.44) & & & (20.44) \\
\hline \multicolumn{2}{|c|}{$121 / 1-1 / 31 / 08$} & 81.1 & (28.39) & & 600.00 & 571.62 \\
\hline \multicolumn{2}{|c|}{ Sum 2/8/07 - 1/31/08 } & 922.6 & (323.05) & $(\mathbf{1 7 0 . 0 0 )}$ & 960.00 & 466.95 \\
\hline \multicolumn{7}{|l|}{$\begin{array}{l}===== \\
\text { Tar }\end{array}$} \\
\hline \multicolumn{2}{|c|}{ 2/8/07 - 9/25/07 } & 671.72 & (235.102) & $(\mathbf{1 7 0 . 0 0 )}$ & 360.00 & (45.1) \\
\hline Plot... & & Displa & lay This Form i & Excel Sheet & & EXIT \\
\hline
\end{tabular}

Figure A30 Food Cost and Revenue from Fish Sales

\subsubsection{Graph}

RDSS provides charts of monthly parameters for each raceway to give an overview of the raceway during the following year.

Step 1 click Plot... on the bottom of the result form for the tank as shown in Figure A30 above. 
Step 2 Select the parameter you want to plot, and then press OK.

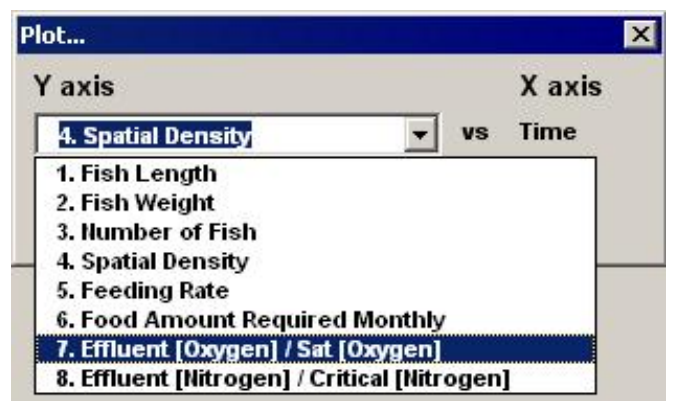

The graph will be automatically generated in an $\operatorname{Excel}^{\mathrm{TM}}$ file named after the tank. For example, if you make a graph for Tank 1_1, the graph will be put in an Excel ${ }^{\mathrm{TM}}$ workbook named "Tank 1_1". This workbook will be placed in the same folder with RDSS.xls.

\section{Note:}

* Charts of the length and the weight of one fish are only available for a tank with a single cohort of fish.

* If you select the food as By Manufacture on the General Data form, charts of the feeding rate and the food amount required monthly will be unavailable.

\subsubsection{Screenshot of a Form}

For convenient view and printing, the screenshots of the result form can be displayed in an Excel ${ }^{\mathrm{TM}}$ worksheet. Press Display This Form in Excel Sheet on the bottom of the result form as shown in Figure A30 above, all pages of the form will be pasted into a worksheet in an Excel $^{\mathrm{TM}}$ workbook named after the tank, i.e., the charts and the screenshots for the same tank will be saved in the same Excel ${ }^{\mathrm{TM}}$ file. 


\subsection{Overview of the Conditions of the Whole System on a Specific Day}

If you set a specific day on the Simulation form (see section 4.3, page 70), after the simulation is finished, the conditions of each tank in the system on this day will be summarized on the right side of the Simulation form as shown in Figure A31.

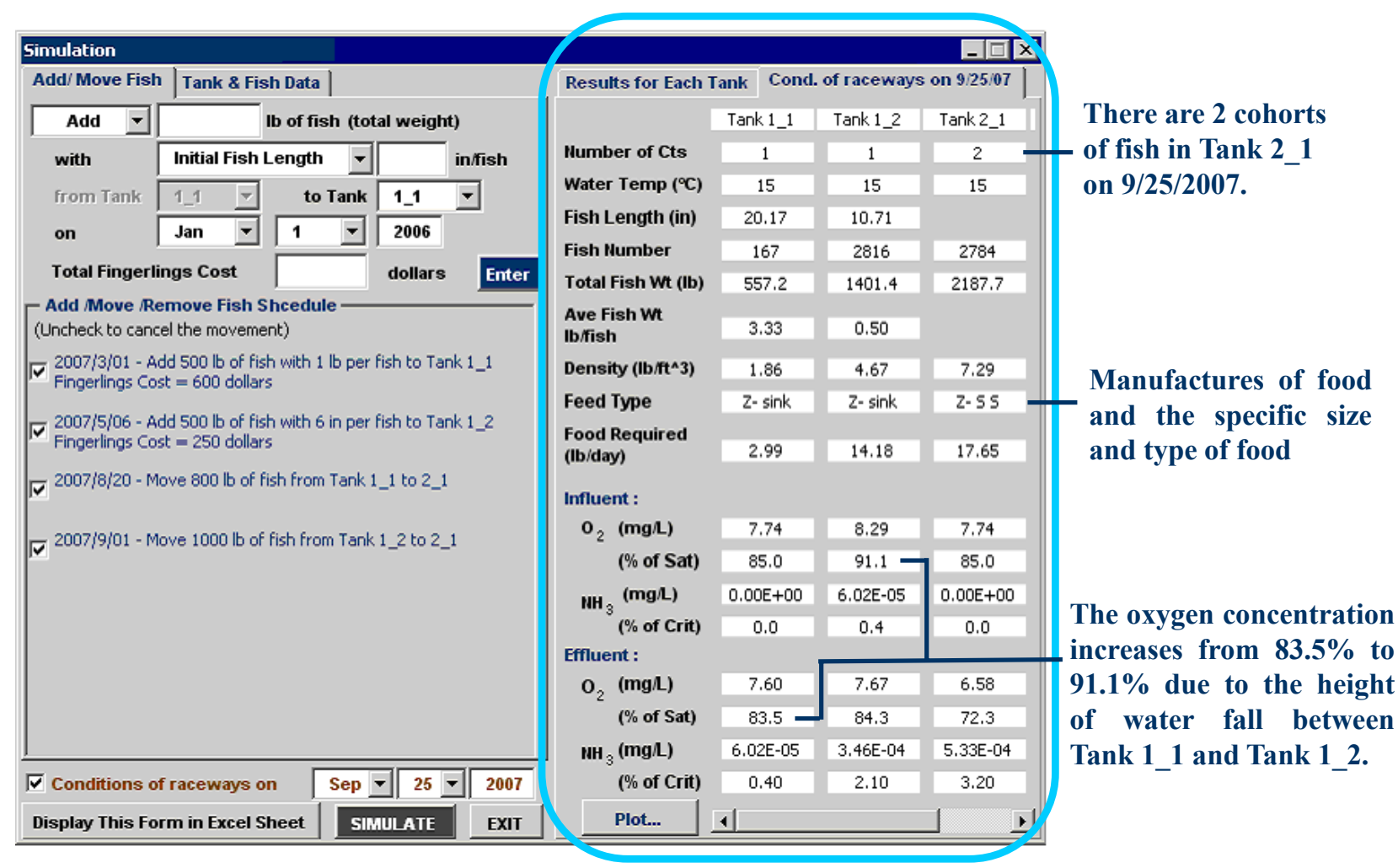

Figure A31 Conditions of the Whole System on a Specific Day

\section{- Feed Type}

If you select the food as By Manufacure on the General Form, the type of food required for a tank on the specific day will be displayed. The capital letter is the first letter of the manufacture, and the words behind "-" are the feed type. For example, "Z-SS" represents that the food is from Zeigler, and the food is a Slow Sink. 


\subsubsection{Graph}

A parameter for all raceways in the system on the specific day can be plotted on the same graph. Click Plot... on the bottom of the Simulation form. Select the parameter you want to plot, and then press $\mathbf{O K}$. The graph will be automatically generated in an Excel $^{\mathrm{TM}}$ file named "Whole System". This Excel ${ }^{\mathrm{TM}}$ file will be saved in the same folder with RDSS.xls.

\subsubsection{Screenshot of the Simulation form}

The screenshots of the Simulation form can be displayed in an $\mathrm{Excel}^{\mathrm{TM}}$ worksheet. Press Display This Form in Excel Sheet on the bottom of the Simulation form as shown in Figure A31 above, all pages of the form will be pasted into a worksheet of an Excel ${ }^{\mathrm{TM}}$ file named "Whole System". 


\section{Today's Condition}

When a simulation has been done, you can check the latest conditions of the fish-rearing system for the current day by clicking Today's Condition on the Start worksheet. A form as shown in Figure A32 with conditions for today will show up.

\begin{tabular}{|c|c|c|c|c|}
\hline & Today's Condition & Beginnir & ng Date of the System : 1/1/2006 & $\mathrm{x}$ \\
\hline & \begin{tabular}{r|r} 
Thu, \\
\end{tabular} & Apr 20 & Water Temp : $13^{\circ} \mathrm{F}$ & \\
\hline current date & & $\begin{array}{c}\text { Tank } \\
1 \_1\end{array}$ & $\begin{array}{l}\text { Tank } \\
1 \_2\end{array}$ & \\
\hline & Cohort & 1 & 1 & \\
\hline & Fish Length (cm) & 41.73 & 39.32 & \\
\hline & $\begin{array}{l}\text { Fish Weight } \\
\text { (gifish) }\end{array}$ & 799.39 & 668.47 & \\
\hline & Fish Number & 267 & 257 & \\
\hline & Total Fish Wt (kg) & 213.2 & 172.0 & \\
\hline & Density (Ib/ft^3) & 1.56 & 1.26 & \\
\hline & Feed Type & & & \\
\hline & $\begin{array}{l}\text { Food Required } \\
\text { (Ib/day) }\end{array}$ & 2.87 & 2.46 & \\
\hline & Effluent : & & & \\
\hline & $\mathrm{O}_{2}$ (\% of Sat) & 90.0 & 95.1 & \\
\hline & $\mathrm{UH}_{3}$ (\% of Crit) & 0.0 & 0.0 & \\
\hline
\end{tabular}

Figure A32 Today’s Condition 


\section{Q \& A}

Q: Why does the font in the Add/ Move/ Remove Fish Schedule become red and disabled?

A: When the font of a "movement" becomes red, it means that the unit of the daily growth rate you set on the General Data form is different from the unit in this "movement". Therefore, if you do not want to reset these movements, you will need to change the unit of the daily growth rate. Otherwise, you will have to enter a new movement with the correct information according to the unit system you just set.
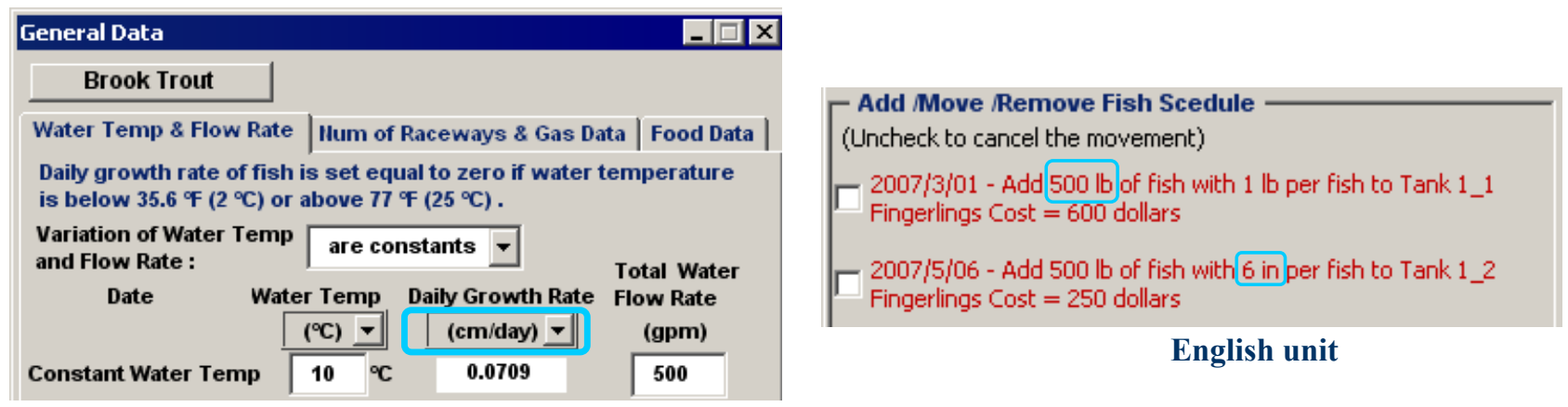

metric unit

Q: When I am setting movements on the Simulation form, do I need to enter them in order of date, i.e. first enter the earliest movement and the latest movement last?

A: No. See Note on page 68. 
Q: When I press SIMULATE on the Simulation form, why do some of the movements automatically become unchecked and grey?

A: It means that the tank involved in this movement is not contained in the system. This situation may happen when you have done a simulation for a multi-tank system, and then reduce the number of tanks for a new simulation.
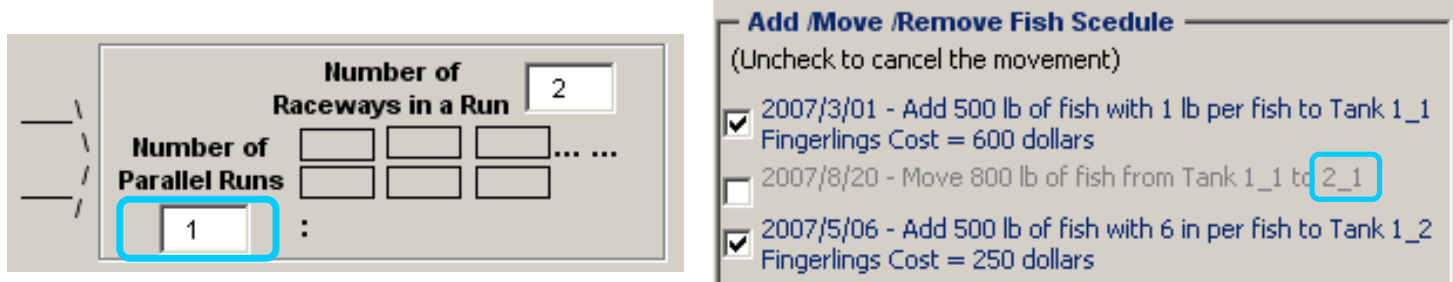

There is only one run in the system.

Q: Can I clear all of the movements to start a new simulation?

A: When the SIMULATE button on the Simulation form is pressed, the unchecked movements will not be saved. Therefore, you can uncheck all of the movements, press SIMULATE, and re-open the Simulation form. The Add/ Move/ Remove Fish Schedule will be empty.

Q: Do I need to set the dimensions and the mortality rate for every tank?

\section{A: (1) Dimensions}

When RDSS finds that the dimensions for a tank are zero, it will use the values for Tank 1 1 for this tank. If the values of Tank 1_1 are zero, Tank 1_2 will be taken and so on.

For example, assuming there are 4 raceways, Tank 1_1, 1_2, 2_1, and 2_2, in the system, and you have entered the length for Tank $1 \_1$ as $20 \mathrm{ft}$. Afterwards you can press SIMULATE directly, the lengths for the rest of the tanks will be assumed to be $20 \mathrm{ft}$.

However, if the dimensions for a tank have been set previously, you still need to re-enter the values for the tank. For example, if the lengths for Tank 1_2 and 1_3 have been set as $15 \mathrm{ft}$, 
and you want to change them to $20 \mathrm{ft}$, you will need to change the length for Tank 1_2, and then press the Next Tank button to enter the value for Tank 1_3.

(2) Mortality Rate

The mortality rate for a tank will be automatically assumed to be zero if you do not enter a value for it.

Q: If the target size of fish for every raceway is the same, do I need to enter it for all of the raceways?

A: Yes. When you enter a target length/weight for a tank, this setting is only for this tank.

Q: Will the simulation results be saved in RDSS when a simulation procedure is done?

A: No. Only the input settings will be saved. However, since all of the settings have been saved, you can just press the SIMULATE button on the Simulation form so that the results will be immediately generated. Besides, you can press the Display This Form in Excel Sheet button on the result form to save the screenshot of the results in an Excel $^{\mathrm{TM}}$ file. Afterwards you can open the Excel ${ }^{\mathrm{TM}}$ file to view the results.

Q: Why is the SAVE button on the General Data form disabled?

A: The SAVE button is disabled when the Simulation form or the "result" form for a certain tank is opened so that the values on the General Data form cannot be changed and saved. Since the outcome on the Simulation and the "result" form is based on the parameters on the General Data form, the disabled SAVE button avoids the confusion between the original parameters and the new parameters.

If you want to change the values on the General Data form, EXIT the Simulation form or the "result" form of the tank first. 
Q: I have set a specific date on the Simulation form to view the conditions of raceways, why are there no results for this day?

A: The date you set is probably earlier than the day you add fish to the raceway. (See "Size of Fish on a Specific Day" on page 74)

Q: I have set a target length/ weight for a tank, why does the Date of Obtaining Target Fish Length/Weight label display "Target is less than Initial"?

A: See pages 73 and 74 .

Q: I have set a target length/ weight for a tank, why does the Date of Obtaining Target Fish Length/Weight label display "NA"?

A: This may happen when the size of fish cannot reach the target value you entered before the day which you want to remove all fish.

For example, assuming that the length of fish in Tank 1_1 on 10/31/2007 is 12 in., and all of fish in Tank 1_1 will be taken out on 11/1/2007, so RDSS will stop simulating Tank 1_1 after 11/1 since there will be no fish in it. However, the target length of fish for Tank $1 \_1$ is 16 in. Therefore, the Date of Obtaining Target Fish Length/Weight in this case will not be obtained. 


\section{Error and Information Messages}

\subsection{Error Message}

When an error box shows up, it means that some of your inputs are inappropriate, and may cause the wrong simulation result. Follow the message on the error box to modify your input.

\section{Error 01}

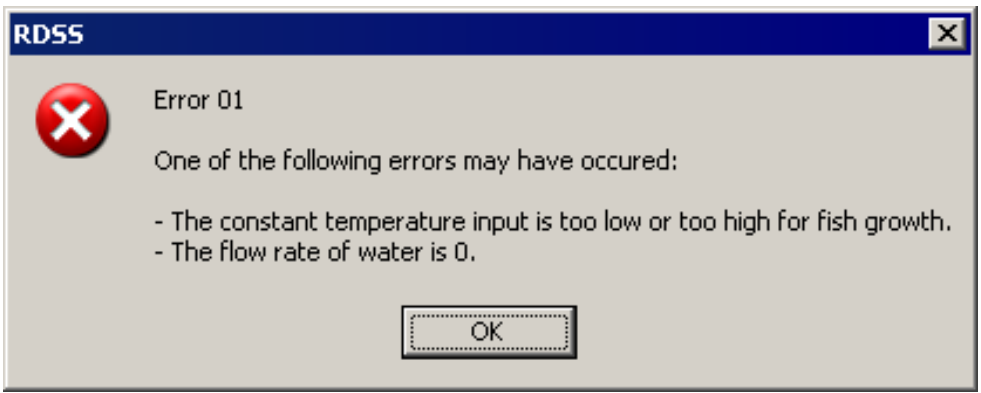

For a constant water temperature system, the temperature entered must be between $2^{\circ} \mathrm{C}$ $\left(35.6^{\circ} \mathrm{F}\right)$ and $25^{\circ} \mathrm{C}\left(77^{\circ} \mathrm{F}\right)$, and the total water flow rate cannot be zero.

\begin{tabular}{|c|c|c|c|c|}
\hline $\begin{array}{l}\text { Variation of Water Temp } \\
\text { and Flow Rate: }\end{array}$ & are co & istants & $\nabla$ & otal Water \\
\hline Date & r Temp & Daily Gro & owth Rate & Flow Rate \\
\hline & $\left({ }^{\circ} \mathrm{F}\right) \nabla$ & (in/d & ay) 17 & (gpm) \\
\hline Constant Water Ten & 24 & & $\mathbf{0}$ & 500 \\
\hline
\end{tabular}

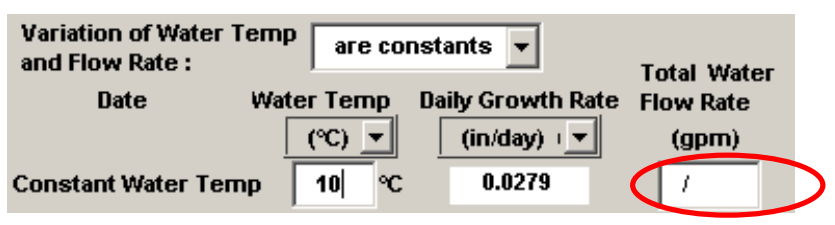

Error 02

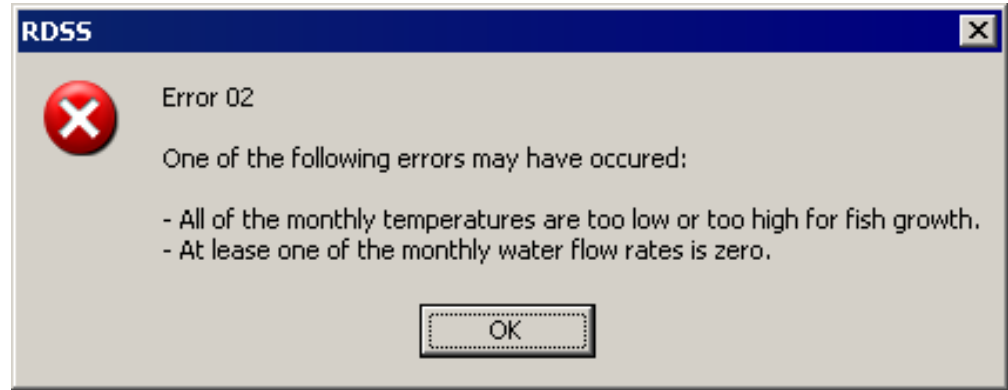

For a monthly-varied temperature system, at least one of monthly water temperatures must be between $2^{\circ} \mathrm{C}\left(35.6^{\circ} \mathrm{F}\right)$ and $25^{\circ} \mathrm{C}\left(77^{\circ} \mathrm{F}\right)$, and all of the total flow rates cannot be zero. 
Error 03

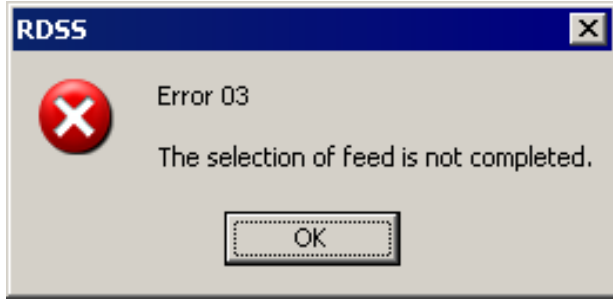

See Note on page 63. The situation in Figure A33 may have happened.

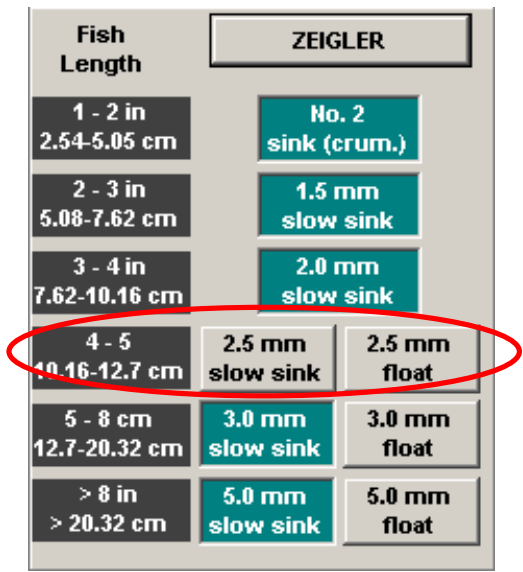

Figure A33 Error in Selection of Food

\section{Error 04}

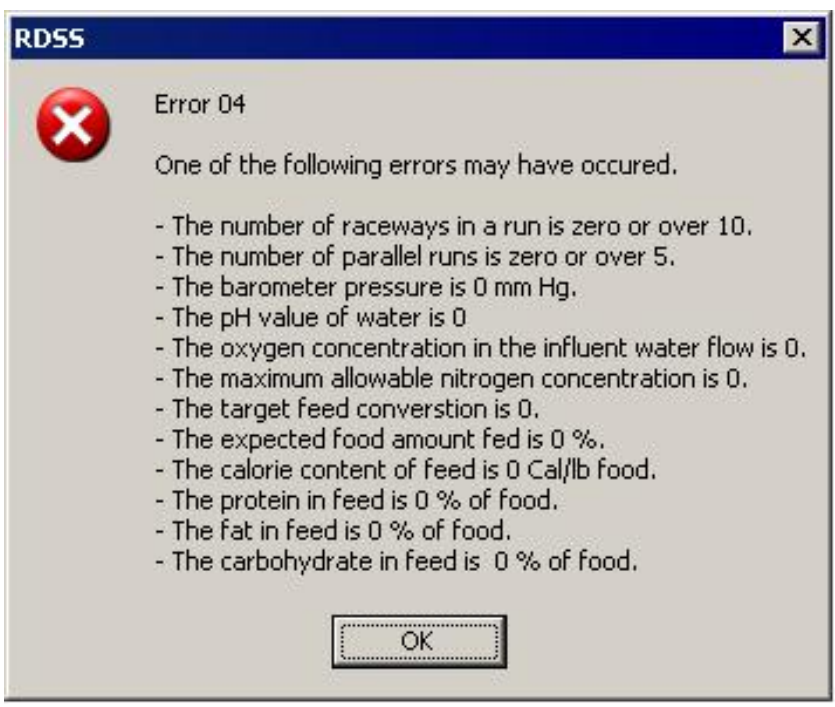

The values of some input parameters have limitations or cannot be zero. The only parameter on the General Data form that can be zero is the salinity of water. 


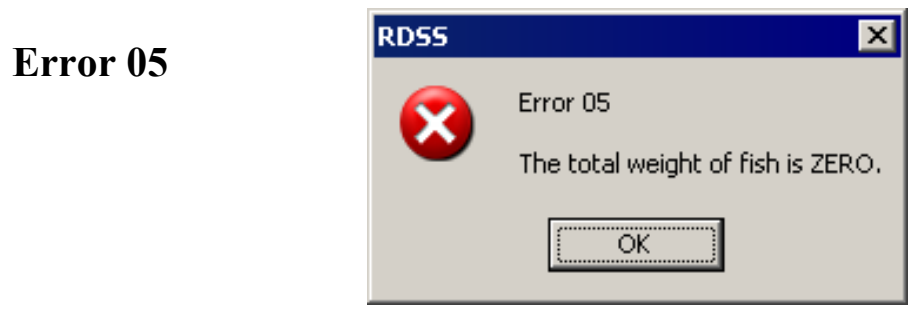

While you are entering a movement, the total weight of fish cannot be zero or empty.

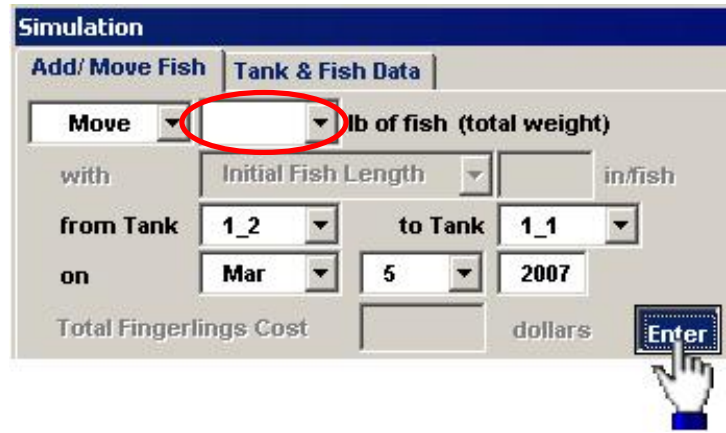

\section{Error 06}

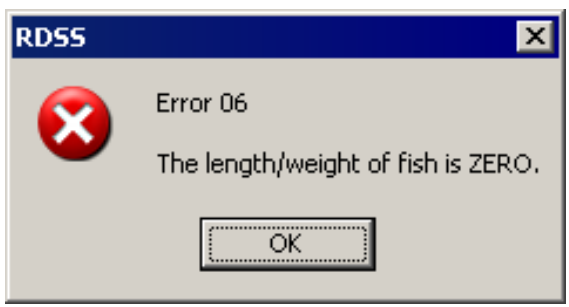

While you are adding a group of fish to a tank, the initial length/weight of fish cannot be zero or empty. You must assign the size for the fish.

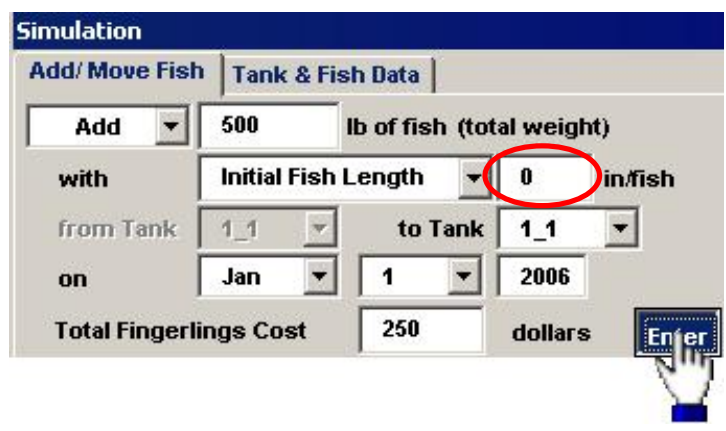




\section{Error 07 Error 08 Error 09}
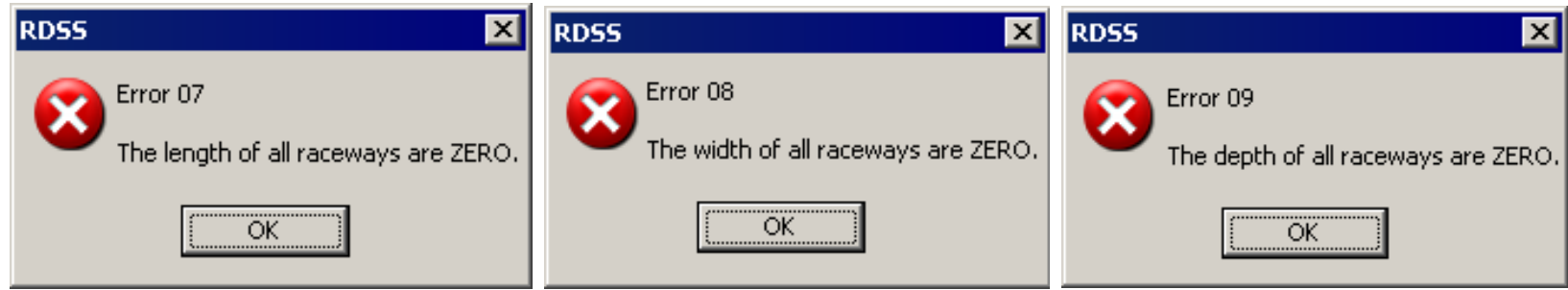

In these situations, you need to enter the length, the width or the depth for at least one tank, and then RDSS will take these values as the dimensions for the rest of the tanks.

\section{Error 10}

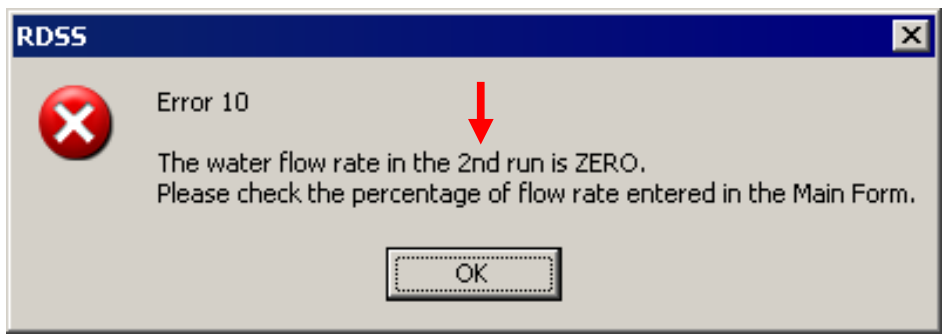

In this situation, you need to go back to Main Form to enter a percentage for the run indicated in the error message.

However, if you will not put any fish in the raceways in a specific run, the percentage can be zero. Compare the situations in Figure A34 and Figure A35.

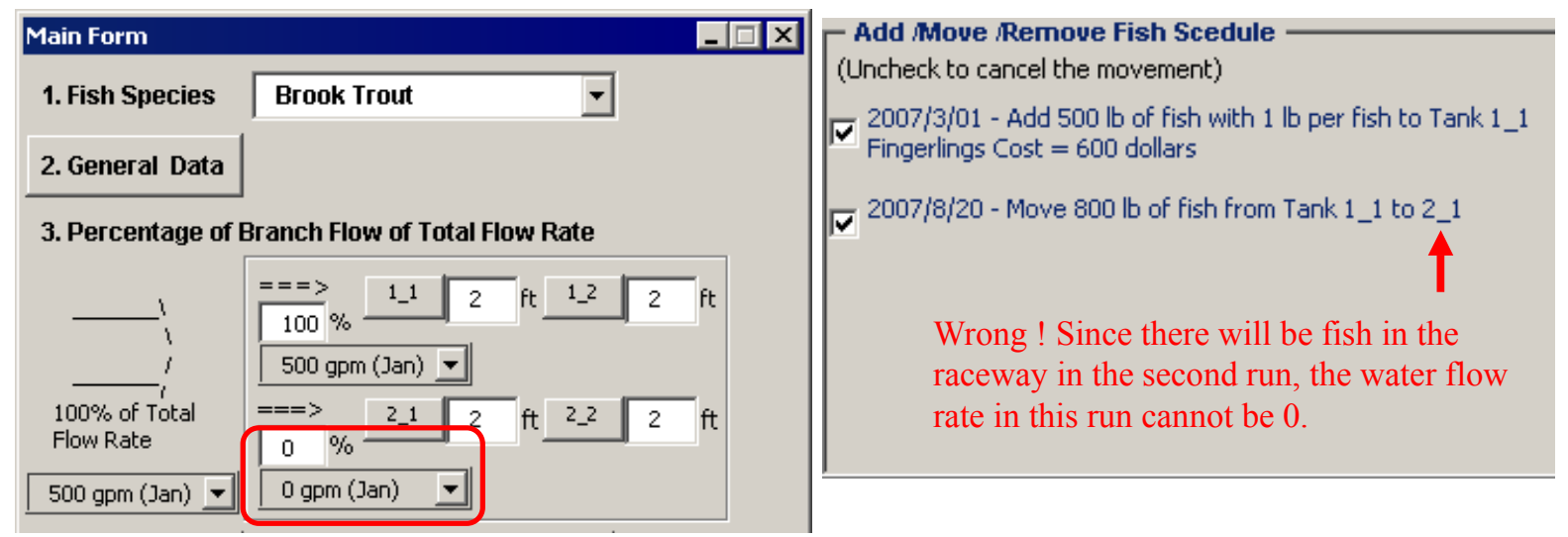

Figure A34 Inappropriate Input for Water Flow Rate of Branch Flow 


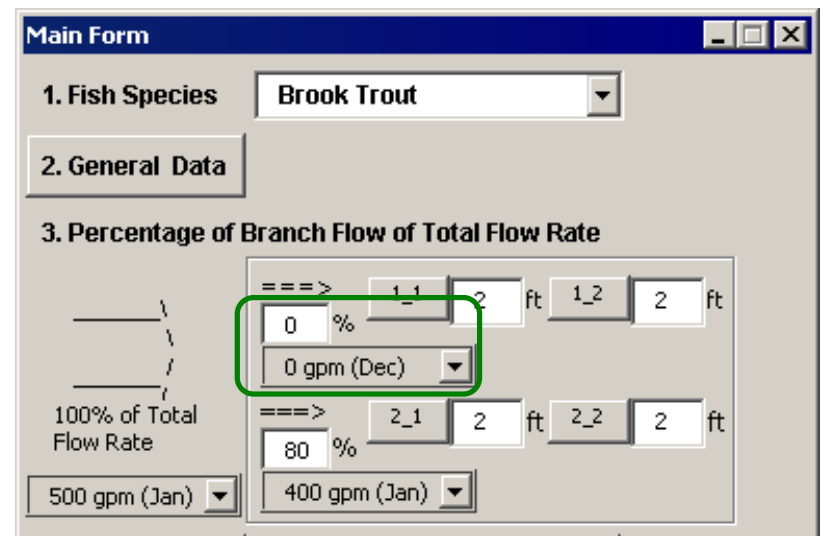

Add Move Remove Fish Scedule
(Uncheck to cancel the movement)
$\sqrt{\checkmark}$ 2007/3/01 - Add $300 \mathrm{lb}$ of fish with $0.5 \mathrm{lb}$ per fish to Tank 2 Fingerlings Cost $=300$ dollars
$\sqrt{\checkmark}$ Fingerlings Cost $=300$ dollars
OK! Because you will not put any fish in $1 \mathrm{lb}$ per fish to Tank 2_2
the first run of raceways, the water flow
rate to the first run can be zero

Figure A35 Acceptable Input for Water Flow Rate of Branch Flow

\section{Error 11}

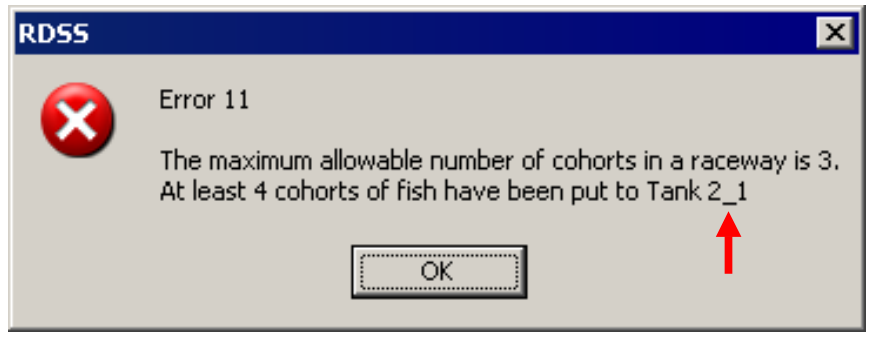

You will need to go back to your Add/ Move/ Remove Fish Schedule in the Simulation

form to check if the number of cohorts in the tank indicated in the error message is over 3.

For example:

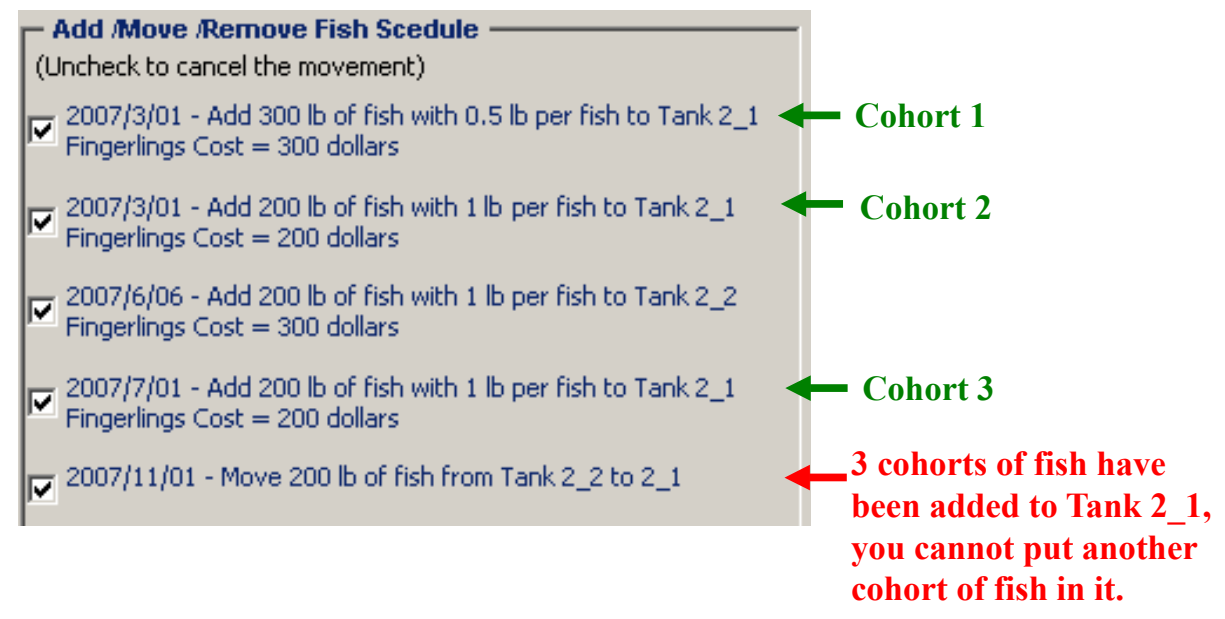




\section{Error 12}

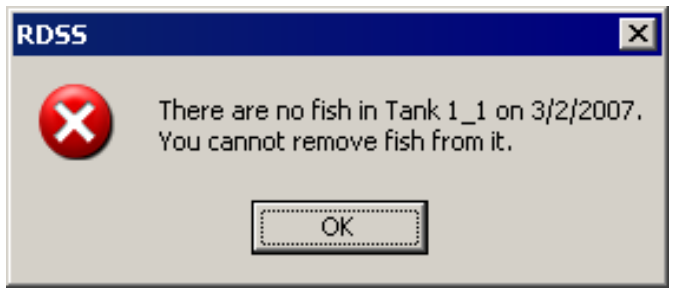

You will need to go back to your Add/ Move/ Remove Fish Schedule in the Simulation form to check if the day you want to move/remove fish from a tank is earlier than the day you add fish to it. (See Note on page 68)

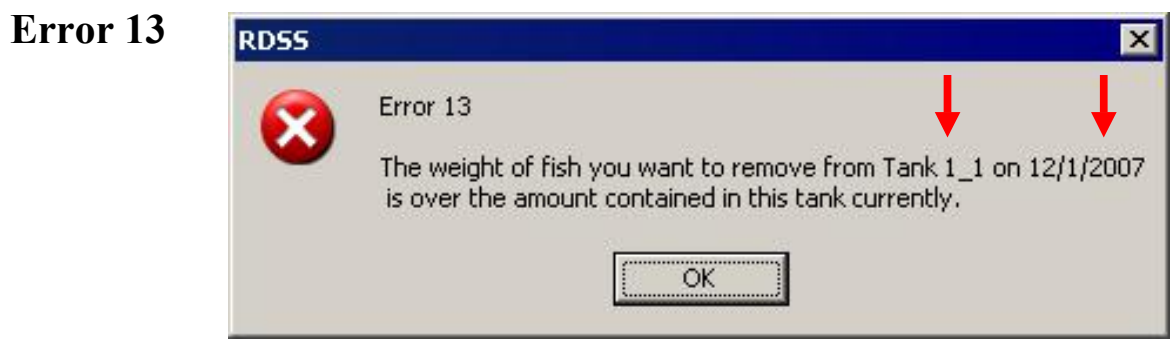

For example:

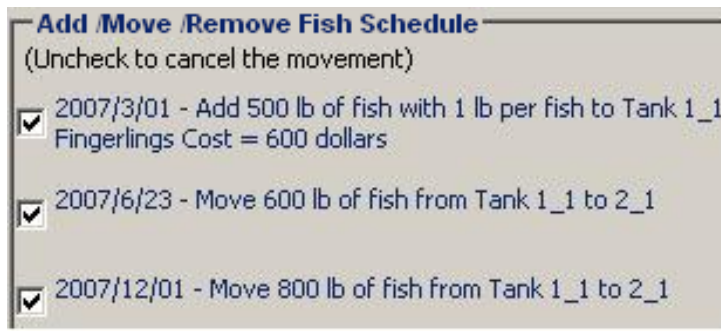

The total weight of fish in Tank 1_1 on 12/1 is less than $800 \mathrm{lb}$; therefore, you cannot move $800 \mathrm{lb}$ of fish from it.

When the program finds that the weight of fish you want to remove from a tank is greater than the amount of fish in that tank, an error box will show up. It will indicate which movement you want to do is wrong.

If you are not sure of the amount of fish in a tank on a certain day, you can run the simulation without the removal of fish first to see the original weight of fish on that day. Alternatively, removing all fish will be a safe way if you do not know the total weight of fish in a tank. 


\subsection{Information Message}

An information box will show up when a plot of a parameter is not available.

Info 1

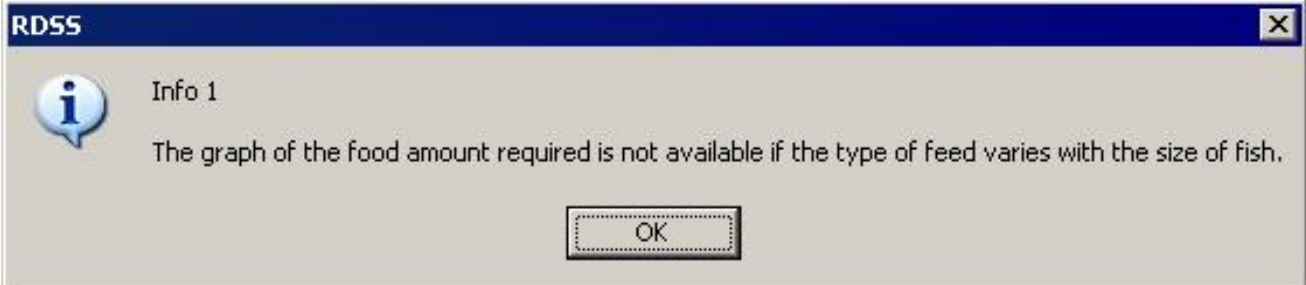

If you select the feed as By Manufacture on the General Data form, the graph of food amount for tanks on a specific day will not be available.

Info 2

i) Info 2

- The graphs of length and weight of fish are not available if there are multiple cohorts in a tank.

- The graph of the feeding rate is not available if the type of feed varies with the size of fish.

- The graph of the food amount required monthly is not available if the type of feed varies with the size of fish.

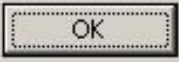

- The plots of the length and the weight of fish are only for the tank with a single cohort.

- If you select the feed as By Manufacture on the General Data form, the graphs for the food required monthly and the feeding rate will not be available. 


\section{Example Problem}

An example will be performed in this section to illustrate the application of RDSS.

Problem: A brook trout rearing system with 2 x 2 raceways ( 2 parallels and 2 raceways in a run), wherein $40 \mathrm{lb}$ of 6 " long fish were put in Tank 1_1, and another $40 \mathrm{lb}$ were put in Tank 2_1 on 2006/2/15. $240 \mathrm{lb}$ of $0.8 \mathrm{lb}$ fish were put in Tank 1_2, and another $240 \mathrm{lb}$ were put in Tank $2 \_2$ on 2006/4/1. The price for $40 \mathrm{lb}$ of 6 " long brook trout is $\$ 360$, and $240 \mathrm{lb}$ of 0.8 lb brook trout is $\$ 130$.

The water temperature of this system is changed monthly, and the total water flow rate is constant, $700 \mathrm{gpm}$.

(1) A buyer orders 600lb of 15" long fish on 2006/8/11, can fish achieve this request on 8/11?

Solution:

Step 1: Set the background parameters

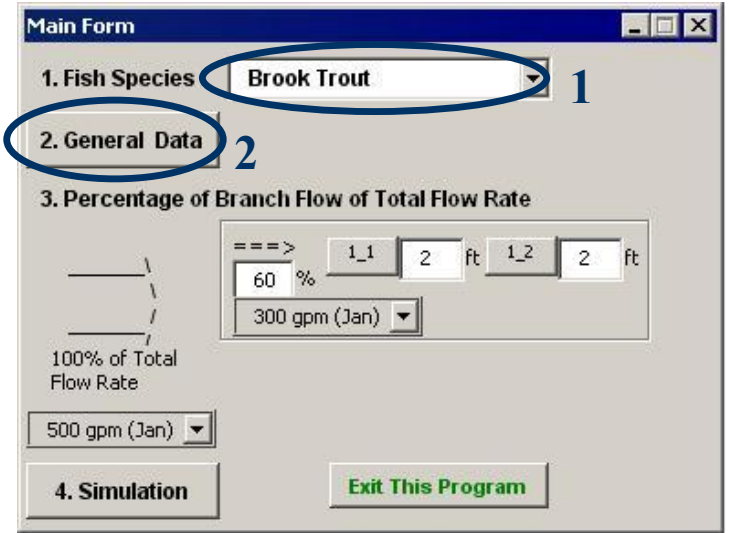




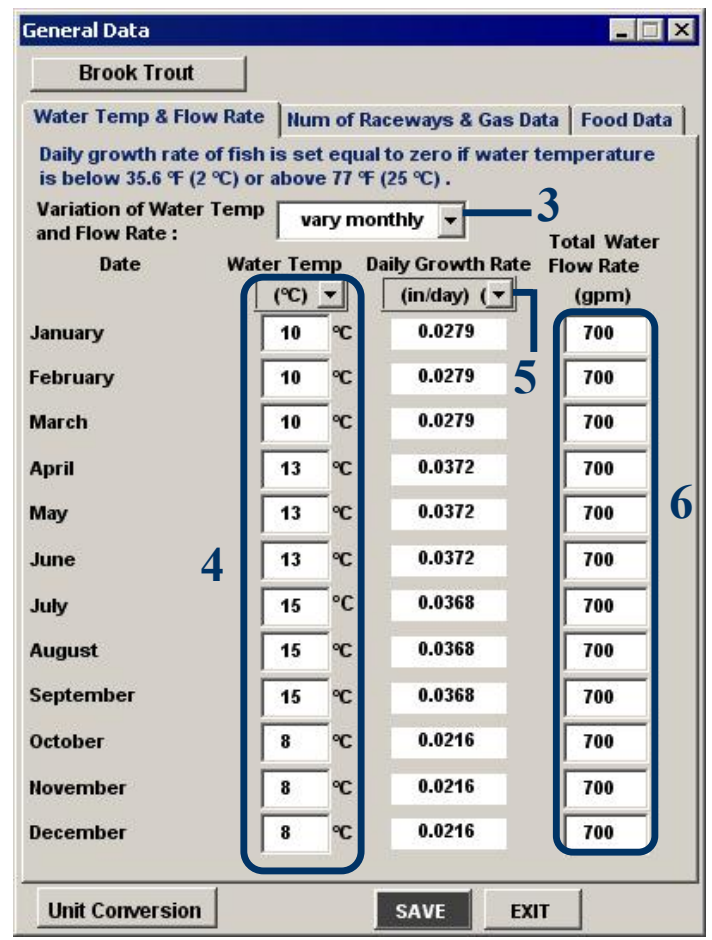

\section{General Data \\ Brook Trout}

Water Temp \& Flow Rate Num of Raceways \& Gas Data |Food Data |

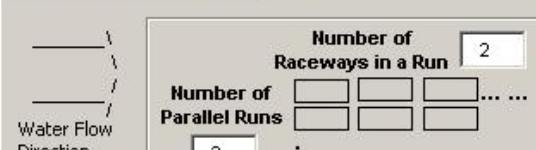

Direction

$\sqrt{2}$

Barometer Pressure $700 \mathrm{~mm} \mathrm{Hg}$

pH value of Water

Salinity

\begin{tabular}{ll|l} 
Initial Oxy Conc & $\%$ of Saturated Oxy. Conc. & 90
\end{tabular}

$\begin{array}{ll}\text { Max Allowable } & 100 \% \text { of critical HH conc ( } 0.0166 \mathrm{mg} \text { L })\end{array}$

7

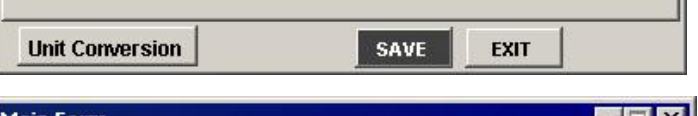

\section{Main Form}

1. Fish Species Brook Trout

$\rightarrow$

2. General Data

3. Percentage of Branch Flow of Total Flow Rate

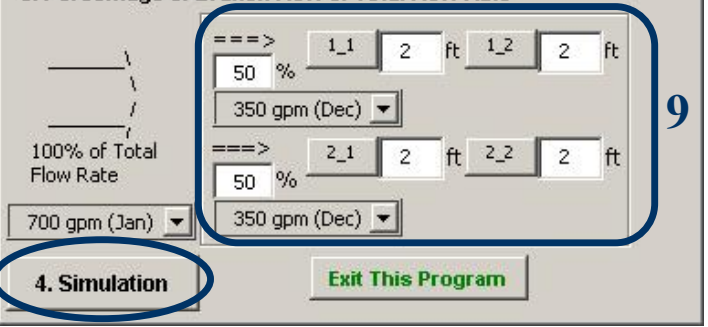

Brook Trout

Water Temp \& Flow Rate | Mum of Raceways \& Gas Data Food Data

$C$ Calorie Content of Food

C Mutrition Facts of Food

$C$ By Manufacture

\begin{tabular}{l|l||l}
$\begin{array}{l}\text { Target Feed } \\
\text { Conversion }\end{array}$ & Depends on food $-1,3$ & Food Fed \\
WWt gain
\end{tabular}

Expected Food $\%$ of Food Amount Required

Amount Fed 90 for Optimal Fish Growth

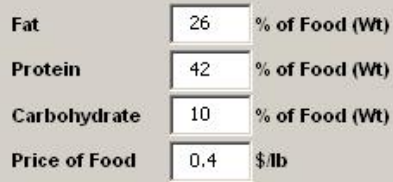

Price of Food 0.4 \$ת

\section{8}

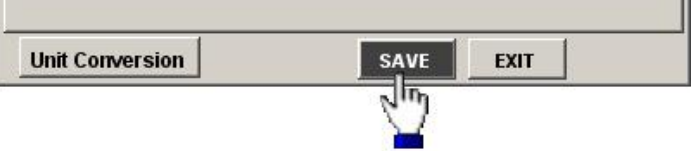


Step 2: Add fish and set dimensions of tanks
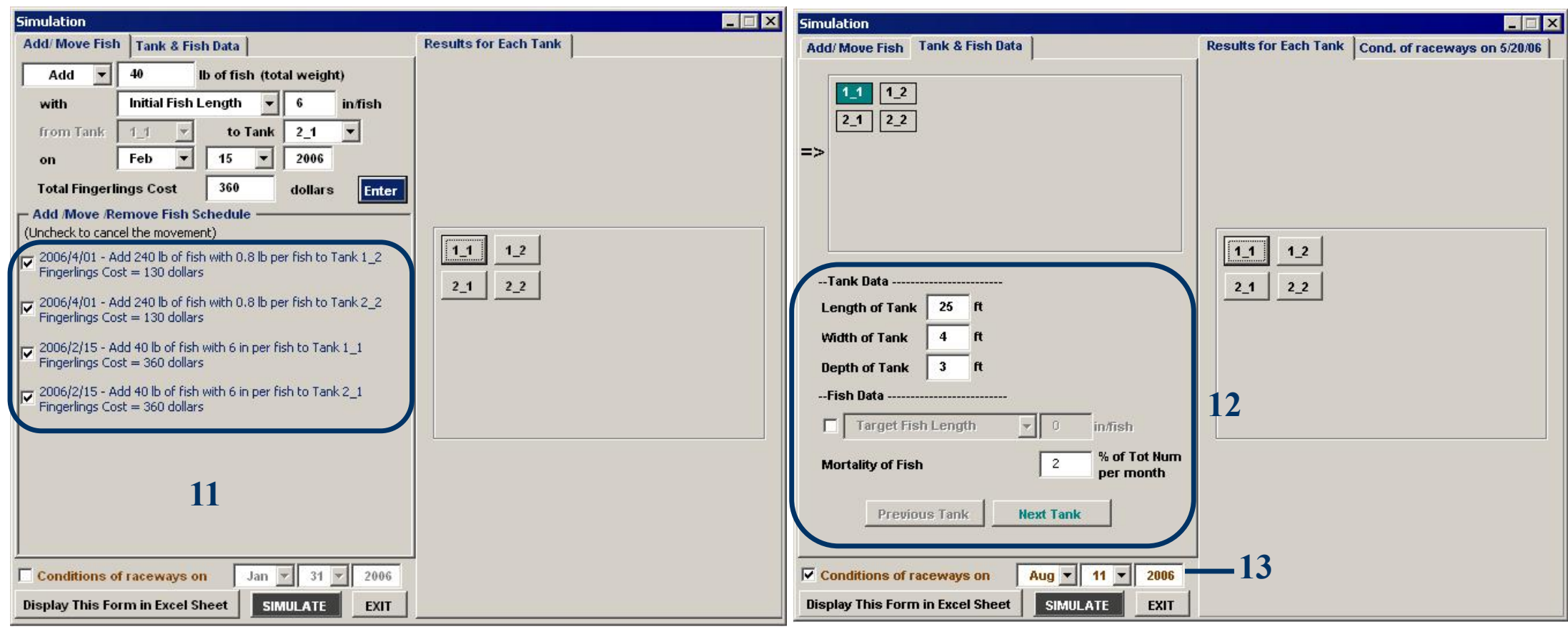
Step 3: Read the conditions on 8/11/06

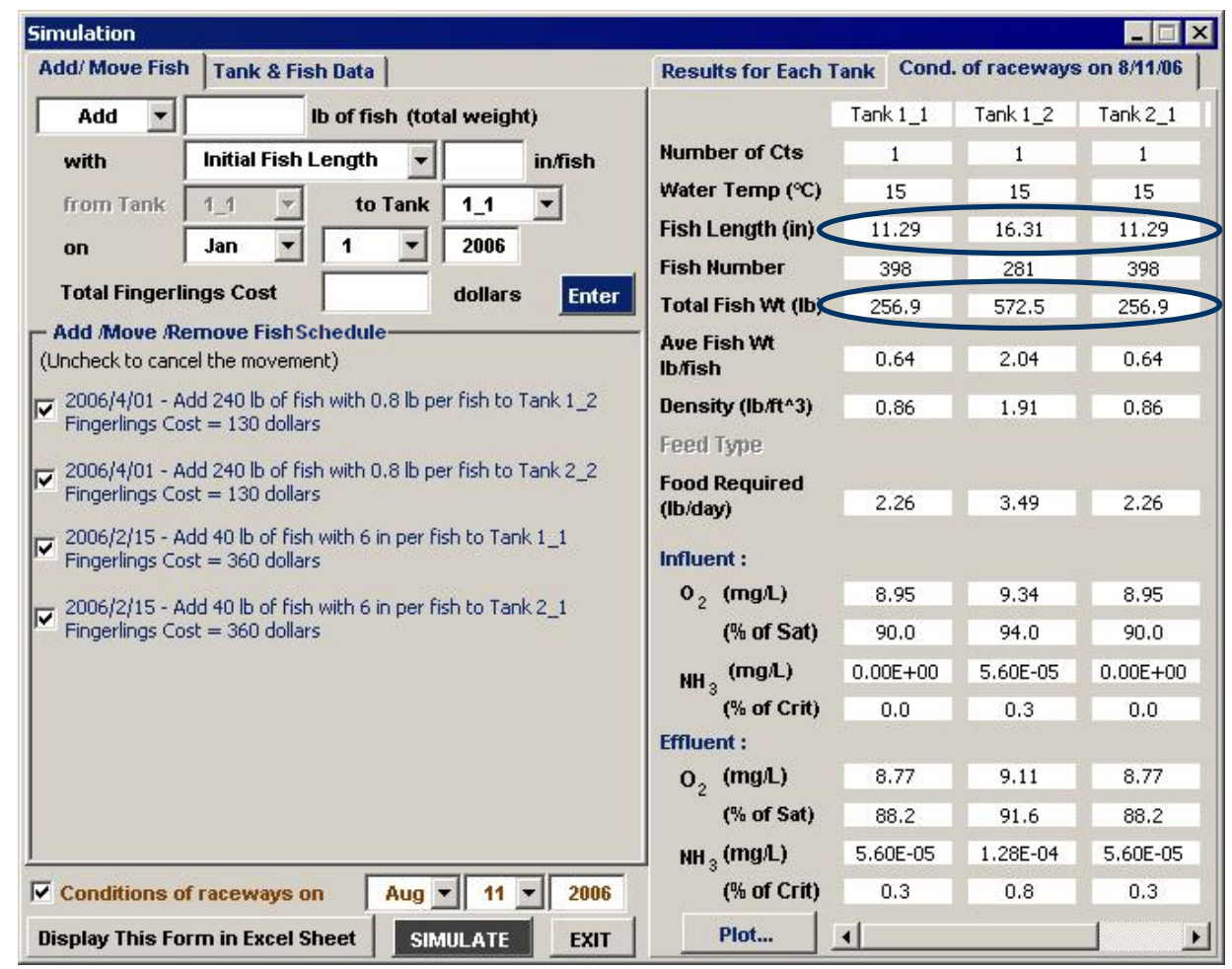

The length of fish in Tank 1_2 and Tank 2_2 is

beyond 15 " on $8 / 11$, and the total weight of fish in these two tanks are $572.5+572.5=1145 \mathrm{lb}>600 \mathrm{lb}$

Therefore, the buyer's request can be achieved. 


\section{(2) Then, when does the length of fish in Tanks 1_1 and 2_1 reach 15"?}

\section{Solution:}

Enter the target length of fish for Tank 1_1 and 2_1.

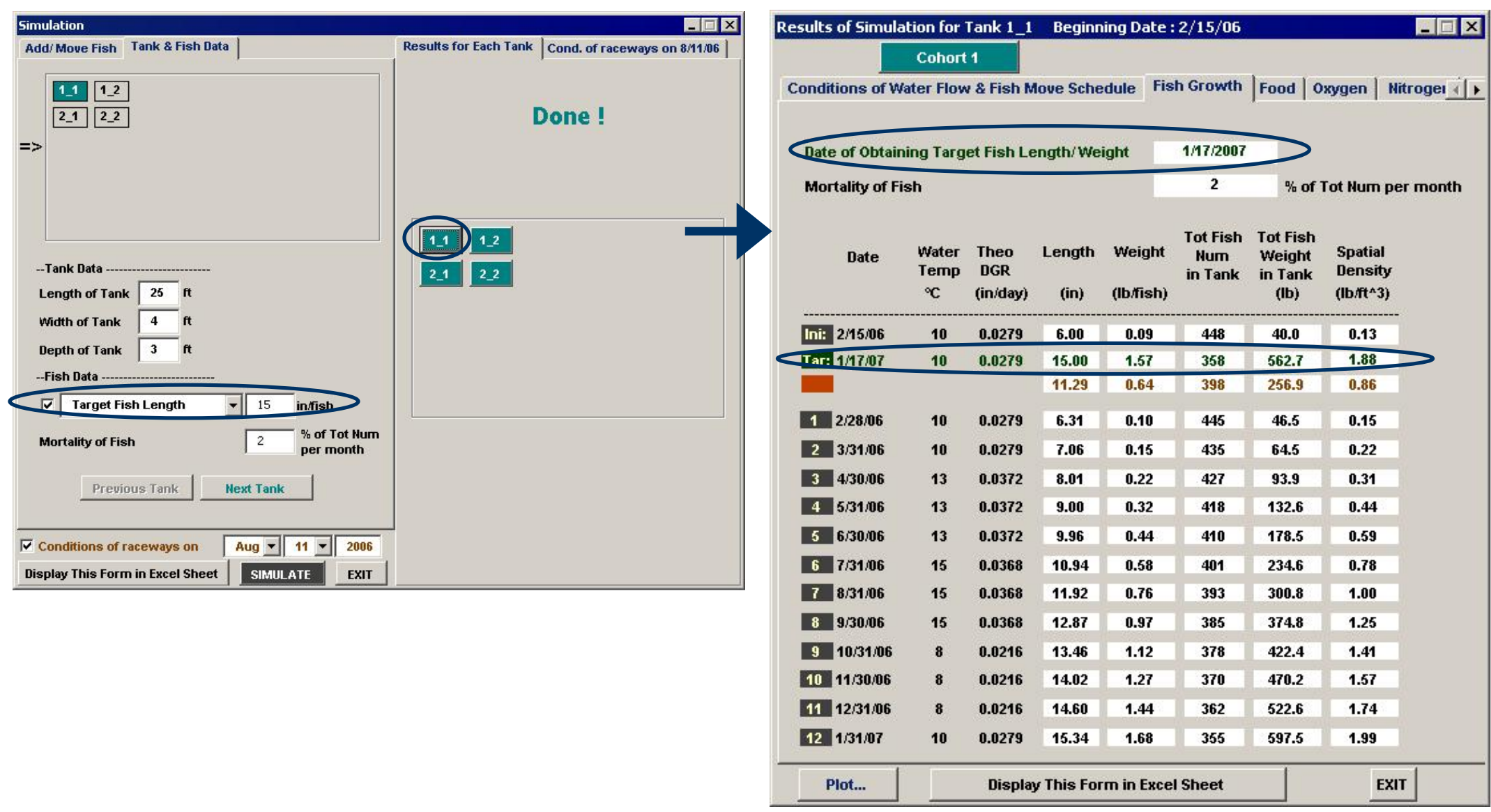

The length of fish in Tank 1_1 and 2_1 will reach 15" on 1/17/2007. 
(3) Continuing, if all fish in this system will be sold at the end of 2006, what is the revenue based on the costs of fingerlings and food?

\section{Solution:}

Input the "removal action" for each tank in the system, and enter the specific date as 12/31/2006.

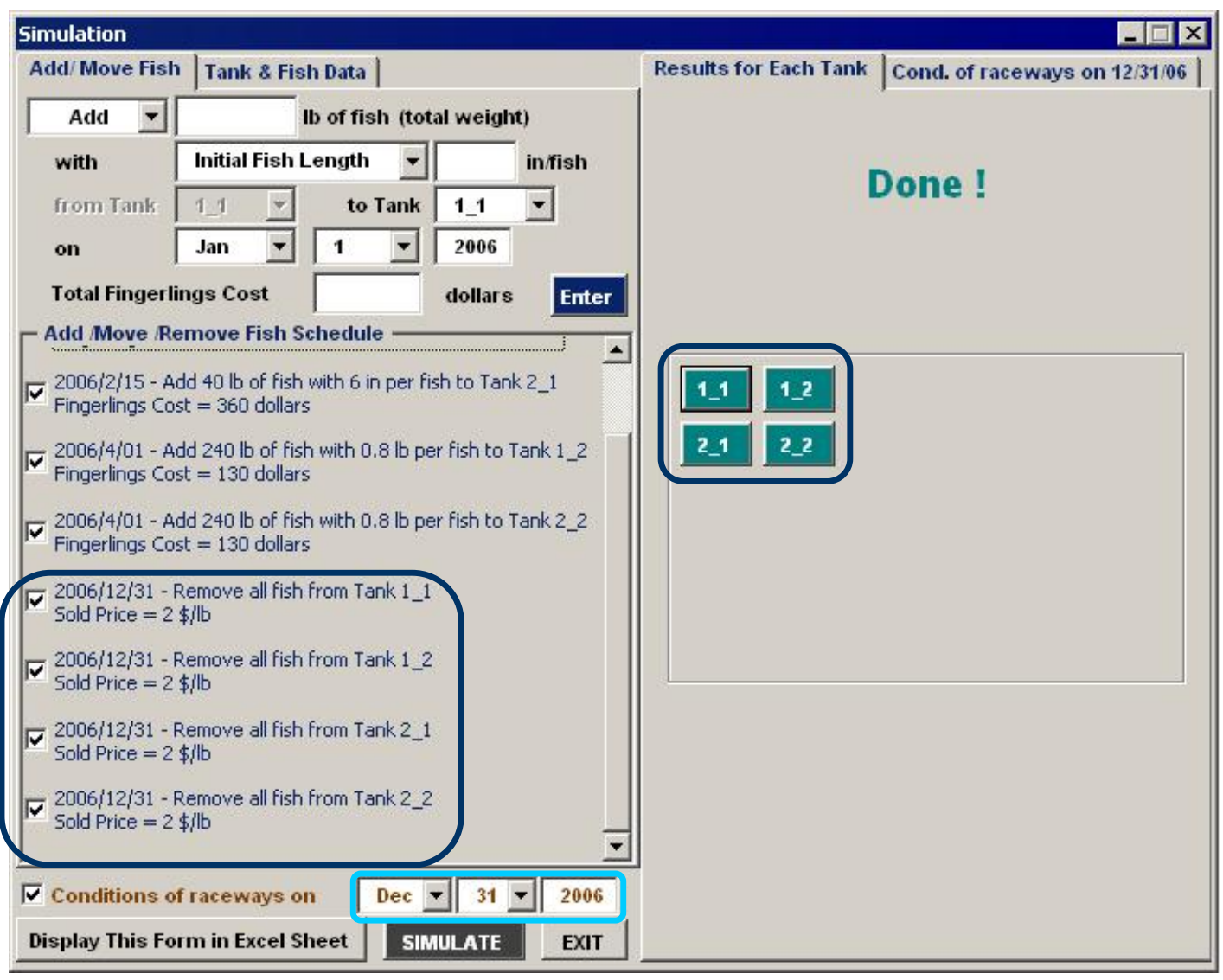




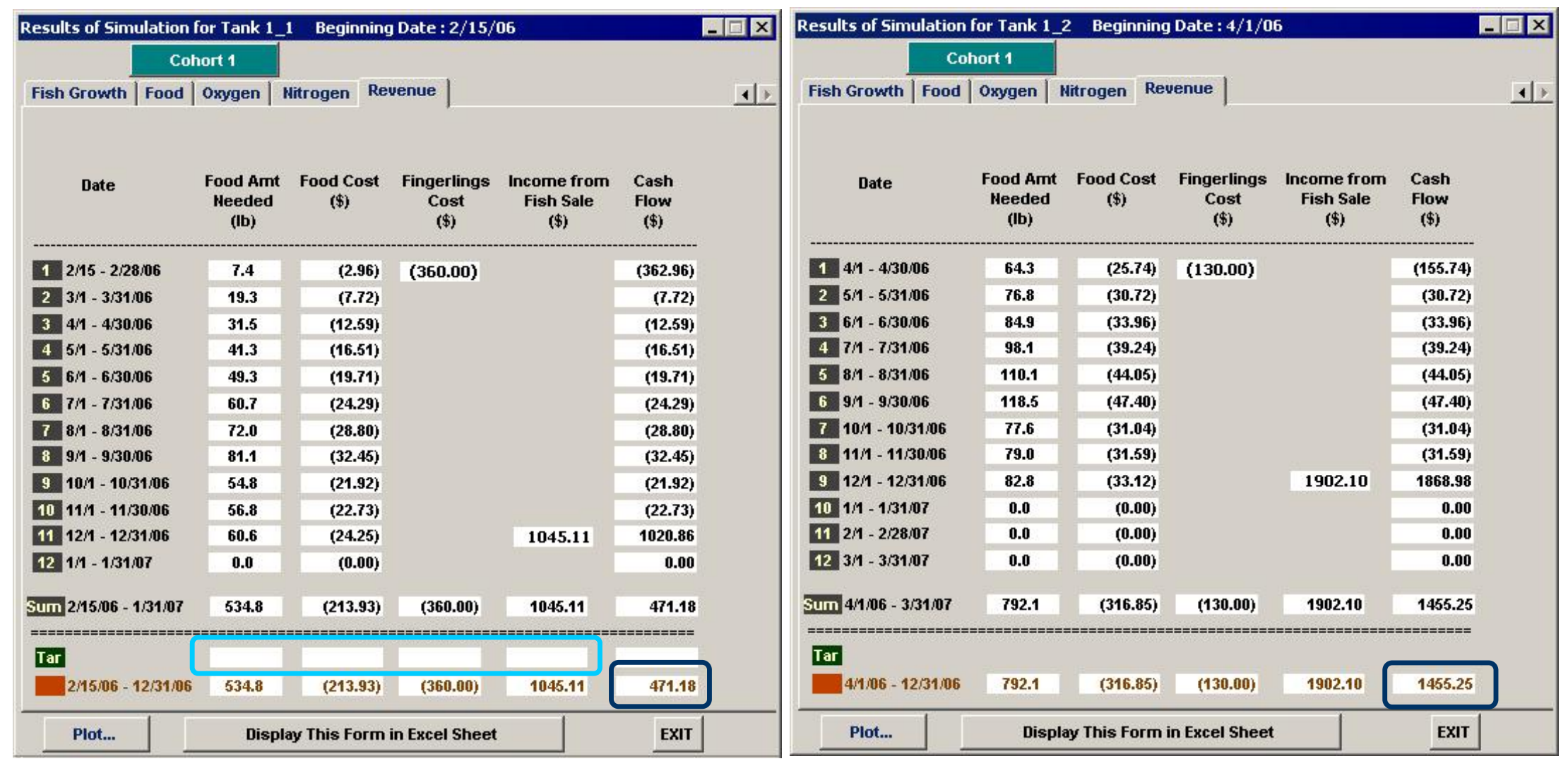

Figure A36 Revenue

Therefore, the profits based on cost of food, fingerlings, and fish sales for these four raceways will be

$2(471.18+1455.25)=\$ 3852.86$

Note:

* From problem (2), we know that fish in Tanks 1_1 and 2_1 will reach the target length, 15", on 1/17/07. However, there are no results available for 1/17/07 in Figure A36 above. This is because all fish are removed on 12/31/06 in problem (3), 
the program cannot continue to do the simulations after 12/31/06. In another words, if fish cannot reach the target conditions before the day on which all of fish in the tank will be removed, the results concerned with the day on which fish achieve the target size will be unavailable. 